\title{
Aziridinyl fluorophores demonstrate bright fluorescence and superior photostability through effectively inhibiting twisted intramolecular charge transfer
}

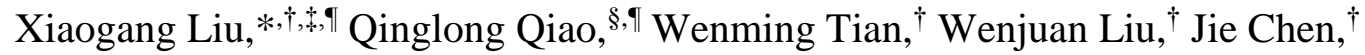
Matthew J. Lang, ${ }^{+, \perp}$ Zhaochao Xu ${ }^{*, \dagger}$

${ }^{\dagger}$ Key Laboratory of Separation Science for Analytical Chemistry, Dalian Institute of Chemical Physics, Chinese Academy of Sciences, 457 Zhongshan Road, Dalian 116023, China.

${ }^{\ddagger}$ Singapore-MIT Alliance for Research and Technology (SMART), 1 CREATE Way, Singapore 138602, Singapore.

${ }^{\S}$ State Key Laboratory of Fine Chemicals, Dalian University of Technology, 2 Linggong Road, Dalian 116012, China.

${ }^{\perp}$ Department of Chemical and Biomolecular Engineering and Department of Molecular Physiology and Biophysics, Vanderbilt University, Nashville, TN 37235, United States.

*Email: xiaogang@smart.mit.edu; Tel: +65-6516-1462.

*Email: zcxu@dicp.ac.cn; Tel: +86-411-84379648; Fax: +86-411-84379648.

IX.L. and Q.Q. contributed equally to this work. 


\section{Table of Contents}

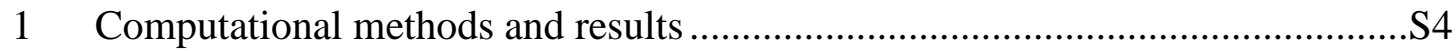

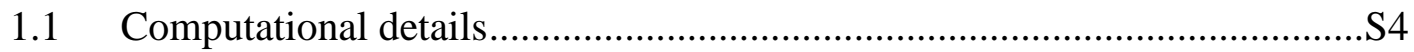

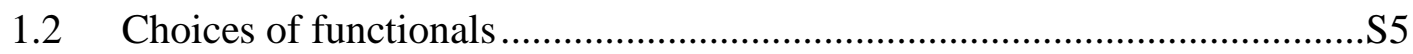

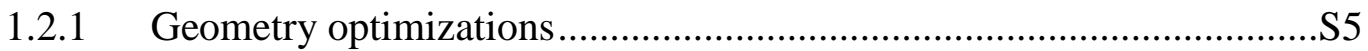

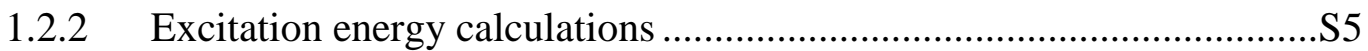

1.3 Impact of medium polarity on the molecular structures of $\mathbf{1}-\mathbf{7}$ in the $\mathrm{S}_{0}$ state

1.3.1 Theoretically optimized molecular structures of $\mathbf{1}-\mathbf{7}$ in ethanol in the $\mathrm{S}_{0}$ state .S5

1.3.2 Theoretically optimized molecular structures of $\mathbf{1}-\mathbf{3}$ in the $S_{0}$ state in various medium .S6

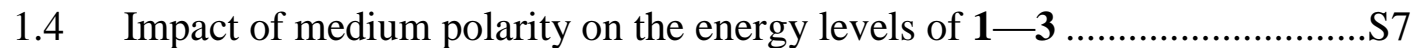

1.5 Molecular structures and energy levels of $\mathbf{1}$ in the TICT state ...................S9

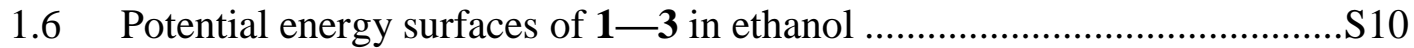

1.7 Geometry change in aziridinyl naphthalimide $\mathbf{1}$ upon photoexcitation ......S12

1.8 Relative energy levels of the Franck-Condon (FC, absorption), local excited (LE), and twisted intramolecular charge transfer (TICT) states in coumarin, phthalimide and NBD dyes in ethanol

1.9 Quantum yield vulnerability to hydrogen bond interactions ......................S14

2 Chemical synthesis and characterizations ..................................................... 17

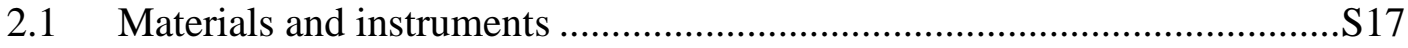

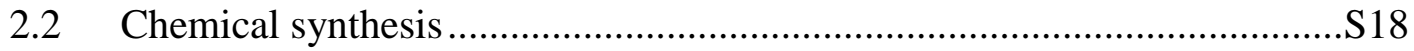

2.2.1 N-Methyl-4-(aziridin-1-yl)-1,8-naphthalimide (1) ...........................S18

2.2.2 N-Methyl-4-(azetidin-1-yl)-1,8-naphthalimide (2) ...........................S18

2.2.3 N-Methyl-4-(pyrrolidin-1-yl)-1,8-naphthalimide (3)........................S19

2.2.4 N-Methyl-4-morpholino-1,8-naphthalimide (4) ...............................S19

2.2.5 $\quad N$-Methyl-4-(piperidin-1-yl)-1,8-naphthalimide (5) .........................S20

2.2.6 N-Methyl-4-(hexamethyleneimin-1-yl)-1,8-naphthalimide (6) ...........S20

2.2.7 N-Methyl-4- dimethylamino-1,8-naphthalimide (7) ..........................S21

2.2.8 2-(6-(aziridin-1-yl)-1,3-dioxo-1H-benzo[de]isoquinolin-2(3H)-yl)acetic acid $(\mathbf{8})$

2.2.9 2-(6-(azetidin-1-yl)-1,3-dioxo-1H-benzo[de]isoquinolin-2(3H)-yl)acetic

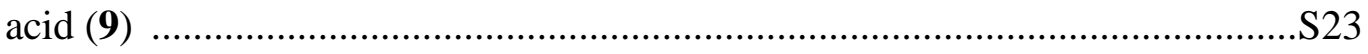

2.2.10 7-(aziridin-1-yl)-4-methyl-coumarin (10)........................................S24

2.2.11 7-(azetidin-1-yl)-4-methyl-coumarin (11) ......................................S24 
2.2.12 3'-(aziridin-1-yl)-6'-(diethylamino)-3H-spiro[isobenzofuran-1,9'xanthen]-3-one (12)

2.2.13 3'-(azetidin-1-yl)-6'-(diethylamino)-3H-spiro[isobenzofuran-1,9'xanthen]-3-one (13) S26

2.2.14 4-(aziridin-1-yl)-N-methylphthalimide (14) S26

2.2.15 4-(azetidin-1-yl)-N-methylphthalimide (15) S27

2.2.16 4-(aziridin-1-yl)-7-nitrobenzofurazan (16) S27

2.2.17 4-(azetidin-1-yl)-7-nitrobenzofurazan (17) $\mathrm{S} 28$

$2.3{ }^{1} \mathrm{H}-\mathrm{NMR},{ }^{13} \mathrm{C}-\mathrm{NMR}, \mathrm{HRMS}$ and analytical HPLC spectra of $\mathbf{1}-\mathbf{1 7}$ and other intermediate products. S29

2.4 UV - vis and fluorescence spectral data of $\mathbf{1}-\mathbf{9}$ S65

2.5 Fluorescence lifetime of $\mathbf{1}-\mathbf{7}$. S69

2.5.1 Fluorescence lifetime of $\mathbf{1}-\mathbf{7}$ in ethanol S69

2.5.2 Fluorescence lifetime of $\mathbf{1}$ and $\mathbf{2}$ in various solvents S69

2.6 Quantum yields of $\mathbf{1}-\mathbf{7}$ in various solvents . S70

2.7 Photo-physical properties of $\mathbf{8}$ and $\mathbf{9}$ in water. S70

2.8 Photostability of $\mathbf{8}$ and $\mathbf{9}$ in water. S70

2.9 Chemical stability of $\mathbf{1}$ in water S71

2.10 Quantum yields of conventional dialkylamino fluorophores S72 


\section{Computational methods and results}

\subsection{Computational details}

Density functional theory (DFT) and time dependent (TD)-DFT calculations were performed using Gaussian 09. ${ }^{1}$ Geometry optimizations for $\mathbf{1}-\mathbf{7}$ in the ground state $\left(S_{0}\right)$ and for $\mathbf{1}-\mathbf{3}$ in the first excited singlet state $\left(S_{1}\right)$ were performed in vacuo, cyclohexane, ethanol and water. Similar optimizations for $\mathbf{1 0}-\mathbf{1 7}$ in both the $S_{0}$ and $\mathrm{S}_{1}$ states were performed in ethanol only. These geometry optimizations employ the B3LYP functional, ${ }^{2-4}$ in combination with the $6-31+\mathrm{G}(\mathrm{d}, \mathrm{p})$ basis set. ${ }^{5}$ Solvent effects were taken into account using the IEFPCM model. Frequency checks were carried out after each geometry optimization to ensure that the minima on the potential energy surfaces (PES) were found.

Atomic contributions to the highest occupied molecular orbital (HOMO) and the lowest unoccupied molecular orbital (LUMO) in selected compounds were calculated using Mulliken population analysis, based on the optimized molecular structures at the $\mathrm{S}_{0}$ state.

We also constructed the PES of $\mathbf{1}-\mathbf{3}$ in ethanol as a function of the dihedral angle between their amino substituents and main scaffolds. Unless otherwise stated, the dihedral angles were fixed at various values, while other geometry parameters were freely optimized employing B3LYP/6-31+G(d,p) in the $S_{1}$ state. The LE and TICT minima in the $S_{1}$ state were optimised without any constraint. During the geometry optimization of all TICT structures, we pre-twisted the amino groups to a nearly perpendicular conformation to order to reach the TICT minima.

TD-DFT and single point calculations were carried out on the optimized molecular structures using CAM-B3LYP/6-31+G(d,p), ${ }^{6}$ in order to determine their relative energy levels in the Franck-Condon (FC), local excited (LE), and twisted intramolecular charge transfer (TICT) states. For all de-excitation processes, such as the LE and TICT emissions and the PES scans in ethanol, the $\mathrm{S}_{0}$ energy levels were calculated with non-equilibrium solvation. 


\subsection{Choices of functionals}

\subsubsection{Geometry optimizations}

B3LYP functional offers excellent performance in geometry optimization. ${ }^{7}$ This functional was employed to optimize the molecular structures of $\mathbf{1}-\mathbf{7}$ and $\mathbf{1 0}-\mathbf{1 7}$ in both the $\mathrm{S}_{0}$ and $\mathrm{S}_{1}$ states.

\subsubsection{Excitation energy calculations}

While B3LYP predicts the excitation energy of the LE state accurately, it severally underestimates the excitation energy of the TICT state, where a significant extent of charge transfer is involved. ${ }^{8}$ In contrast, the CAM-B3LYP functional describes the overall PES profile accurately in systems involving varied amount of charge transfer (i.e., when both LE and TICT states are of concern). ${ }^{8}$ We have thus used CAMB3LYP to calculate the excitation energies of 1-7, based on B3LYP optimized molecular structures.

\subsection{Impact of medium polarity on the molecular structures of $1-7$ in the $\mathrm{S}_{0}$ state}

Figure $\mathrm{S} 1$ shows the atom and bond labelling convention of naphthalimide dyes, used in this paper.

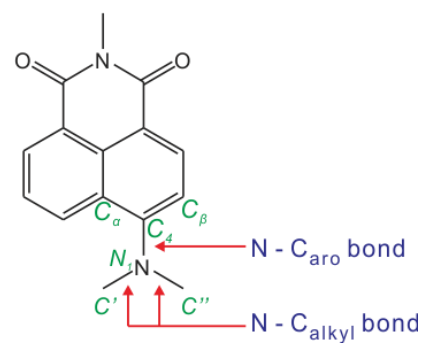

Figure S1. Atom and bond labelling of naphthalimide dyes.

\subsubsection{Theoretically optimized molecular structures of $\mathbf{1}-\mathbf{7}$ in ethanol in the $\mathrm{S}_{0}$ state}

The molecular structures of $\mathbf{1}-\mathbf{7}$ in the ground state have been theoretically optimized using B3LYP/6-31+G(d,p) in ethanol (Figure 1c). The three-membered aziridine ring in $\mathbf{1}$ possess the up-up conformation. The four-membered azetidine ring affords the flat conformation. The rest molecules $3-\mathbf{7}$ all adopt the up-down conformation.

Detailed geometry parameters and the conformations between the amino groups and the fluorophore scaffolds are available in Table S1. 
Table S1. Dihedral angles along the $\mathrm{N}-\mathrm{C}_{\text {aro }}$ bond in the theoretically optimized molecular structures of $\mathbf{1}-\mathbf{7}$ and their conformations in ethanol in the $\mathrm{S}_{0}$ state.

\begin{tabular}{|c|c|c|c|}
\hline Compound & $\angle \mathrm{C}_{\alpha}-\mathrm{C}_{4}-\mathrm{N}_{1}-\mathrm{C}^{\prime}\left(^{\circ}\right)$ & $\angle \mathrm{C}_{\beta}-\mathrm{C}_{4}-\mathrm{N}_{1}-\mathrm{C}^{\prime}\left(^{\circ}\right)$ & Conformation \\
\hline $\mathbf{1}$ & -69.02 & 40.11 & up-up \\
\hline $\mathbf{2}$ & 0.02 & -0.01 & flat \\
\hline $\mathbf{3}$ & -23.29 & -5.19 & up-down \\
\hline $\mathbf{4}$ & -65.40 & -18.86 & up-down \\
\hline $\mathbf{5}$ & -63.87 & -19.75 & up-down \\
\hline $\mathbf{6}$ & -66.49 & -24.99 & up-down \\
\hline $\mathbf{7}$ & -55.16 & -16.45 & up-down \\
\hline
\end{tabular}

\subsubsection{Theoretically optimized molecular structures of $\mathbf{1}-\mathbf{3}$ in the $\mathrm{S}_{0}$ state in various} medium

The molecular structures of $\mathbf{1}-\mathbf{7}$ also depend on the solvent in use. Compounds $\mathbf{1}-\mathbf{3}$ are selected to represent the up-up, flat, and up-down conformations, respectively. These three compounds undergo further theoretical analysis in various medium of different polarities, including vacuo, cyclohexane, ethanol and water.

The molecular structures of $\mathbf{1}$ adopt the up-up conformation in all studied medium; while $\mathbf{3}$ always affords the up-down conformation. Slight flattering of the amino groups in both $\mathbf{1}$ and $\mathbf{3}$, however, is observed as the solvent polarity rises (Table S2).

Table S2. Dihedral angles along the $\mathrm{N}-\mathrm{C}_{\text {aro }}$ bond in the theoretically optimized molecular structures of $\mathbf{1}-\mathbf{3}$ in the ground state in various solvents.

\begin{tabular}{|l|c|c|c|}
\hline Medium & $\angle \mathrm{C}_{\alpha}-\mathrm{C}_{4}-\mathrm{N}_{1}-\mathrm{C}^{\prime}\left(^{\circ}\right)$ & $\left.\angle \mathrm{C}_{\beta}-\mathrm{C}_{4}-\mathrm{N}_{1}-\mathrm{C}^{\prime}{ }^{(}{ }^{\circ}\right)$ & Conformation \\
\hline $\mathbf{1}$ & -70.87 & 38.55 & $u p-u p$ \\
\hline vacuum & -70.16 & 39.20 & $u p-u p$ \\
\hline cyclohexane & -69.02 & 40.11 & $u p-u p$ \\
\hline ethanol & -69.00 & 40.13 & up-up \\
\hline water & -33.15 & 13.63 & up-up \\
\hline $\mathbf{2}$ & -26.71 & 12.02 & up-up \\
\hline vacuum & 0.02 & -0.01 & flat \\
\hline cyclohexane & 0.01 & -0.01 & flat \\
\hline ethanol & &
\end{tabular}




\begin{tabular}{|l|l|l|l|}
\hline $\mathbf{3}$ \\
\hline vacuum & -32.37 & -5.30 & up-down \\
\hline cyclohexane & -28.69 & -5.06 & up-down \\
\hline ethanol & -23.29 & -5.19 & up-down \\
\hline water & -22.87 & -5.23 & up-down \\
\hline
\end{tabular}

The electron-donating group in $\mathbf{2}$ is a four-membered azetidine ring. This ring exhibits different geometries as a function of solvent polarity (Figure S2).

In non-polar environment (i.e., in vacuo or cyclohexane; Figure S2a, b), the azetidine ring bends up and affords the up-up conformation, owing to its high strain energy.

In polar solvents, (i.e., in ethanol and water; Figure S2c, d), the azetidine ring is planar and affords the flat conformation. This planarization is due to increased intramolecular charge transfer and enhanced resonance effect in $\mathbf{2}$.

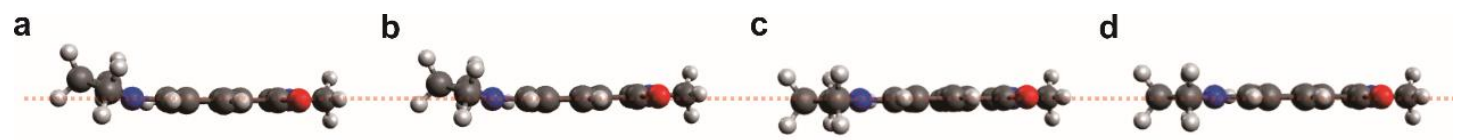

Figure S2. Side view of theoretically optimized molecular structures of $\mathbf{2}$ in the ground state in (a) vacuo; (b) cyclohexane; (c) ethanol and (d) water.

\subsection{Impact of medium polarity on the energy levels of $1-3$}

The energy levels of $\mathbf{1}-\mathbf{3}$ in Franck-Condon (absorption), LE (emission) and TICT states have been calculated in vacuo, cyclohexane, ethanol and water (Figure S3). These compounds are selected to represent the up-up, flat and up-down conformations, respectively.

In non-polar environment (such as in vacuo), our calculations show that dyes $\mathbf{1}-\mathbf{3}$ energetically favor local excited (LE) state, but not the TICT state (Figure S3a). Not surprisingly, our experiments demonstrate that $\mathbf{1}-\mathbf{7}$ all exhibit high quantum yields in non-polar solvents (Table S8).

In polar environment (such as in ethanol and water), our calculations show that $\mathbf{1}$ remains resistant to TICT rotation. The TICT state of $\mathbf{2}$, however, becomes slightly more stable than the LE state. A strong tendency to the TICT state is most evident in $\mathbf{3}$. Consequently, 1 (the up-up conformation) exhibits the highest quantum yields $(0.708$ in ethanol), followed by $\mathbf{2}$ (the flat conformation, 0.631 in ethanol). Compounds $\mathbf{3}$ (as 
well as 4-7; the up-down conformation) affords very low quantum yields (Figure S3c, d; Table S8).

1

a

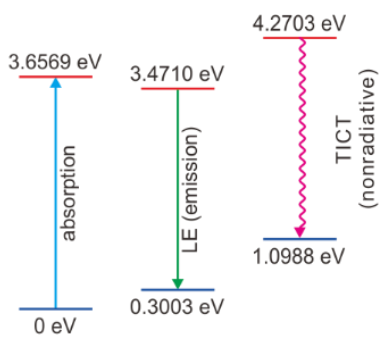

b

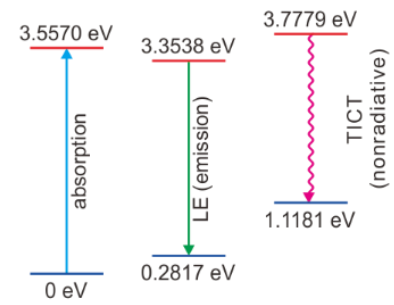

C

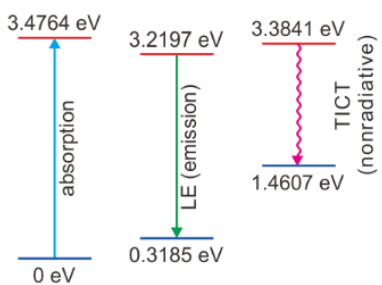

d

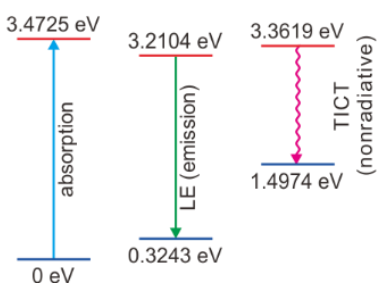

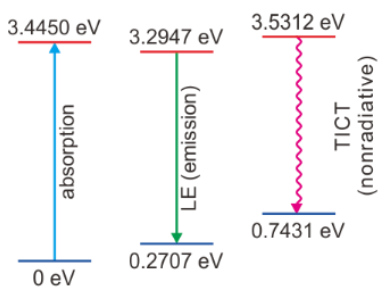
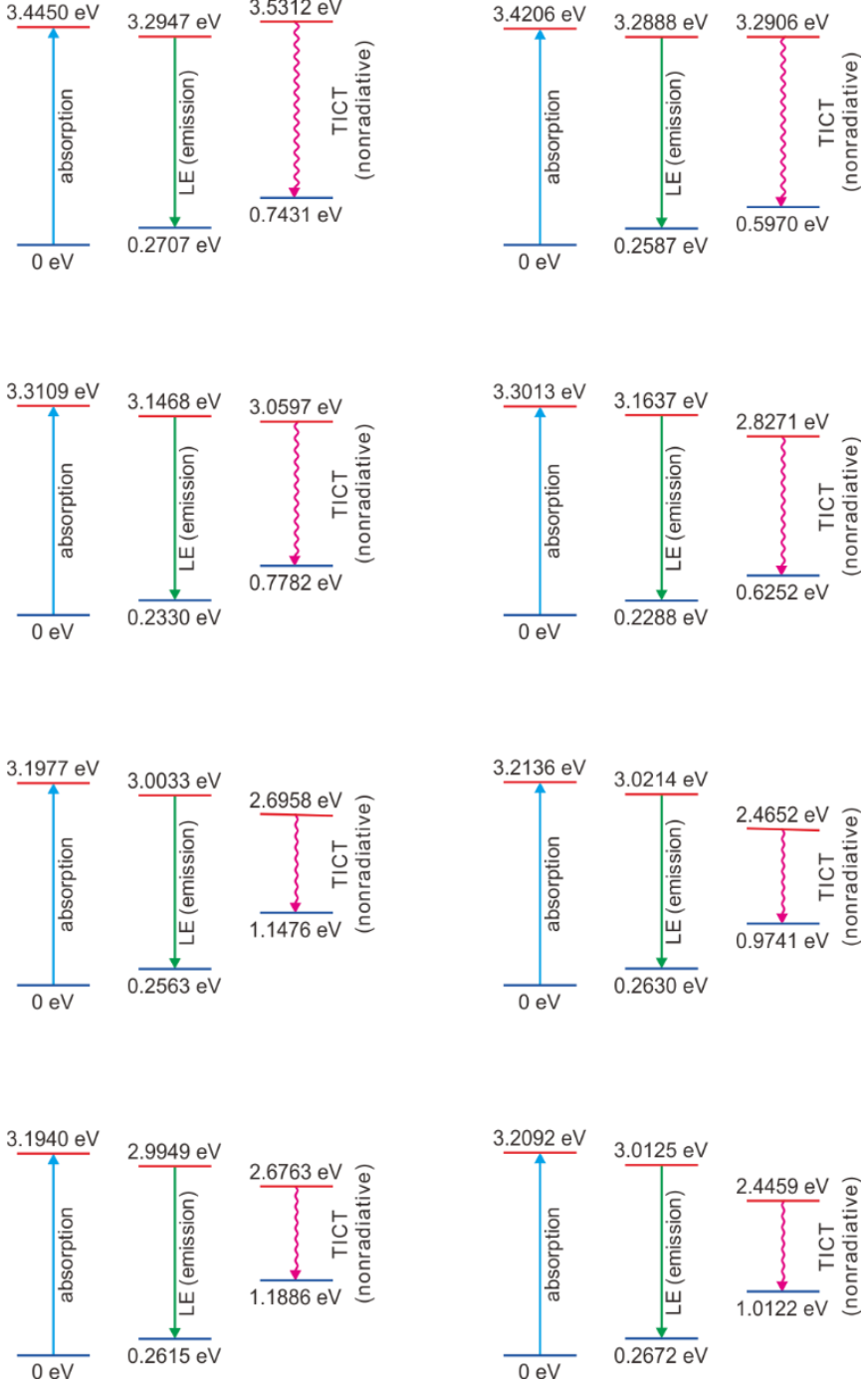

Figure S3. Calculated relative $S_{0}$ (blue) and $S_{1}$ (red) energy levels corresponding to the Franck-Condon (absorption), LE (emission) and TICT states of 1, 2, and $\mathbf{3}$ in (a) vacuo, (b) cyclohexane, (c) ethanol and (d) water.

We have also quantitatively compared the excitation energy in the FC, LE and TICT states, derived from both experimental measurements and theoretical calculations (using both B3LYP and CAM-B31YP; Table S3). Indeed, B3LYP predicts the excitation energy of the FC and LE states quite accurately. However, it severally underestimates the excitation energy of the TICT state. While CAM-B3LYP generally overestimates the excitation energy, it has been shown that CAM-B3LYP correctly 
describes the overall PES profile. ${ }^{8}$ We thus use CAM-B3LYP results to construct the PES of $\mathbf{1}-\mathbf{3}$.

Table S3. Comparison of the experimental and theoretical (calculated using both B3LYP and CAM-B3LYP functional) excitation energy.

\begin{tabular}{|c|c|c|c|}
\hline & experimental & B3LYP & CAM-B3LYP \\
\hline & \multicolumn{3}{|c|}{ FC (absorption) } \\
\hline $\mathbf{1}$ & $3.2457 \mathrm{eV}(382 \mathrm{~nm})$ & $3.0704 \mathrm{eV}(404 \mathrm{~nm})$ & $3.4764 \mathrm{eV}(357 \mathrm{~nm})$ \\
\hline $\mathbf{2}$ & $2.7862 \mathrm{eV}(445 \mathrm{~nm})$ & $2.8324 \mathrm{eV}(438 \mathrm{~nm})$ & $3.1977 \mathrm{eV}(388 \mathrm{~nm})$ \\
\hline $\mathbf{3}$ & $2.7675 \mathrm{eV}(448 \mathrm{~nm})$ & $2.8494 \mathrm{eV}(435 \mathrm{~nm})$ & $3.2136 \mathrm{eV}(386 \mathrm{~nm})$ \\
\hline & \multicolumn{3}{|c|}{ LE (emission) } \\
\hline $\mathbf{1}$ & $2.4358 \mathrm{eV}(509 \mathrm{~nm})$ & $2.5165 \mathrm{eV}(493 \mathrm{~nm})$ & $2.9012 \mathrm{eV}(427 \mathrm{~nm})$ \\
\hline $\mathbf{2}$ & $2.3262 \mathrm{eV}(533 \mathrm{~nm})$ & $2.3688 \mathrm{eV}(523 \mathrm{~nm})$ & $2.7470 \mathrm{eV}(451 \mathrm{~nm})$ \\
\hline $\mathbf{3}$ & $2.3437 \mathrm{eV}(529 \mathrm{~nm})$ & $2.3742 \mathrm{eV}(522 \mathrm{~nm})$ & $2.7584 \mathrm{eV}(449 \mathrm{~nm})$ \\
\hline & - & \multicolumn{3}{|c|}{ TICT (non-radiative de-excitation) } \\
\hline $\mathbf{1}$ & - & $1.1258 \mathrm{eV}(1101 \mathrm{~nm})$ & $2.1200 \mathrm{eV}(585 \mathrm{~nm})$ \\
\hline $\mathbf{2}$ & - & $0.7144 \mathrm{eV}(1736 \mathrm{~nm})$ & $1.5482 \mathrm{eV}(801 \mathrm{~nm})$ \\
\hline $\mathbf{3}$ & - & $0.6392 \mathrm{eV}(1940 \mathrm{~nm})$ & $1.4911 \mathrm{eV}(832 \mathrm{~nm})$ \\
\hline
\end{tabular}

\subsection{Molecular structures and energy levels of $\mathbf{1}$ in the TICT state}

The theoretically optimized molecular structures of $\mathbf{1}$ are different from those of other dyes (Figure S4). In the LE state, 1 exhibits the unique up-up conformation (Figure S4a). In the TICT state, the perpendicular alignment between the amino group and the main fluorophore scaffold is stable for $\mathbf{2}-\mathbf{7}$, but not for $\mathbf{1}$ (Figure S4b). When reaching a stable TICT state in $\mathbf{1}$, its amino group exhibits a pyramidal structure (Figure S4c).
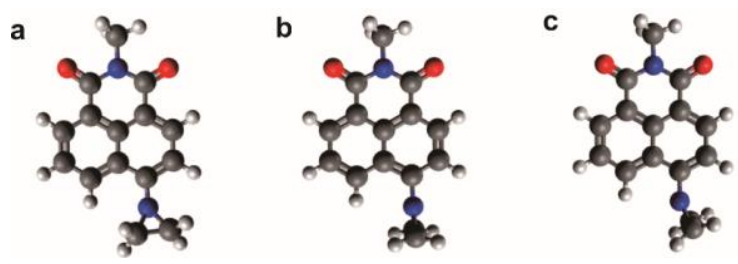

Figure S4. Theoretically optimized molecular structures of $\mathbf{1}$ in the $S_{1}$ state. (a) in the LE state; (b) in the nonstable TICT state; and (c) in the stable TICT state.

The stable TICT (pyramidal) states have lower energy levels in comparison to the nonstable TICT (perpendicular) states in 1 (Figure S5). Both TICT states have higher energy levels than the corresponding LE (emission) states. As a result, compound $\mathbf{1}$ is resistant to TICT rotation in all studied solvents. 
a

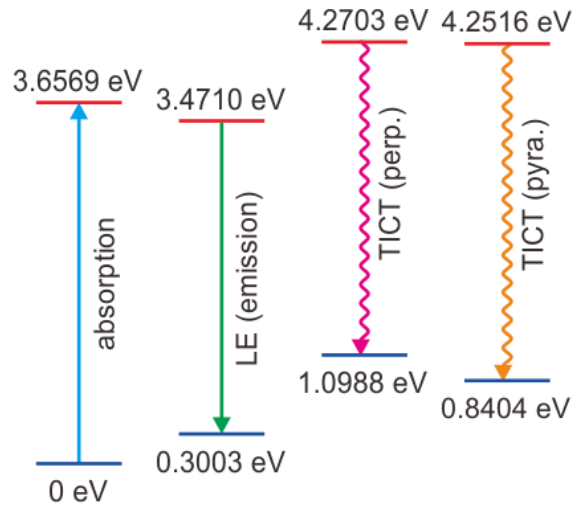

c

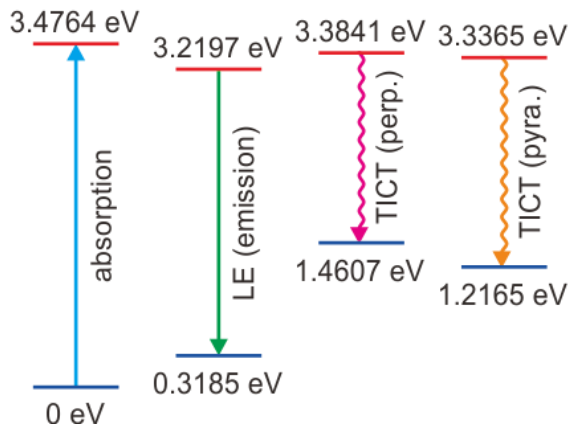

b
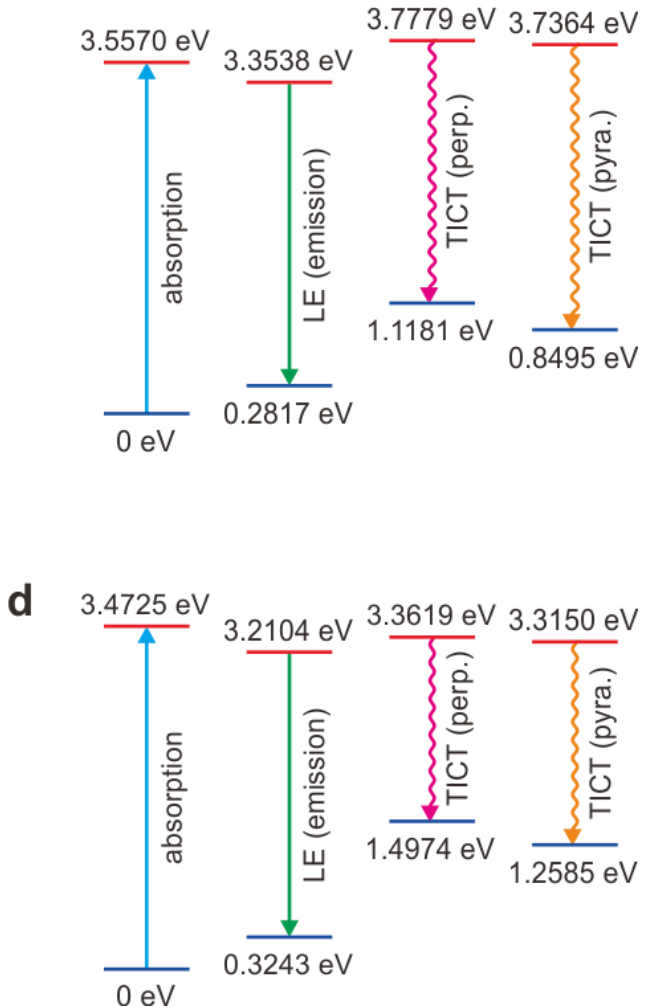

Figure S5. Calculated relative $S_{0}$ (blue) and $S_{1}$ (red) energy levels corresponding to the Franck-Condon (absorption), LE (emission) and TICT (perpendicular, nonstable) and TICT (pyramidal, stable) states of $\mathbf{1}$ in (a) vacuo, (b) cyclohexane, (c) ethanol and (d) water.

\subsection{Potential energy surfaces of $\mathbf{1} \mathbf{- 3}$ in ethanol}

Forming the TICT state requires two conditions: (1) the TICT state has a lower energy level than the LE state in the $S_{1}$ PES, and (2) the energy barrier between the LE and TICT states is small (comparable to thermal energy at room temperature; Figure S6). Note that we use the LE state to denote the more planar conformation with less charge transfer (compared to the TICT state). In some studies, this "LE" state is referred as the intramolecular charge transfer (ICT) state.

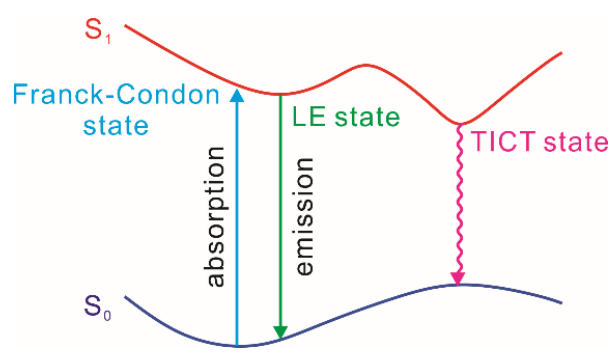

Figure S6. Illustration of the $S_{0}$ and $S_{1}$ potential energy surfaces, as well as the corresponding Franck-Condon, local excited (LE), and twisted intramolecular charge transfer (TICT) states. 
In order to study the TICT tendency of $\mathbf{1}-\mathbf{3}$, we have computed their $\mathrm{S}_{0}$ and $\mathrm{S}_{1}$ PES in ethanol as well as the corresponding energy barriers between their LE and TICT states (Figure S7).
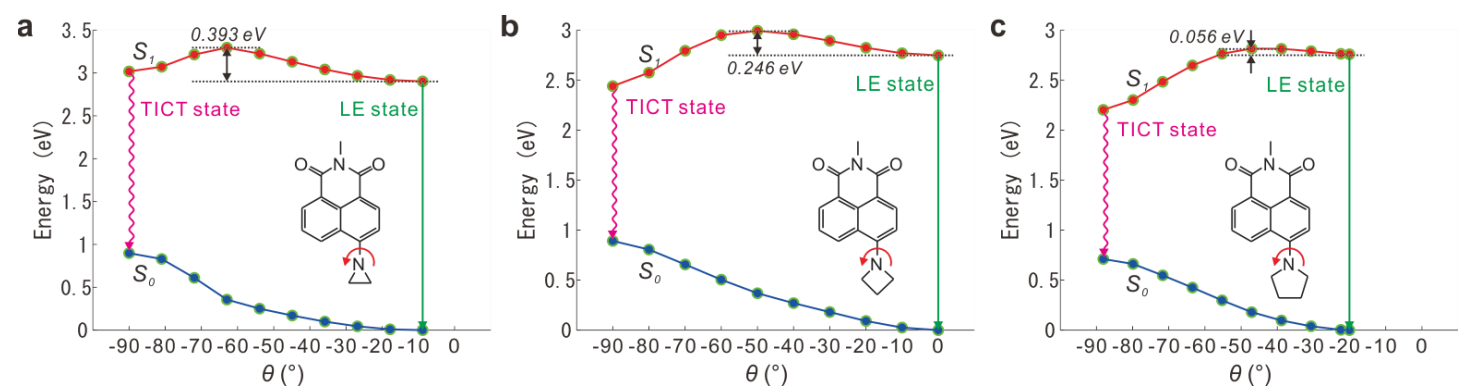

Figure S7. Calculated potential energy surfaces (PES) of the ground $\left(\mathrm{S}_{0}\right.$, in blue) and the first excited singlet ( $\mathrm{S}_{1}$, in red) states of $\mathbf{1}$ (a), $\mathbf{2}$ (b) and $\mathbf{3}$ (c) in ethanol, as a function of the rotational angle $(\theta)$ between the amino substituent and the main fluorophore scaffold. $\theta$ is defined as the average value of $\angle \mathrm{C}_{\alpha}-\mathrm{C}_{4}-\mathrm{N}_{1}-\mathrm{C}^{\prime}$ and $\angle \mathrm{C}_{\beta}-\mathrm{C}_{4}-\mathrm{N}_{1}-\mathrm{C}^{\prime \prime}$ (see Figure S1).

In the case of $\mathbf{1}$, the energy barrier is particularly large, indicating significant TICT resistance. Moreover, the TICT state of $\mathbf{1}$ is energetically unfavourable with respect to the LE state (even in ethanol and water). Compound $\mathbf{1}$ is thus not likely to enter the TICT state upon photoexcitation (Figure S7a).

For compound 2, our calculations suggest that the TICT state corresponds to a lower energy level than the LE state in the $S_{1}$ PES in ethanol (Figure S7b, c). Nevertheless, a large energy barrier $(0.246 \mathrm{eV})$ exists between the LE and TICT states (Figure S7b). Compound 2 is thus non prone to TICT rotation, affording a high quantum yield in ethanol (0.631).

However, substantial TICT rotations in $\mathbf{2}$ could be activated in more polar solvents. In fact, a complete charge transfer from the donor to the acceptor moiety of a fluorophore occurs in the TICT state. This TICT state is highly polarized and become stabilized through intensive dye-solvent electrostatic interactions. This stabilization effect is particularly strong in highly polar solvents, such as water. Consequently, significant TICT formation (along with hydrogen bond interactions) substantially lowers the quantum yield of 2 to 0.199 in water.

In the case of $\mathbf{3}$, its TICT state is more stable and the energy barrier to the TICT state is very small $(0.056 \mathrm{eV})$. This small value is comparable to the thermal energy at 
room temperature $(0.039 \mathrm{eV}$; Figure S7c). Substantial TICT formation is thus expected, leading to negligible quantum yields of $\mathbf{3}$ in polar solvents.

Note that the assignment of the LE and TICT states is further corroborated by their associated charge transfer upon photoexcitation (Figure S8). The TICT state exhibits a greater extent of charge transfer than the LE state.

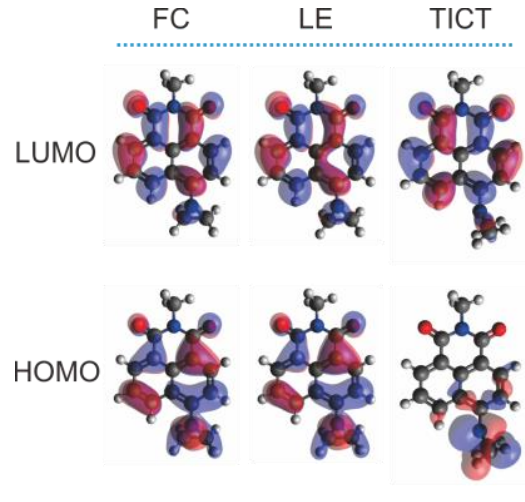

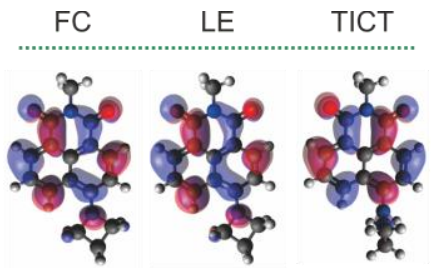

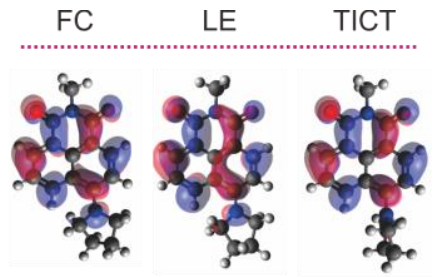

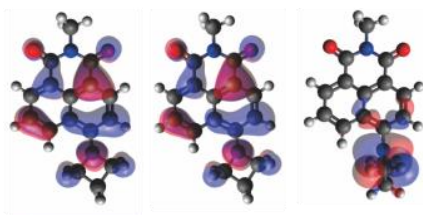

2

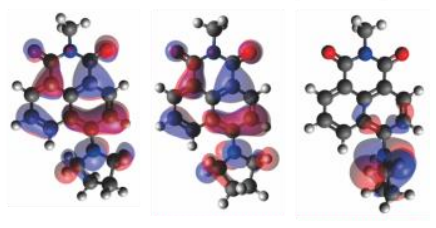

Figure S8. LUMOs and HOMOs of $\mathbf{1}-\mathbf{3}$ in ethanol (red: positive; blue: negative; isovalue: $0.02)$.

It is also worth noting that calculating PES, excitation energy, and oscillator strength of higher energy states (such as $\mathrm{S}_{2}$ ) will provide more insights about the photophysics of azacyclic ring substituted fluorophores and the relative stability of the LE and (twisted) ICT states.

\subsection{Geometry change in aziridinyl naphthalimide 1 upon photoexcitation}

The aziridine ring in $\mathbf{1}$ exhibits the up-up conformation. After photoexcitation, the $\mathrm{C} 4-\mathrm{N} 1$ bond gains more double-bond character in conjunction with intramolecular charge transfer from the aziridine ring to naphthalimide scaffold. Consequently, a slight flattering of the aziridine ring occurs in $\mathbf{1}$. This structural change is reflected in the associated dihedral angles, $\angle \mathrm{C}_{\alpha}-\mathrm{C}_{4}-\mathrm{N}_{1}-\mathrm{C}^{\prime}$ and $\angle \mathrm{C}_{\beta}-\mathrm{C}_{4}-\mathrm{N}_{1}-\mathrm{C}^{\prime}$ (Table S4). In contrast, the molecular structure of $\mathbf{2}$ remains flat both before and after photoexcitation. The greater geometry relaxation in $\mathbf{1}$ leads to a larger Stokes shift (127 in ethanol), in comparison to that of 2 (88 $\mathrm{nm}$ in ethanol).

Table S4. Dihedral angles along the $\mathrm{N}-\mathrm{C}_{\text {aro }}$ bond in the theoretically optimized molecular structures of $\mathbf{1}$ in both the $\mathrm{S}_{0}$ and $\mathrm{S}_{1}$ state in ethanol.

\begin{tabular}{|l|l|l|}
\hline & the $\mathrm{S}_{0}$ state & the $\mathrm{S}_{1}$ state \\
\hline
\end{tabular}




\begin{tabular}{|c|c|c|}
\hline$\angle \mathrm{C}_{\alpha}-\mathrm{C}_{4}-\mathrm{N}_{1}-\mathrm{C}^{\prime}\left(^{\circ}\right)$ & -69.02 & -56.72 \\
\hline$\angle \mathrm{C}_{\beta}-\mathrm{C}_{4}-\mathrm{N}_{1}-\mathrm{C}^{\prime \prime}\left(^{\circ}\right)$ & 40.11 & 39.11 \\
\hline
\end{tabular}

1.8 Relative energy levels of the Franck-Condon (FC, absorption), local excited (LE), and twisted intramolecular charge transfer (TICT) states in coumarin, phthalimide and NBD dyes in ethanol

Comparing the $\mathrm{S}_{1}$ energy level differences between the LE and TICT states, we notice that aziridinyl fluorophores demonstrate the highest TICT resistance, followed by azetidinyl dyes (Figure S9). In contrast, conventional dimethylamino groups lead to the largest energy reduction via LE-to-TICT transitions, indicating a strong TICT tendency.

The assignment of the LE and TICT states is corroborated by their associated charge transfer upon photoexcitation (Figures S10-S12). The TICT state exhibits a greater extent of charge transfer than the LE state.<smiles>[R]c1ccc2c(C)cc(=O)oc2c1</smiles>

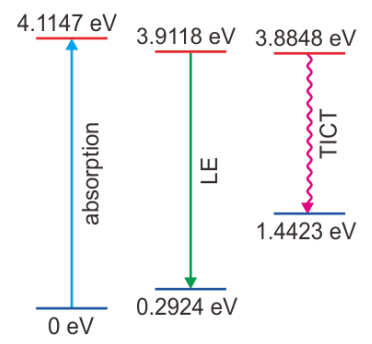<smiles>[R]c1ccc2c(c1)C(=O)N(C)C2=O</smiles>

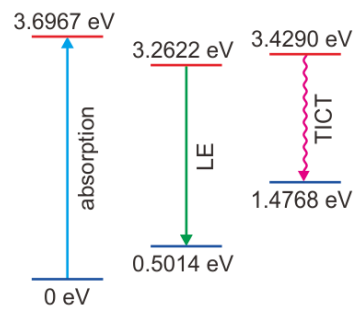<smiles>[R]c1ccc([N+](=O)[O-])c2nonc12</smiles>

$R=\frac{\xi}{\xi} N$
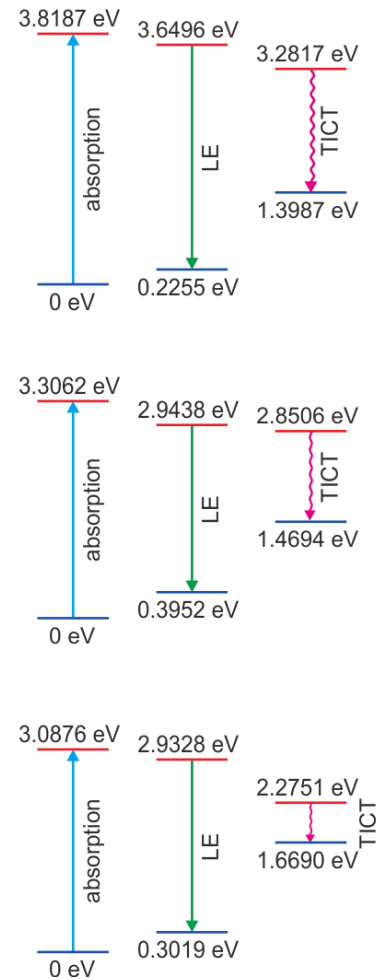

$$
R=\frac{\xi}{\xi} N^{\prime}
$$
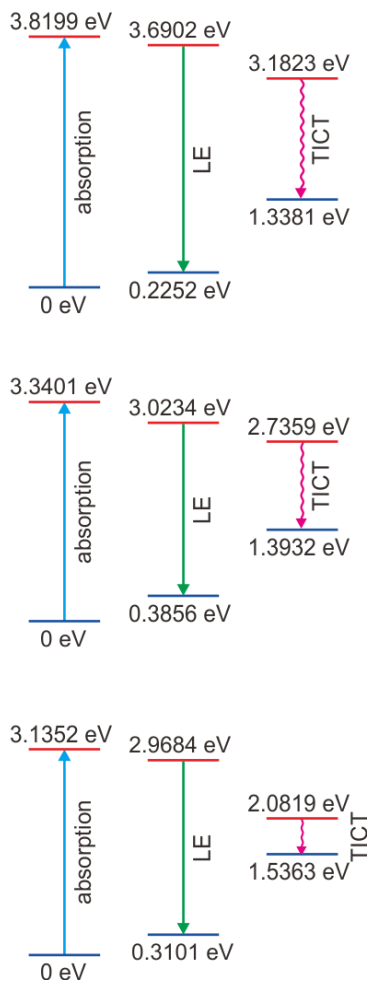

Figure S9. Calculated relative $S_{0}$ (blue) and $S_{1}$ (red) energy levels corresponding to the Franck-Condon (absorption), LE (emission) and TICT (non-radiative) states of selected coumarin, phthalimide and NBD dyes in ethanol. 


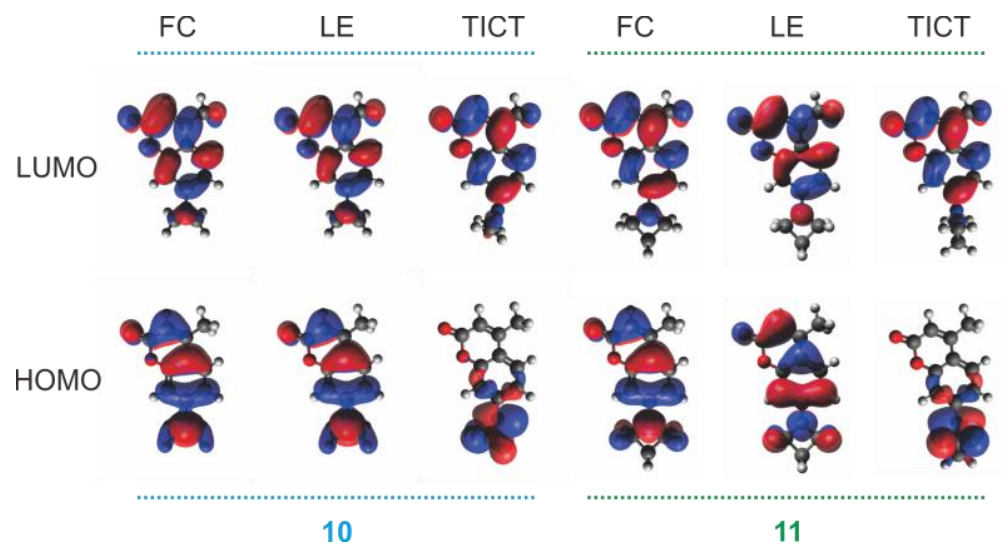

Figure S10. LUMOs and HOMOs of $\mathbf{1 0}$ and $\mathbf{1 1}$ in ethanol (red: positive; blue: negative; isovalue: 0.02 ).

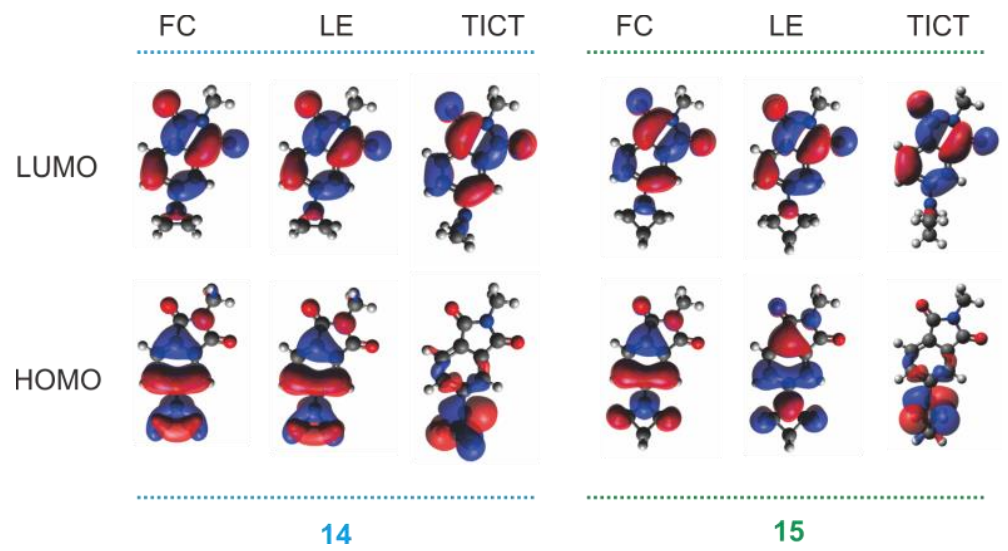

Figure S11. LUMOs and HOMOs of $\mathbf{1 4}$ and $\mathbf{1 5}$ in ethanol (red: positive; blue: negative; isovalue: 0.02 ).

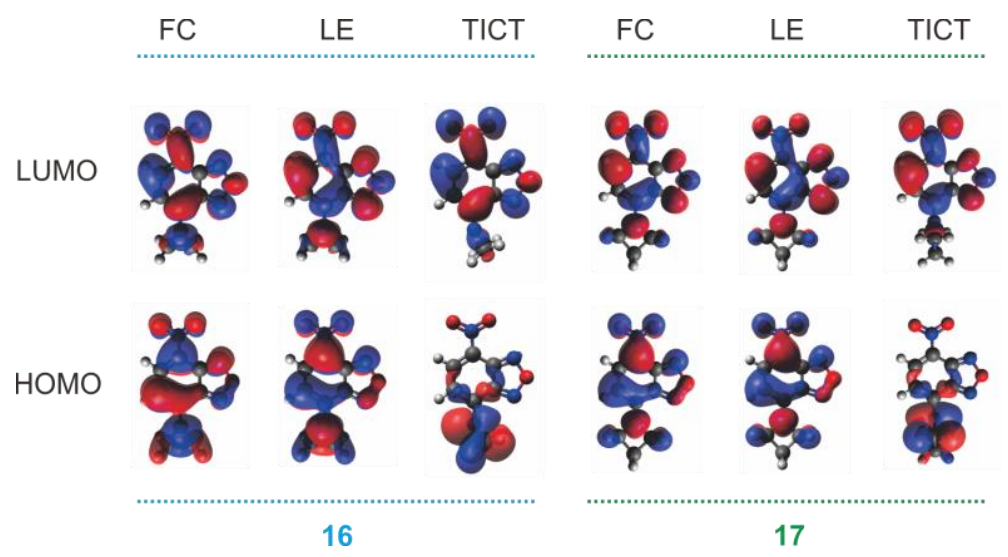

Figure S12. LUMOs and HOMOs of $\mathbf{1 6}$ and $\mathbf{1 7}$ in ethanol (red: positive; blue: negative; isovalue: 0.02).

\subsection{Quantum yield vulnerability to hydrogen bond interactions}

We have found one plausible mechanism to explain quantum yield vulnerabilities to hydrogen bond interactions among different fluorophores. This vulnerability is closely related to the partial charge increase upon photoexcitation, at hydrogen bond 
formation sites in the fluorophore scaffolds. We denote the total change at these sites during $\mathrm{HOMO} \rightarrow$ LUMO transition as $\Delta$.

In fluorophores with small $\Delta$ changes, the quantum yields are relatively high in general (Figure S13). In stark contrast, in fluorophores with large $\Delta$ changes, their quantum yields are significantly lower, conceivably due to significant hydrogen bond interactions upon the photoexcitation of these fluorophores (Figure S14). This contrast becomes even more obvious in aqueous solution (Figure 2c). Note that quantum yields of compounds A (2), E (15), and F (17) are from our in-house measurements, while other known values are reported by Lavis et al. ${ }^{9}$

Based on this mechanism we predict that compounds $\mathbf{H}, \mathbf{I}$, and $\mathbf{J}$ (and other compounds from these fluorophore families) possess relatively low quantum yields in protonic solvents (Figure S14).

A

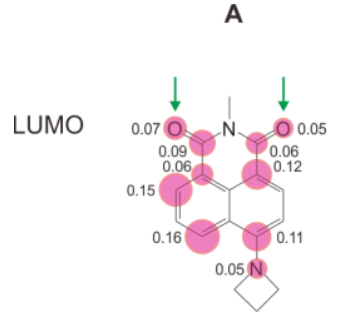

HOMO

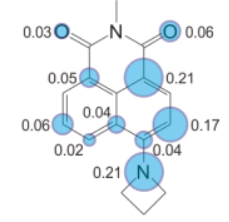

$$
\begin{gathered}
\text { EtOH } \\
\Delta=0.03 \\
\Phi=0.63
\end{gathered}
$$
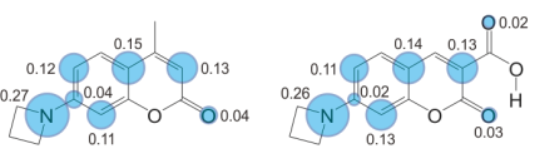

$$
\begin{aligned}
& \text { EtOH } \\
& \Delta=0.07 \\
& \Phi=0.96
\end{aligned}
$$
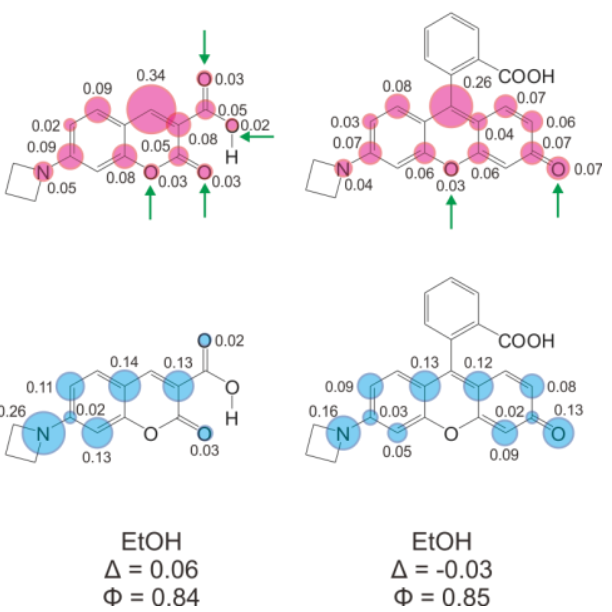

Figure S13. The atomic contributions to the HOMO and LUMO electron densities of representative compounds whose quantum yields are less vulnerable to hydrogen bond interactions. The blue/pink circle size represents the atomic contribution; only contributions greater than 0.02 are shown. Hydrogen bond formation sites are highlighted by arrows. 


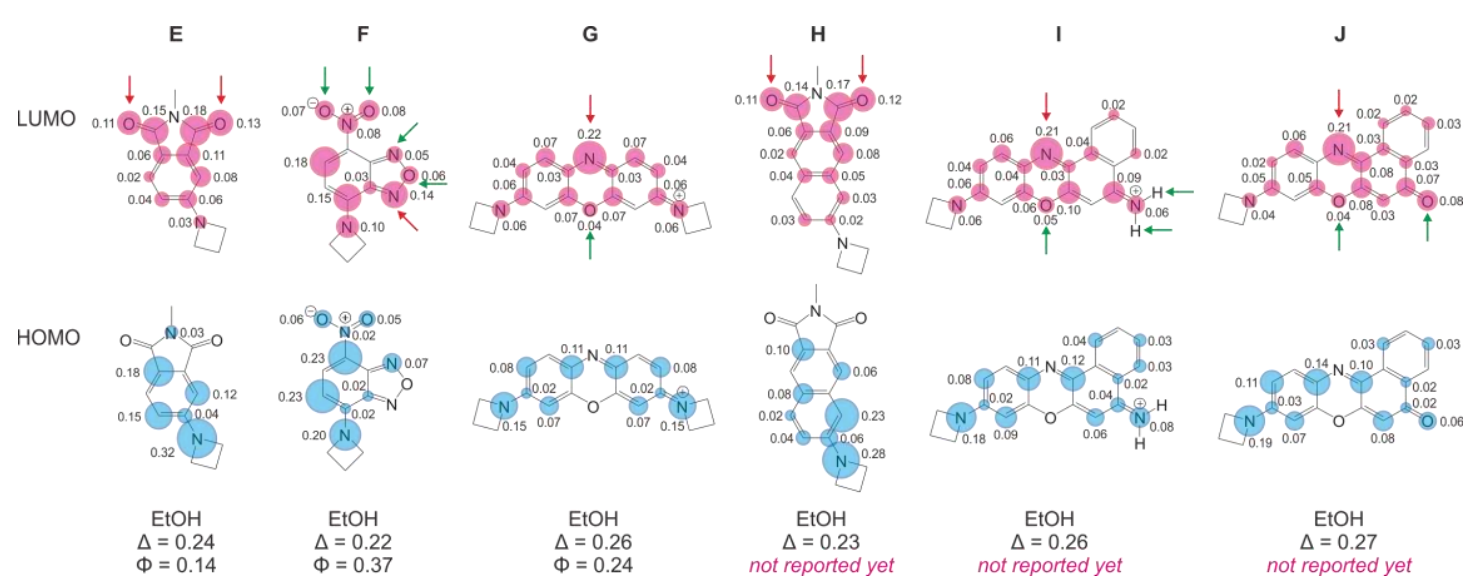

Figure S14. The atomic contributions to the HOMO and LUMO electron densities of representative compounds whose quantum yields are considerably vulnerable to hydrogen bond interactions. The blue/pink circle size represents the atomic contribution; only contributions greater than 0.02 are shown. Hydrogen bond formation sites are indicated by arrows. Molecular sites that experience significant partial charge increase upon photoexcitation are highlighted by red arrows. 


\section{Chemical synthesis and characterizations}

\subsection{Materials and instruments}

Unless otherwise stated, all reagents were purchased from commercial suppliers and used without further purification.

${ }^{1} \mathrm{H}-\mathrm{NMR}$ and ${ }^{13} \mathrm{C}-\mathrm{NMR}$ spectra were recorded on a Bruker 400 spectrometer, using TMS as an internal standard. Chemical shifts were given in ppm and coupling constants $(J)$ in Hz. Mass spectrometry data were obtained with a HP1100LC/MSD mass spectrometer and a LC/Q-TOF MS spectrometer.

HPLC was monitored on Waters e2695 (separations module), 2998PDA detector and SunFire@ C18 (4.6 mm × 150 mm $5 \mu \mathrm{m}$ C18 column; $10 \mu \mathrm{L}$ injection; $\mathrm{MeOH} / \mathrm{H}_{2} \mathrm{O}$, linear gradient, $30 \mathrm{~min}$ run; $1 \mathrm{~mL} / \mathrm{min}$ flow; UV detection at $254 \mathrm{~nm}$ ). High-resolution mass spectrometry (HRMS) data were obtained using ESI (6540 UHD Q-TOF, positive ion).

UV-vis absorption spectra were collected on an Agilent Cary 60 UV-Vis Spectrophotometer. Fluorescence measurements were performed on an Agilent CARY Eclipse fluorescence spectrophotometer.

The fluorescence lifetime of $\mathbf{1}-\mathbf{7}$ in various solvents were measured using Fluoromax-4 spectro-fluorometer equipped with a NanoLED-370 pulsed diode (excitation wavelength, $368 \mathrm{~nm}$ ) and a DeltaHub TCSPC controller. The fluorescence lifetime of all samples was monitored at their respective peak emission wavelengths.

The quantum yields of $\mathbf{1}-\mathbf{1 7}$ were determined via the relative determination method, with Coumarin 153, quinine sulphate and Rhodamine 101 as a reference compound. ${ }^{10}$ For photostability tests under white light, a 500W tungsten lamp was used to irradiate dyes 1, 2, and Rhodamine B dissolved in DMSO/water mixture (volume ratio, 30:70) continuously. Their emission intensities were measured after $0,1,2,3,4,5,6,7,8,9$, 10 , and 12 hours of irradiation. 
<smiles>CN1C(=O)c2cccc3c(Br)ccc(c23)C1=O</smiles><smiles>[R]Nc1ccc2c3c(cccc13)C(=O)N(C)C2=O</smiles><smiles>CN1C(=O)c2cccc3c(N4CC4)ccc(c23)C1=O</smiles>

1<smiles>CN1C(=O)c2cccc3c(N4CCC4)ccc(c23)C1=O</smiles>

2<smiles>CN1C(=O)c2cccc3c(N4CCCC4)ccc(c23)C1=O</smiles>

3<smiles>CN1C(=O)c2cccc3c(N4CCOCC4)ccc(c23)C1=O</smiles>

4<smiles>CN1C(=O)c2cccc3c(N4CCCCC4)ccc(c23)C1=O</smiles>

5<smiles>CN1C(=O)c2cccc3c(N4CCCCCC4)ccc(c23)C1=O</smiles>

6<smiles>CN1C(=O)c2cccc3c(N(C)C)ccc(c23)C1=O</smiles>

7

Figure S15. Synthesis of Compound 1-7.

\subsubsection{N-Methyl-4-(aziridin-1-yl)-1,8-naphthalimide (1)}<smiles>CN1C(=O)c2cccc3c(N4CC4)ccc(c23)C1=O</smiles>

$150 \mathrm{mg}$ (3.5 mmol, 5 eq.) aziridine was added dropwise to a solution of $200 \mathrm{mg}(0.69$ mmol) $N$-methyl-4-Bromo-1,8-naphthalimide in $5 \mathrm{~mL} 2$-methoxyethanol. The mixture was heated to $80{ }^{\circ} \mathrm{C}$ for $10 \mathrm{~h}$. The solvent was removed under reduced pressure and the crude product was then purified by column chromatography $\left(\mathrm{SiO}_{2}\right.$, $\left.\mathrm{CHCl}_{3}\right)$ to give 1 as a yellow solid in $18 \%$ yield $(32 \mathrm{mg}) .{ }^{1} \mathrm{H}-\mathrm{NMR}\left(\mathrm{CDCl}_{3}, 400 \mathrm{MHz}\right)$ $\delta 2.47(\mathrm{~s}, 4 \mathrm{H}), 3.54(\mathrm{~s}, 3 \mathrm{H}), 7.15(\mathrm{~d}, J=8.0 \mathrm{~Hz}, 1 \mathrm{H}), 7.75(\mathrm{t}, J=8.0 \mathrm{~Hz}, 1 \mathrm{H}), 8.48(\mathrm{~d}$, $J=8.0 \mathrm{~Hz}, 1 \mathrm{H}), 8.65(\mathrm{~d}, J=8.0 \mathrm{~Hz}, 1 \mathrm{H}) .{ }^{13} \mathrm{C}-\mathrm{NMR}\left(\mathrm{CDCl}_{3}, 100 \mathrm{MHz}\right) \delta 26.91,28.79$, $115.95,116.77,122.99,126.06,126.17,129.03,129.06,131.30,132.51,156.89$, 164.22, 164.71. Analytical HPLC: $99.51 \%$ purity $(4.6 \mathrm{~mm} \times 150 \mathrm{~mm} 5 \mu \mathrm{m} \mathrm{C18}$ column; $10 \mu \mathrm{L}$ injection; 55-45\% $\mathrm{CH}_{3} \mathrm{OH} / \mathrm{H}_{2} \mathrm{O}$, linear gradient; 30 min run; 1 $\mathrm{mL} / \mathrm{min}$ flow; detection at $254 \mathrm{~nm}$ ). HRMS (ESI) calcd for $\mathrm{C}_{15} \mathrm{H}_{13} \mathrm{~N}_{2} \mathrm{O}_{2}\left[\mathrm{MH}^{+}\right]$ 253.0977, found 253.0984.

\subsubsection{N-Methyl-4-(azetidin-1-yl)-1,8-naphthalimide (2)}<smiles>CN1C(=O)c2cccc3c(N4CCC4)ccc(c23)C1=O</smiles> 
$200 \mathrm{mg}$ ( $3.5 \mathrm{mmol}, 5$ eq.) azetidine was added dropwise to a solution of $200 \mathrm{mg}(0.69$ mmol) $N$-methyl-4-Bromo-1,8-naphthalimide in $5 \mathrm{~mL}$ 2-methoxyethanol. The mixture was heated to reflux for $2 \mathrm{~h}$, while monitored by TLC. After the reaction was completed, the solution was cooled to room temperature to give yellow needle crystals. The product was filtered off and then washed with hexane to give compound 2 in $66 \%$ yield $(120 \mathrm{mg}) .{ }^{1} \mathrm{H}-\mathrm{NMR}\left(\mathrm{CDCl}_{3}, 400 \mathrm{MHz}\right) \delta 2.56(\mathrm{~m}, J=7.6 \mathrm{~Hz}, 2 \mathrm{H}), 3.53$ $(\mathrm{s}, 3 \mathrm{H}), 4.50(\mathrm{t}, J=7.6 \mathrm{~Hz}, 4 \mathrm{H}), 6.38(\mathrm{~d}, J=8.8 \mathrm{~Hz}, 1 \mathrm{H}), 7.51(\mathrm{t}, J=8.0 \mathrm{~Hz}, 1 \mathrm{H})$, $8.25(\mathrm{~d}, J=8.4 \mathrm{~Hz}, 1 \mathrm{H}), 8.39(\mathrm{~d}, J=8.4 \mathrm{~Hz}, 1 \mathrm{H}), 8.55(\mathrm{~d}, J=7.2 \mathrm{~Hz}, 1 \mathrm{H}) .{ }^{13} \mathrm{C}-\mathrm{NMR}$ $\left(\mathrm{CDCl}_{3}, 100 \mathrm{MHz}\right) \delta 17.08,26.80,55.38,106.25,110.15,120.93,122.59,123.69$, 130.09, 130.46, 131.12, 133.31, 152.55, 164.36, 165.06. Analytical HPLC: $98.96 \%$ purity $\left(4.6 \mathrm{~mm} \times 150 \mathrm{~mm} 5 \mu \mathrm{m} \mathrm{C} 18\right.$ column; $10 \mu \mathrm{L}$ injection; $70-30 \% \mathrm{CH}_{3} \mathrm{OH} / \mathrm{H}_{2} \mathrm{O}$, linear gradient; $30 \mathrm{~min}$ run; $1 \mathrm{~mL} / \mathrm{min}$ flow; detection at $254 \mathrm{~nm}$ ). HRMS (ESI) calcd for $\mathrm{C}_{16} \mathrm{H}_{15} \mathrm{~N}_{2} \mathrm{O}_{2}\left[\mathrm{MH}^{+}\right]$267.1134, found 267.1145.

\subsubsection{N-Methyl-4-(pyrrolidin-1-yl)-1,8-naphthalimide (3)}<smiles>CN1C(=O)c2cccc3c(N4CCCC4)ccc(c23)C1=O</smiles>

$245 \mathrm{mg}$ ( $3.5 \mathrm{mmol}, 5$ eq.) pyrrolidine was added dropwise to a solution of $200 \mathrm{mg}$ (0.69 mmol) $\mathrm{N}$-methyl-4-Bromo-1,8-naphthalimide in $5 \mathrm{~mL} \mathrm{2-methoxyethanol.} \mathrm{The}$ mixture was heated to reflux for $2 \mathrm{~h}$, while monitored by TLC. After the reaction was completed, the solution was cooled to room temperature to give yellow needle crystals. The product was filtered off and then washed with hexane to give compound 3 in $87 \%$ yield $(168 \mathrm{mg}) .{ }^{1} \mathrm{H}-\mathrm{NMR}\left(\mathrm{CDCl}_{3}, 400 \mathrm{MHz}\right) \delta 2.09(\mathrm{t}, J=6.0 \mathrm{~Hz}, 4 \mathrm{H}), 3.51$ $(\mathrm{s}, 3 \mathrm{H}), 3.75(\mathrm{t}, J=6.0 \mathrm{~Hz}, 4 \mathrm{H}), 6.72(\mathrm{~d}, J=8.4 \mathrm{~Hz}, 1 \mathrm{H}), 7.47(\mathrm{t}, J=8.0 \mathrm{~Hz}, 1 \mathrm{H})$, $8.34(\mathrm{~d}, J=8.4 \mathrm{~Hz}, 1 \mathrm{H}), 8.51(\mathrm{~m}, 2 \mathrm{H}) .{ }^{13} \mathrm{C}-\mathrm{NMR}\left(\mathrm{CDCl}_{3}, 100 \mathrm{MHz}\right) \delta 26.08,26.73$, $53.15,108.38,110.40,122.29,122.46,122.90,130.91,130.97,131.93,133.31$, 152.52, 164.24, 165.10. Analytical HPLC: $99.86 \%$ purity $(4.6 \mathrm{~mm} \times 150 \mathrm{~mm} 5 \mu \mathrm{m}$ C18 column; $10 \mu \mathrm{L}$ injection; $70-30 \% \mathrm{CH}_{3} \mathrm{OH} / \mathrm{H}_{2} \mathrm{O}$, linear gradient; 30 min run; 1 $\mathrm{mL} / \mathrm{min}$ flow; detection at $254 \mathrm{~nm}$ ). HRMS (ESI) calcd for $\mathrm{C}_{17} \mathrm{H}_{17} \mathrm{~N}_{2} \mathrm{O}_{2}\left[\mathrm{MH}^{+}\right]$ 281.1290 , found 281.1295 .

\subsubsection{N-Methyl-4-morpholino-1,8-naphthalimide (4)}<smiles>CN1C(=O)c2cccc3c(N4CCOCC4)ccc(c23)C1=O</smiles> 
$300 \mathrm{mg}$ ( $3.5 \mathrm{mmol}, 5$ eq.) morpholine was added dropwise to a solution of $200 \mathrm{mg}$ (0.69 mmol) $\mathrm{N}$-methyl-4-Bromo-1,8-naphthalimide in $5 \mathrm{~mL} \mathrm{2-methoxyethanol.} \mathrm{The}$ mixture was heated to reflux for $2 \mathrm{~h}$, while monitored by TLC. After the reaction was completed, the solution was cooled to room temperature to give yellow needle crystals. The product was filtered off and then washed with hexane to give compound 4 in $91 \%$ yield $(186 \mathrm{mg}) .{ }^{1} \mathrm{H}-\mathrm{NMR}\left(\mathrm{CDCl}_{3}, 400 \mathrm{MHz}\right) \delta 3.27(\mathrm{t}, J=4.4 \mathrm{~Hz}, 4 \mathrm{H}), 3.53$ $(\mathrm{s}, 3 \mathrm{H}), 4.02(\mathrm{t}, J=4.4 \mathrm{~Hz}, 4 \mathrm{H}), 7.22(\mathrm{~d}, J=8.0 \mathrm{~Hz}, 1 \mathrm{H}), 7.69(\mathrm{t}, J=7.8 \mathrm{~Hz}, 1 \mathrm{H})$, $8.41(\mathrm{~d}, J=8.4 \mathrm{~Hz}, 1 \mathrm{H}), 8.50(\mathrm{~d}, J=8.0 \mathrm{~Hz}, 1 \mathrm{H}), 8.56(\mathrm{~d}, J=7.2 \mathrm{~Hz}, 1 \mathrm{H}) .{ }^{13} \mathrm{C}-\mathrm{NMR}$ $\left(\mathrm{CDCl}_{3}, 100 \mathrm{MHz}\right) \delta 26.88,53.44,66.97,114.93,117.02,123.16,125.81,126.10$, 129.70, 130.05, 131.12, 132.47, 155.61, 164.18, 164.64. Analytical HPLC: $99.47 \%$ purity $\left(4.6 \mathrm{~mm} \times 150 \mathrm{~mm} 5 \mu \mathrm{m} \mathrm{C} 18\right.$ column; $10 \mu \mathrm{L}$ injection; $55-45 \% \mathrm{CH}_{3} \mathrm{OH} / \mathrm{H}_{2} \mathrm{O}$, linear gradient; $30 \mathrm{~min} \mathrm{run;} 1 \mathrm{~mL} / \mathrm{min}$ flow; detection at $254 \mathrm{~nm}$ ). HRMS (ESI) calcd for $\mathrm{C}_{17} \mathrm{H}_{17} \mathrm{~N}_{2} \mathrm{O}_{3}\left[\mathrm{MH}^{+}\right]$297.1239, found 297.1246.

\subsubsection{N-Methyl-4-(piperidin-1-yl)-1,8-naphthalimide (5)}<smiles>CN1C(=O)c2cccc3c(N4CCCCC4)ccc(c23)C1=O</smiles>

$293 \mathrm{mg}$ ( $3.5 \mathrm{mmol}, 5$ eq.) piperidine was added dropwise to a solution of $200 \mathrm{mg}$ (0.69 mmol) $\mathrm{N}$-methyl-4-Bromo-1,8-naphthalimide in $5 \mathrm{~mL} \mathrm{2-methoxyethanol.} \mathrm{The}$ mixture was heated to reflux for $2 \mathrm{~h}$, while monitored by TLC. After the reaction was completed, the solution was cooled to room temperature to give yellow needle crystals. The product was filtered off and then washed with hexane to give compound 5 in $90 \%$ yield $(182 \mathrm{mg}) .{ }^{1} \mathrm{H}-\mathrm{NMR}\left(\mathrm{CDCl}_{3}, 400 \mathrm{MHz}\right) \delta 1.73(\mathrm{~m}, 2 \mathrm{H}), 1.89(\mathrm{~m}, 4 \mathrm{H})$, $3.23(\mathrm{t}, J=5.0 \mathrm{~Hz}, 4 \mathrm{H}), 3.53(\mathrm{~s}, 3 \mathrm{H}), 7.15(\mathrm{~d}, J=8.4 \mathrm{~Hz}, 1 \mathrm{H}), 7.66(\mathrm{t}, J=8.0 \mathrm{~Hz}, 1 \mathrm{H})$, $8.37(\mathrm{~d}, J=8.4 \mathrm{~Hz}, 1 \mathrm{H}), 8.47(\mathrm{~d}, J=8.4 \mathrm{~Hz}, 1 \mathrm{H}), 8.55(\mathrm{~d}, J=7.2 \mathrm{~Hz}, 1 \mathrm{H}) .{ }^{13} \mathrm{C}-\mathrm{NMR}$ $\left(\mathrm{CDCl}_{3}, 100 \mathrm{MHz}\right) \delta 24.35,26.23,26.85,54.55,114.69,115.77,122.95,125.33$, 126.23, 129.78, 130.63, 130.98, 132.66, 157.32, 164.39, 164.88. Analytical HPLC: $99.73 \%$ purity $(4.6 \mathrm{~mm} \times 150 \mathrm{~mm} 5 \mu \mathrm{m} \mathrm{C} 18$ column; $10 \mu \mathrm{L}$ injection; $80-20 \%$ $\mathrm{CH}_{3} \mathrm{OH} / \mathrm{H}_{2} \mathrm{O}$, linear gradient; $30 \mathrm{~min}$ run; $1 \mathrm{~mL} / \mathrm{min}$ flow; detection at $254 \mathrm{~nm}$ ). HRMS (ESI) calcd for $\mathrm{C}_{18} \mathrm{H}_{19} \mathrm{~N}_{2} \mathrm{O}_{2}\left[\mathrm{MH}^{+}\right]$295.1447, found 295.1454.

\subsubsection{N-Methyl-4-(hexamethyleneimin-1-yl)-1,8-naphthalimide (6)}<smiles>CN1C(=O)c2cccc3c(N4CCCCCC4)ccc(c23)C1=O</smiles> 
$341 \mathrm{mg}$ ( $3.5 \mathrm{mmol}, 5$ eq.) hexamethyleneimine was added dropwise to a solution of $200 \mathrm{mg}$ (0.69 mmol) $N$-methyl-4-Bromo-1,8-naphthalimide in $5 \mathrm{~mL} 2$ methoxyethanol. The mixture was heated to reflux for $2 \mathrm{~h}$, while monitored by TLC. After the reaction was completed, the solution was cooled to room temperature to give yellow needle crystals. The product was filtered off and then washed with hexane to give compound 6 in $92 \%$ yield $(197 \mathrm{mg}) .{ }^{1} \mathrm{H}-\mathrm{NMR}\left(\mathrm{CDCl}_{3}, 400 \mathrm{MHz}\right) \delta 1.79(\mathrm{~m}, 4 \mathrm{H})$, $1.94(\mathrm{~m}, 4 \mathrm{H}), 3.53(\mathrm{~s}, 3 \mathrm{H}), 3.59(\mathrm{t}, J=5.4 \mathrm{~Hz}, 4 \mathrm{H}), 7.13(\mathrm{~d}, J=8.4 \mathrm{~Hz}, 1 \mathrm{H}), 7.59$ (t, $J$ $=8.0 \mathrm{~Hz}, 1 \mathrm{H}), 8.42(\mathrm{~m}, 2 \mathrm{H}), 8.54(\mathrm{~d}, J=7.2 \mathrm{~Hz}, 1 \mathrm{H}) .{ }^{13} \mathrm{C}-\mathrm{NMR}\left(\mathrm{CDCl}_{3}, 100 \mathrm{MHz}\right) \delta$ 26.81, 27.68, 28.57, 55.67, 113.66, 113.77, 122.78, 124.31, 125.34, 130.39, 130.96, $131.53,132.63,157.69,164.34,165.01$. Analytical HPLC: $99.70 \%$ purity $(4.6 \mathrm{~mm} \times$ $150 \mathrm{~mm} 5 \mu \mathrm{m} \mathrm{C18}$ column; $10 \mu \mathrm{L}$ injection; 80-20\% $\mathrm{CH}_{3} \mathrm{OH} / \mathrm{H}_{2} \mathrm{O}$, linear gradient; 30 min run; $1 \mathrm{~mL} / \mathrm{min}$ flow; detection at $254 \mathrm{~nm}$ ). HRMS (ESI) calcd for $\mathrm{C}_{19} \mathrm{H}_{21} \mathrm{~N}_{2} \mathrm{O}_{2}$ $\left[\mathrm{MH}^{+}\right]$309.1603, found 309.1606.

\subsubsection{N-Methyl-4- dimethylamino-1,8-naphthalimide (7)}<smiles>CN1C(=O)c2cccc3c(N(C)C)ccc(c23)C1=O</smiles>

$155 \mathrm{mg}$ (3.5 mmol, 5 eq.) dimethylamine was added dropwise to a solution of $200 \mathrm{mg}$ (0.69 mmol) $\mathrm{N}$-methyl-4-Bromo-1,8-naphthalimide in $5 \mathrm{~mL} \mathrm{2-methoxyethanol.} \mathrm{The}$ mixture was heated to reflux for $2 \mathrm{~h}$, while monitored by TLC. After the reaction was completed, the solution was cooled to room temperature to give yellow needle crystals. The product was filtered off and then washed with hexane to give compound 7 in $90 \%$ yield $(157 \mathrm{mg}) .{ }^{1} \mathrm{H}-\mathrm{NMR}\left(\mathrm{CDCl}_{3}, 400 \mathrm{MHz}\right) \delta 3.10(\mathrm{~s}, 6 \mathrm{H}), 3.53(\mathrm{~s}, 3 \mathrm{H})$, $7.09(\mathrm{~d}, J=8.4 \mathrm{~Hz}, 1 \mathrm{H}), 7.63(\mathrm{t}, J=8.0 \mathrm{~Hz}, 1 \mathrm{H}), 8.42(\mathrm{~d}, J=8.4 \mathrm{~Hz}, 1 \mathrm{H}), 8.45(\mathrm{~d}, J=$ $8.0 \mathrm{~Hz}, 1 \mathrm{H}), 8.54(\mathrm{~d}, J=7.2 \mathrm{~Hz}, 1 \mathrm{H}) .{ }^{13} \mathrm{C}-\mathrm{NMR}\left(\mathrm{CDCl}_{3}, 100 \mathrm{MHz}\right) \delta 26.82,44.78$, $113.27,114.85,122.92,124.84,125.24,130.07,130.94,131.17,132.59,156.94$, 164.31, 164.86. Analytical HPLC: $99.81 \%$ purity $(4.6 \mathrm{~mm} \times 150 \mathrm{~mm} 5 \mu \mathrm{m} \mathrm{C18}$ column; $10 \mu \mathrm{L}$ injection; 70-30\% $\mathrm{CH}_{3} \mathrm{OH} / \mathrm{H}_{2} \mathrm{O}$, linear gradient; $30 \mathrm{~min}$ run; $1 \mathrm{~mL} / \mathrm{min}$ flow; detection at $254 \mathrm{~nm}$ ). HRMS (ESI) calcd for $\mathrm{C}_{15} \mathrm{H}_{15} \mathrm{~N}_{2} \mathrm{O}_{2}\left[\mathrm{MH}^{+}\right] 255.1134$, found 255.1133 .

2.2.8 2-(6-(aziridin-1-yl)-1,3-dioxo-1H-benzo[de]isoquinolin-2(3H)-yl)acetic acid (8)<smiles>CCOC(=O)CN1C(=O)c2cccc3c(Br)ccc(c23)C(=O)N1CC(=O)OCC</smiles> 
4-Bromo-1,8-naphthalic anhydride $(2.77 \mathrm{~g}, 10 \mathrm{mmol})$, glycine hydrochloride $(1.12 \mathrm{~g}$, $10 \mathrm{mmol})$ and TEA $(1.52 \mathrm{~g}, 15 \mathrm{mmol})$ were added into $50 \mathrm{~mL}$ ethanol. The solution was heated to reflux for $6 \mathrm{~h}$. The mixture was cooled to room temperature, and the precipitate was collected as grey solid (3.2 g) without further purification in $88 \%$ yield. ${ }^{1} \mathrm{H}$ NMR (400 MHz, DMSO) $\delta 8.69-8.54(\mathrm{~m}, 2 \mathrm{H}), 8.39(\mathrm{~d}, J=7.9 \mathrm{~Hz}, 1 \mathrm{H})$, 8.27 (d, $J=7.9 \mathrm{~Hz}, 1 \mathrm{H}), 8.10-7.95(\mathrm{~m}, 1 \mathrm{H}), 4.82$ (s, 2H), 4.17 (q, $J=7.0 \mathrm{~Hz}, 2 \mathrm{H}$ ), $1.22(\mathrm{t}, J=7.1 \mathrm{~Hz}, 3 \mathrm{H})$.<smiles>CCOC(=O)CN1C(=O)c2cccc3c(Br)ccc(c23)C(=O)N1CC(=O)OCC(O)C(OC)C(C)C</smiles>

Aziridine (119 mg, $2.76 \mathrm{mmol})$ was added dropwise to the solution of $\mathrm{N}$ ethoxycarbonylmethyl-4-Bromo-1,8-naphthalimide $(200 \mathrm{mg}, 0.55 \mathrm{mmol})$ in $5 \mathrm{~mL} 2$ methoxyethanol. The mixture was heated to $80^{\circ} \mathrm{C}$ for $12 \mathrm{~h}$. The solvent was removed under reduced pressure. The residue was purified by column chromatography $\left(\mathrm{SiO}_{2}\right.$, $\mathrm{DCM} / \mathrm{MeOH}, 200: 1, \mathrm{~V} / \mathrm{V})$ to give light yellow powder $(60 \mathrm{mg})$ in $34 \%$ yield. ${ }^{1} \mathrm{H}$ NMR (400 MHz, $\left.\mathrm{CDCl}_{3}\right) \delta 8.69(\mathrm{~d}, J=8.4 \mathrm{~Hz}, 1 \mathrm{H}), 8.63(\mathrm{~d}, J=7.2 \mathrm{~Hz}, 1 \mathrm{H}), 8.50(\mathrm{~d}$, $J=8.0 \mathrm{~Hz}, 1 \mathrm{H}), 7.77(\mathrm{t}, J=7.9 \mathrm{~Hz}, 1 \mathrm{H}), 7.17(\mathrm{~d}, J=8.0 \mathrm{~Hz}, 1 \mathrm{H}), 4.93(\mathrm{~s}, 2 \mathrm{H}), 4.24$ (q, $J=7.1 \mathrm{~Hz}, 2 \mathrm{H}), 2.48(\mathrm{~s}, 4 \mathrm{H}), 1.29(\mathrm{t}, J=7.1 \mathrm{~Hz}, 3 \mathrm{H})$.

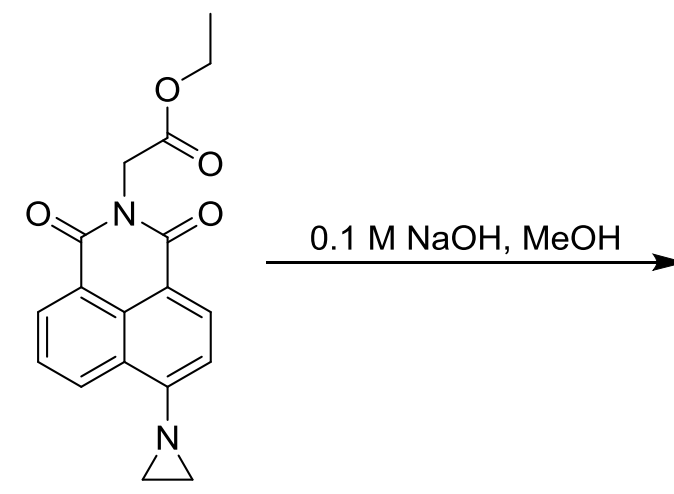<smiles>O=C(O)CN1C(=O)c2cccc3c(N4CC4)ccc(c23)C1=O</smiles>

8

$2 \mathrm{~mL} 0.1 \mathrm{M} \mathrm{NaOH}$ was slowly added to the solution of N-ethoxycarbonylmethyl-4azetidinly-1,8-naphthalimide $(50 \mathrm{mg}, 0.15 \mathrm{mmol})$ in $10 \mathrm{~mL}$ methanol at room temperature. After $4 \mathrm{~h}$, the solvent was removed under reduced pressure, and the product was purified by column chromatography $\left(\mathrm{SiO}_{2}, \mathrm{DCM} / \mathrm{MeOH}, 10: 1, \mathrm{~V} / \mathrm{V}\right)$ to give yellow powder $(25 \mathrm{mg})$ in $55 \%$ yield. ${ }^{13} \mathrm{C}$ NMR (101 MHz, DMSO) $\delta 172.40$, $163.77,163.29,157.31,132.40$, 131.06, 129.51, 128.85, 126.79, 126.15, 123.18, 116.52, 116.50, 43.99, 28.93. HRMS (ESI) calcd for $\mathrm{C}_{16} \mathrm{H}_{13} \mathrm{~N}_{2} \mathrm{O}_{4}\left[\mathrm{MH}^{+}\right]$297.0875, found 297.0863 . 
2.2.9 2-(6-(azetidin-1-yl)-1,3-dioxo-1H-benzo[de]isoquinolin-2(3H)-yl)acetic acid

(9)<smiles>CCOC(=O)CN1C(=O)c2cccc3c(Br)ccc(c23)C(=O)N1CC(=O)OCC</smiles>

Azetidine (157 mg, $2.76 \mathrm{mmol}$ ) was added dropwise to the solution of $\mathrm{N}$ ethoxycarbonylmethyl-4-Bromo-1,8-naphthalimide $(200 \mathrm{mg}, 0.55 \mathrm{mmol})$ in $5 \mathrm{~mL} 2$ methoxyethanol. The mixture was heated to reflux for $2 \mathrm{~h}$, while monitored by TLC. After the reaction was completed, the solution was cooled to room temperature to give yellow needle crystals. The product was filtered off and then washed with hexane to give $\mathrm{N}$-ethoxycarbonylmethyl-4-azetidinly-1,8-naphthalimide in 59\% yield $(110 \mathrm{mg})$. ${ }^{1} \mathrm{H}$ NMR $\left(400 \mathrm{MHz}, \mathrm{CDCl}_{3}\right) \delta 8.49(\mathrm{~d}, J=6.8 \mathrm{~Hz}, 1 \mathrm{H}), 8.33(\mathrm{~d}, J=8.5 \mathrm{~Hz}, 1 \mathrm{H}), 8.17$ $(\mathrm{d}, J=8.0 \mathrm{~Hz}, 1 \mathrm{H}), 7.45(\mathrm{t}, J=7.9 \mathrm{~Hz}, 1 \mathrm{H}), 6.29(\mathrm{~d}, J=8.5 \mathrm{~Hz}, 1 \mathrm{H}), 4.92(\mathrm{~s}, 2 \mathrm{H})$, $4.45(\mathrm{t}, J=7.5 \mathrm{~Hz}, 4 \mathrm{H}), 4.24(\mathrm{q}, J=7.1 \mathrm{~Hz}, 2 \mathrm{H}), 2.61-2.45(\mathrm{~m}, 2 \mathrm{H}), 1.29$ (t, $J=7.1$ $\mathrm{Hz}, 3 \mathrm{H}) .{ }^{13} \mathrm{C}$ NMR $\left(101 \mathrm{MHz}, \mathrm{CDCl}_{3}\right) \delta 168.56,164.42,163.53,152.54,133.59$, $131.42,130.80,130.51,123.59,122.04,120.81,109.21,106.07,61.35,55.31,41.26$, 17.00, 14.19.

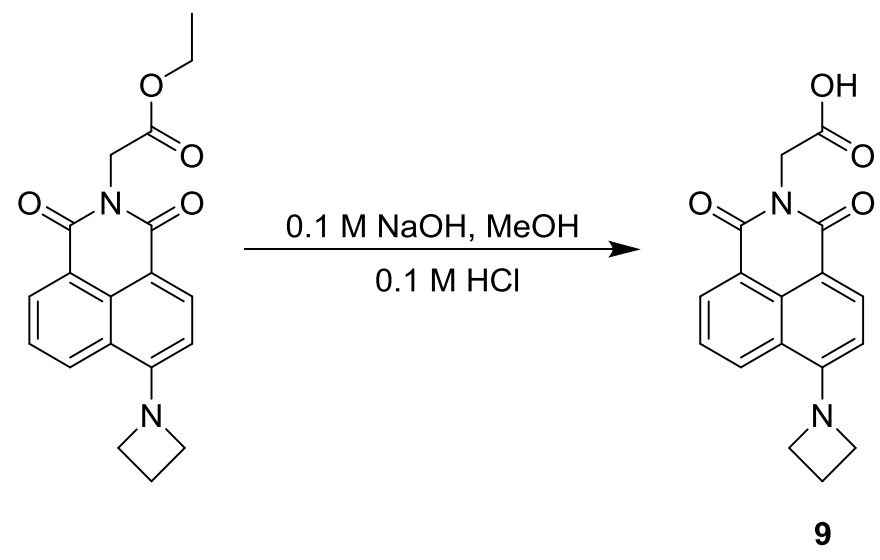

$5 \mathrm{~mL} 0.1 \mathrm{M} \mathrm{NaOH}$ was slowly added into the solution of N-ethoxycarbonylmethyl-4azetidinly-1,8-naphthalimide (100 $\mathrm{mg}, 0.30 \mathrm{mmol})$ dissolved in $20 \mathrm{~mL} \mathrm{MeOH}$ at room temperature. After $2 \mathrm{~h}, 0.1 \mathrm{M} \mathrm{HCl}$ was added into the solution to make its $\mathrm{pH}$ value to $2 . \mathrm{MeOH}$ was removed under reduced pressure, and the product was filtered off and washed with DCM to give $80 \mathrm{mg}$ yellow powder in $87 \%$ yield. ${ }^{1} \mathrm{H}$ NMR (400 MHz, DMSO) $\delta 12.92(\mathrm{~s}, 1 \mathrm{H}), 8.45(\mathrm{~d}, J=7.7 \mathrm{~Hz}, 2 \mathrm{H}), 8.24(\mathrm{~d}, J=8.5 \mathrm{~Hz}, 1 \mathrm{H}), 7.64$ $(\mathrm{t}, J=7.9 \mathrm{~Hz}, 1 \mathrm{H}), 6.51(\mathrm{~d}, J=8.6 \mathrm{~Hz}, 1 \mathrm{H}), 4.69(\mathrm{~s}, 2 \mathrm{H}), 4.53(\mathrm{t}, J=7.4 \mathrm{~Hz}, 4 \mathrm{H})$, 2.44-2.52 (2H). ${ }^{13} \mathrm{C}$ NMR (101 MHz, DMSO) $\delta$ 170.12, 163.94, 162.92, 153.02, 133.59, 131.79, 131.48, 130.63, 124.45, 121.71, 120.68, 108.03, 106.63, 55.79, 41.34, 16.91. HRMS (ESI) calcd for $\mathrm{C}_{17} \mathrm{H}_{15} \mathrm{~N}_{2} \mathrm{O}_{4}\left[\mathrm{MH}^{+}\right] 311.1032$, found 311.1026. 
<smiles>Cc1cc(=O)oc2cc(Br)ccc12</smiles>

3-Bromophenol (1.73 g, $10 \mathrm{mmol})$ was slowly added to $40 \mathrm{~mL} 80 \% \mathrm{H}_{2} \mathrm{SO}_{4}$ at $0{ }^{\circ} \mathrm{C}$. The mixture was stirred for over $20 \mathrm{~min}$, and ethyl acetoacetate $(1.30 \mathrm{~g}, 10 \mathrm{mmol})$ was added dropwise in $30 \mathrm{~min}$. After stirring for $24 \mathrm{~h}$ at room temperature, the reaction mixture was poured into $50 \mathrm{~mL}$ ice water and stirred for another $30 \mathrm{~min}$. The precipitate was collected and dried under reduced pressure to give $500 \mathrm{mg}$ white solid, yield $21 \% .{ }^{1} \mathrm{H}$ NMR $\left(400 \mathrm{MHz}, \mathrm{CDCl}_{3}\right) \delta 7.52(\mathrm{~d}, J=1.3 \mathrm{~Hz}, 1 \mathrm{H}), 7.47(\mathrm{~d}, J=8.4 \mathrm{~Hz}$, $1 \mathrm{H}), 7.43(\mathrm{dd}, J=8.5,1.6 \mathrm{~Hz}, 1 \mathrm{H}), 6.31(\mathrm{~d}, J=0.9 \mathrm{~Hz}, 1 \mathrm{H}), 2.43(\mathrm{~d}, J=1.0 \mathrm{~Hz}, 3 \mathrm{H})$. HRMS (ESI) calcd for $\mathrm{C}_{10} \mathrm{H}_{8} \mathrm{BrO}_{2}\left[\mathrm{MH}^{+}\right]$238.9708, found 238.9700.

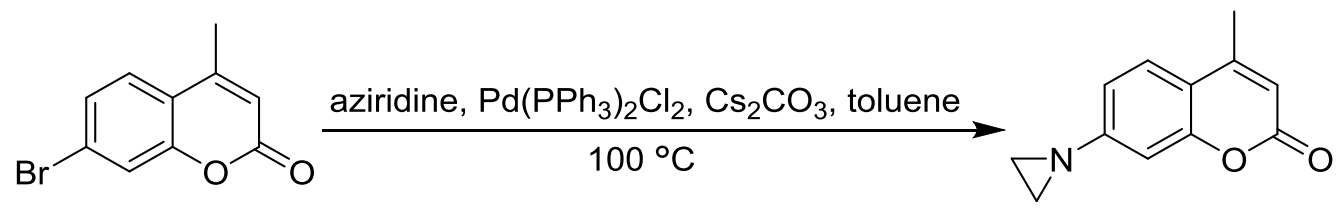

10

7-Bromo-4-methylcoumarin (100 mg, $0.42 \mathrm{mmol}), \mathrm{Cs}_{2} \mathrm{CO}_{3}(411 \mathrm{mg}, 1.26 \mathrm{mmol}$ ), $\mathrm{Pd}\left(\mathrm{PPh}_{3}\right)_{2} \mathrm{Cl}_{2}(19 \mathrm{mg}, 5 \% \mathrm{mmol})$, aziridine $(90 \mathrm{mg}, 2.10 \mathrm{mmol})$ were dissolved in 8 $\mathrm{mL}$ dry toluene under $\mathrm{N}_{2}$. The reaction mixture was slowly heated to $100{ }^{\circ} \mathrm{C}$ and stirred for $10 \mathrm{~h}$. The solvent was removed under reduced pressure, and the residue was further purified by column chromatography $\left(\mathrm{SiO}_{2}, \mathrm{DCM} / \mathrm{MeOH}, 400: 1, \mathrm{~V} / \mathrm{V}\right)$ to give $15 \mathrm{mg}$ white solid, yield $18 \% .{ }^{1} \mathrm{H}$ NMR $\left(400 \mathrm{MHz}, \mathrm{CDCl}_{3}\right) \delta 7.46(\mathrm{~d}, J=8.5 \mathrm{~Hz}, 1 \mathrm{H})$, $6.97(\mathrm{dd}, J=8.5,1.8 \mathrm{~Hz}, 1 \mathrm{H}), 6.91(\mathrm{~d}, J=1.8 \mathrm{~Hz}, 1 \mathrm{H}), 6.14(\mathrm{~s}, 1 \mathrm{H}), 2.39$ (s, 3H), $2.21(\mathrm{~s}, 4 \mathrm{H}) .{ }^{13} \mathrm{C}$ NMR $\left(101 \mathrm{MHz}, \mathrm{CDCl}_{3}\right) \delta 161.23,158.87,154.54,152.39,125.20$, $117.75,115.03,112.52,108.62,28.09,18.67$. Analytical HPLC: $98.13 \%$ purity $(4.6$ $\mathrm{mm} \times 150 \mathrm{~mm} 5 \mu \mathrm{m} \mathrm{C} 18$ column; $20 \mu \mathrm{L}$ injection; 45-55\% $\mathrm{MeOH} / \mathrm{H}_{2} \mathrm{O}$, linear gradient; $30 \mathrm{~min}$ run; $1 \mathrm{~mL} / \mathrm{min}$ flow; detection at $254 \mathrm{~nm}$ ). HRMS (ESI) calcd for $\mathrm{C}_{12} \mathrm{H}_{12} \mathrm{NO}_{2}\left[\mathrm{MH}^{+}\right] 202.0868$, found 202.0865.

\subsubsection{7-(azetidin-1-yl)-4-methyl-coumarin (11)}

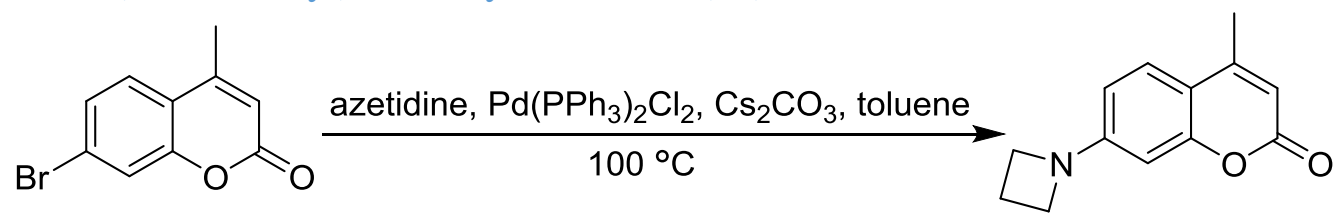

11

7-Bromo-4-methylcoumarin (100 mg, $0.42 \mathrm{mmol}), \mathrm{Cs}_{2} \mathrm{CO}_{3}(411 \mathrm{mg}, 1.26 \mathrm{mmol}$ ), $\mathrm{Pd}\left(\mathrm{PPh}_{3}\right)_{2} \mathrm{Cl}_{2}(19 \mathrm{mg}, 5 \% \mathrm{mmol})$, azetidine $(120 \mathrm{mg}, 2.10 \mathrm{mmol})$ were dissolved in 8 $\mathrm{mL}$ dry toluene under $\mathrm{N}_{2}$. The reaction mixture was slowly heated to $100{ }^{\circ} \mathrm{C}$ and stirred for $10 \mathrm{~h}$. The solvent was removed under reduced pressure, and the residue was further purified by column chromatography $\left(\mathrm{SiO}_{2}, \mathrm{DCM} / \mathrm{MeOH}, 200: 1\right.$, V/V) to give $62 \mathrm{mg}$ white solid, yield $66 \% .{ }^{1} \mathrm{H}$ NMR $\left(400 \mathrm{MHz}, \mathrm{CDCl}_{3}\right) \delta 7.37(\mathrm{~d}, J=8.6 \mathrm{~Hz}, 1 \mathrm{H})$, $6.30(\mathrm{dd}, J=8.6,2.0 \mathrm{~Hz}, 1 \mathrm{H}), 6.20(\mathrm{~d}, J=1.9 \mathrm{~Hz}, 1 \mathrm{H}), 5.96(\mathrm{~s}, 1 \mathrm{H}), 3.98(\mathrm{t}, J=7.3$ 
$\mathrm{Hz}, 4 \mathrm{H}), 2.48-2.38(\mathrm{~m}, 2 \mathrm{H}), 2.34(\mathrm{~s}, 3 \mathrm{H}) .{ }^{13} \mathrm{C} \mathrm{NMR}\left(101 \mathrm{MHz}, \mathrm{CDCl}_{3}\right) \delta$ 161.97, 155.59, 153.94, 153.04, 125.37, 110.27, 109.37, 107.68, 97.04, 51.75, 18.60, 16.50. Analytical HPLC: $99.05 \%$ purity $(4.6 \mathrm{~mm} \times 150 \mathrm{~mm} 5 \mu \mathrm{m} \mathrm{C} 18$ column; $10 \mu \mathrm{L}$ injection; $60-40 \% \mathrm{MeOH} / \mathrm{H}_{2} \mathrm{O}$, linear gradient; $30 \mathrm{~min}$ run; $1 \mathrm{~mL} / \mathrm{min}$ flow; detection at $254 \mathrm{~nm}$ ). HRMS (ESI) calcd for $\mathrm{C}_{13} \mathrm{H}_{14} \mathrm{NO}_{2}\left[\mathrm{MH}^{+}\right] 216.1025$, found 216.1015 .

\subsubsection{3'-(aziridin-1-yl)-6'-(diethylamino)-3H-spiro[isobenzofuran-1,9'-xanthen]-3-} one $(12)$

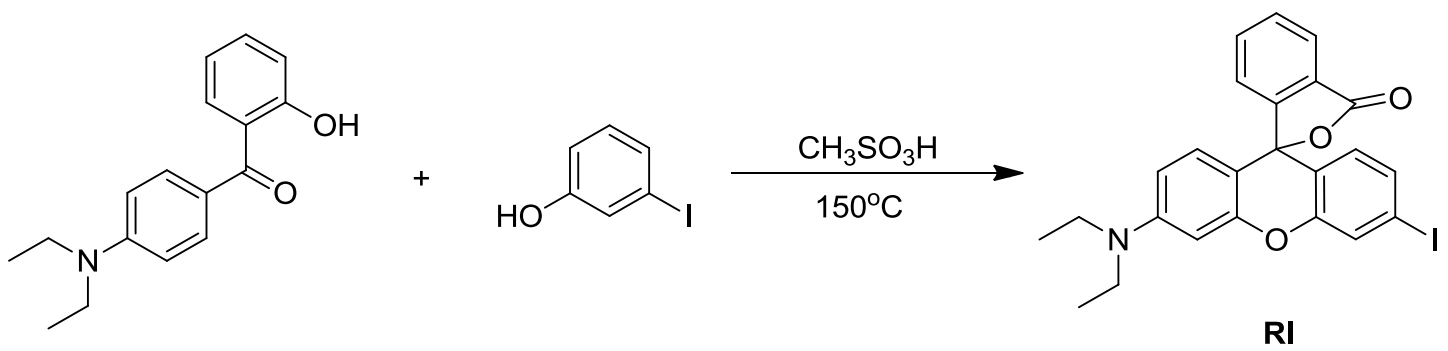

Solution of 2-(4-diethylamino-2-hydroxybenzoyl) benzoic acid (313 mg, $1.00 \mathrm{mmol}$ ) and 3-iodophenol (260 mg, $1.18 \mathrm{mmol})$ in $10 \mathrm{~mL} \mathrm{CH}_{3} \mathrm{SO}_{3} \mathrm{H}$ was slowly heated to $150{ }^{\circ} \mathrm{C}$. After 8 hours, saturated $\mathrm{Na}_{2} \mathrm{CO}_{3}$ was added till the $\mathrm{pH}$ value of the solution rises to 9 . The mixture was then extracted with $\mathrm{DCM}(3 \times 50 \mathrm{~mL})$. The organic product was dried with anhydrous $\mathrm{Na}_{2} \mathrm{SO}_{4}$ overnight and concentrated by rotary evaporation. The residue was further purified by column chromatography $\left(\mathrm{SiO}_{2}, \mathrm{DCM}\right)$ to give light pink solid $380 \mathrm{mg}$, yield 77\%. ${ }^{1} \mathrm{H}$ NMR $\left(400 \mathrm{MHz}, \mathrm{CDCl}_{3}\right) \delta 8.01(\mathrm{~d}, J=7.3 \mathrm{~Hz}$, $1 \mathrm{H}), 7.69-7.63(\mathrm{~m}, 3 \mathrm{H}), 7.61(\mathrm{td}, J=7.4,1.0 \mathrm{~Hz}, 1 \mathrm{H}), 7.30(\mathrm{dd}, J=8.3,1.7 \mathrm{~Hz}, 1 \mathrm{H})$, $7.16(\mathrm{t}, J=7.2 \mathrm{~Hz}, 1 \mathrm{H}), 6.56(\mathrm{~d}, J=8.9 \mathrm{~Hz}, 1 \mathrm{H}), 6.48(\mathrm{~d}, J=8.3 \mathrm{~Hz}, 1 \mathrm{H}), 6.44(\mathrm{~d}, J=$ $2.6 \mathrm{~Hz}, 1 \mathrm{H}), 6.40-6.34(\mathrm{~m}, 1 \mathrm{H}), 3.36(\mathrm{q}, J=7.1 \mathrm{~Hz}, 4 \mathrm{H}), 1.17(\mathrm{t}, J=7.1 \mathrm{~Hz}, 6 \mathrm{H})$. ${ }^{13} \mathrm{C}$ NMR $\left(101 \mathrm{MHz}, \mathrm{CDCl}_{3}\right) \delta 169.45,152.92,152.43,152.04,149.75,134.95$, $132.31,129.68,129.44,128.84,126.95,126.15,125.02,123.96,119.41,108.68$, $104.61,97.57,95.02,83.42,44.51,12.50$.

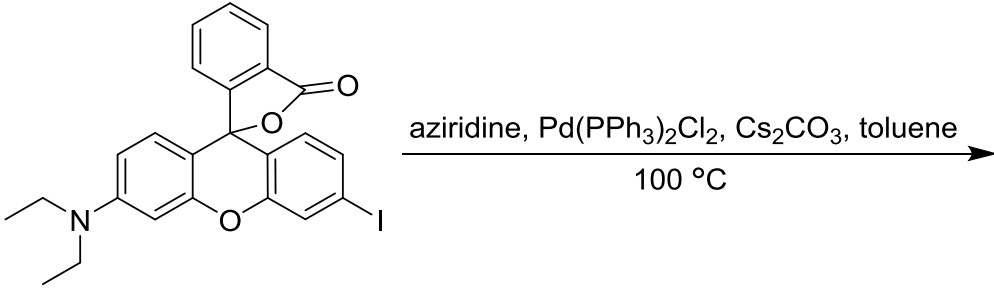

RI

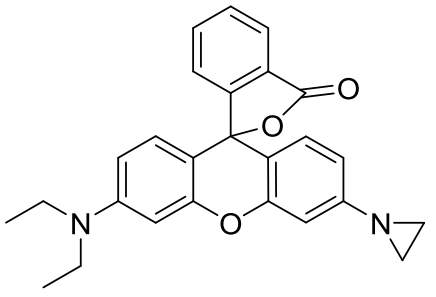

12

Compounds RI (100 mg, $0.20 \mathrm{mmol}), \mathrm{Cs}_{2} \mathrm{CO}_{3}(196 \mathrm{mg}, 0.60 \mathrm{mmol}), \mathrm{Pd}\left(\mathrm{PPh}_{3}\right)_{2} \mathrm{Cl}_{2}(9$ $\mathrm{mg}, 5 \% \mathrm{mmol}$ ), aziridine (43 $\mathrm{mg}, 1.0 \mathrm{mmol}$ ) were dissolved in $8 \mathrm{~mL}$ dry toluene under $\mathrm{N}_{2}$. The mixture was heated to $100{ }^{\circ} \mathrm{C}$ and stirred for $18 \mathrm{~h}$. The solvent was then removed under reduced pressure, and the residue was further purified by column chromatography $\left(\mathrm{SiO}_{2}, \mathrm{DCM} / \mathrm{MeOH}, 300: 1, \mathrm{~V} / \mathrm{V}\right)$ to give light pink solid $15 \mathrm{mg}$, yield 18\%. ${ }^{1} \mathrm{H}$ NMR $\left(400 \mathrm{MHz}, \mathrm{CDCl}_{3}\right) \delta 8.00(\mathrm{~d}, J=7.0 \mathrm{~Hz}, 1 \mathrm{H}), 7.69-7.62(\mathrm{~m}$, $1 \mathrm{H}), 7.62-7.55(\mathrm{~m}, 1 \mathrm{H}), 7.20(\mathrm{~d}, J=7.5 \mathrm{~Hz}, 1 \mathrm{H}), 6.86(\mathrm{~d}, J=1.9 \mathrm{~Hz}, 1 \mathrm{H}), 6.72-$ $6.65(\mathrm{~m}, 1 \mathrm{H}), 6.61(\mathrm{~d}, J=8.4 \mathrm{~Hz}, 1 \mathrm{H}), 6.55(\mathrm{~d}, J=8.9 \mathrm{~Hz}, 1 \mathrm{H}), 6.44(\mathrm{~d}, J=2.4 \mathrm{~Hz}$, $1 \mathrm{H}), 6.35(\mathrm{~d}, J=8.8 \mathrm{~Hz}, 1 \mathrm{H}), 3.36(\mathrm{dd}, J=14.1,7.1 \mathrm{~Hz}, 4 \mathrm{H}), 2.14(\mathrm{~s}, 4 \mathrm{H}), 1.21-$ 1.07 (m, 6H). HRMS (ESI) calcd for $\mathrm{C}_{26} \mathrm{H}_{25} \mathrm{~N}_{2} \mathrm{O}_{3}\left[\mathrm{MH}^{+}\right] 413.1865$, found 413.1847. 


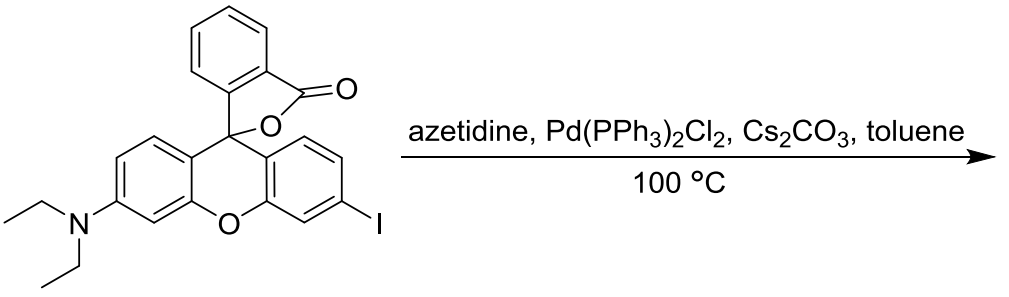

$\mathbf{R} \mathbf{I}$

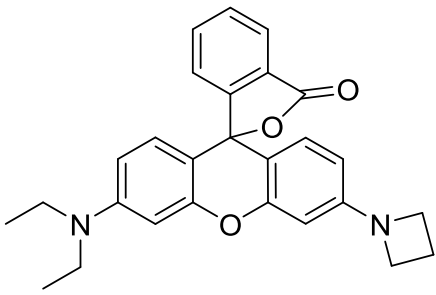

13

Compounds RI (100 mg, $0.20 \mathrm{mmol}), \mathrm{Cs}_{2} \mathrm{CO}_{3}(196 \mathrm{mg}, 0.60 \mathrm{mmol}), \mathrm{Pd}\left(\mathrm{PPh}_{3}\right)_{2} \mathrm{Cl}_{2}(9$ $\mathrm{mg}, 5 \% \mathrm{mmol})$, azetidine $(57 \mathrm{mg}, 1.0 \mathrm{mmol})$ were dissolved in $8 \mathrm{~mL}$ dry toluene under $\mathrm{N}_{2}$. The mixture was heated to $100{ }^{\circ} \mathrm{C}$ and stirred for $12 \mathrm{~h}$. The solvent was removed under reduced pressure, and the residue was further purified by column chromatography $\left(\mathrm{SiO}_{2}, \mathrm{DCM} / \mathrm{MeOH}, 30: 1, \mathrm{~V} / \mathrm{V}\right)$ to give purple powder $40 \mathrm{mg}$, yield 47\%. ${ }^{1} \mathrm{H}$ NMR (400 MHz, MeOD) $\delta 8.13-8.05$ (m, 1H), $7.68-7.57$ (m, 2H), $7.27-$ $7.16(\mathrm{~m}, 3 \mathrm{H}), 6.97(\mathrm{dd}, J=9.5,2.4 \mathrm{~Hz}, 1 \mathrm{H}), 6.89(\mathrm{~d}, J=2.4 \mathrm{~Hz}, 1 \mathrm{H}), 6.57(\mathrm{dd}, J=$ 9.1, 2.1 Hz, 1H), $6.50(\mathrm{~d}, J=2.1 \mathrm{~Hz}, 1 \mathrm{H}), 4.27(\mathrm{t}, J=7.6 \mathrm{~Hz}, 4 \mathrm{H}), 3.64(\mathrm{q}, J=7.1 \mathrm{~Hz}$, $4 \mathrm{H}), 2.60-2.40(\mathrm{~m}, 2 \mathrm{H}), 1.28(\mathrm{t}, J=6.9 \mathrm{~Hz}, 6 \mathrm{H})$. HRMS (ESI) calcd for $\mathrm{C}_{27} \mathrm{H}_{27} \mathrm{~N}_{2} \mathrm{O}_{3}\left[\mathrm{MH}^{+}\right]$427.2022, found 427.2028.

\subsubsection{4-(aziridin-1-yl)-N-methylphthalimide (14)}

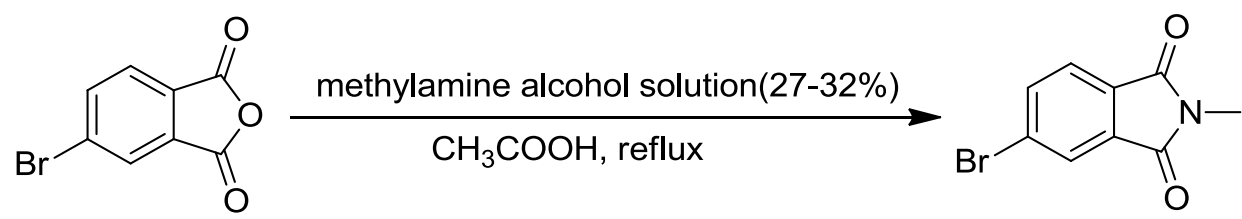

4-Br-phthalimide (1.0 g, $4.41 \mathrm{mmol})$ in $30 \mathrm{~mL}$ glacial acetic acid was slowly added into $1 \mathrm{~mL}$ methylamine alcohol solution at room temperature. The mixture was heated and stirred for $2 \mathrm{~h}$ to reflux. The precipitate was collected and washed with water. The product was obtained as $900 \mathrm{mg}$ white powder, yield $85 \% .{ }^{1} \mathrm{H}$ NMR (400 MHz, $\left.\mathrm{CDCl}_{3}\right) \delta 7.98(\mathrm{~d}, J=0.5 \mathrm{~Hz}, 1 \mathrm{H}), 7.85(\mathrm{~d}, J=7.5 \mathrm{~Hz}, 1 \mathrm{H}), 7.71(\mathrm{~d}, J=7.9 \mathrm{~Hz}, 1 \mathrm{H})$, $3.18(\mathrm{~s}, 3 \mathrm{H})$.

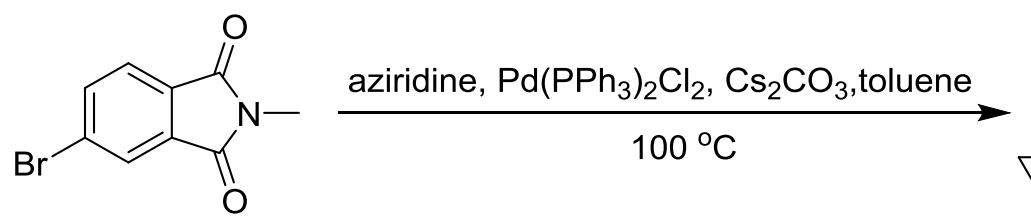<smiles>CN1C(=O)c2ccc(N3CC3)cc2C1=O</smiles>

14

4-Br-N-methylphthalimide (100 mg, $0.42 \mathrm{mmol}), \mathrm{Cs}_{2} \mathrm{CO}_{3}(411 \mathrm{mg}, 1.26 \mathrm{mmol}$ ), $\mathrm{Pd}\left(\mathrm{PPh}_{3}\right)_{2} \mathrm{Cl}_{2}$ (19 mg, 5\% mmol), aziridine $(90 \mathrm{mg}, 2.10 \mathrm{mmol})$ were dissolved in 5 $\mathrm{mL}$ dry toluene under $\mathrm{N}_{2}$. The mixture was heated to $100{ }^{\circ} \mathrm{C}$ and stirred for $10 \mathrm{~h}$. The solvent was removed under reduced pressure, and the residue was further purified by column chromatography $\left(\mathrm{SiO}_{2}, \mathrm{DCM} / \mathrm{MeOH}, 200: 1, \mathrm{~V} / \mathrm{V}\right)$ to give $30 \mathrm{mg}$ white solid, yield 36\%. ${ }^{1} \mathrm{H}$ NMR $\left(400 \mathrm{MHz}, \mathrm{CDCl}_{3}\right) \delta 7.62(\mathrm{~d}, J=8.0 \mathrm{~Hz}, 1 \mathrm{H}), 7.35(\mathrm{~s}, 1 \mathrm{H}), 7.18$ 
$(\mathrm{dd}, J=8.1,1.8 \mathrm{~Hz}, 1 \mathrm{H}), 3.07(\mathrm{~s}, 3 \mathrm{H}), 2.18(\mathrm{~s}, 4 \mathrm{H}) .{ }^{13} \mathrm{C} \mathrm{NMR}\left(101 \mathrm{MHz}, \mathrm{CDCl}_{3}\right) \delta$ 168.42, 168.30, 161.00, 133.99, 125.67, 125.53, 124.24, 115.64, 28.25, 23.91. Analytical HPLC: $98.65 \%$ purity $(4.6 \mathrm{~mm} \times 150 \mathrm{~mm} 5 \mu \mathrm{m}$ C18 column; $10 \mu \mathrm{L}$ injection; $45-55 \% \mathrm{MeOH} / \mathrm{H}_{2} \mathrm{O}$, linear gradient; $30 \mathrm{~min}$ run; $1 \mathrm{~mL} / \mathrm{min}$ flow; detection at $254 \mathrm{~nm}$ ). HRMS (ESI) calcd for $\mathrm{C}_{11} \mathrm{H}_{11} \mathrm{~N}_{2} \mathrm{O}_{2}\left[\mathrm{MH}^{+}\right] 203.0821$, found 203.0816 .

\subsubsection{4-(azetidin-1-yl)-N-methylphthalimide (15)}

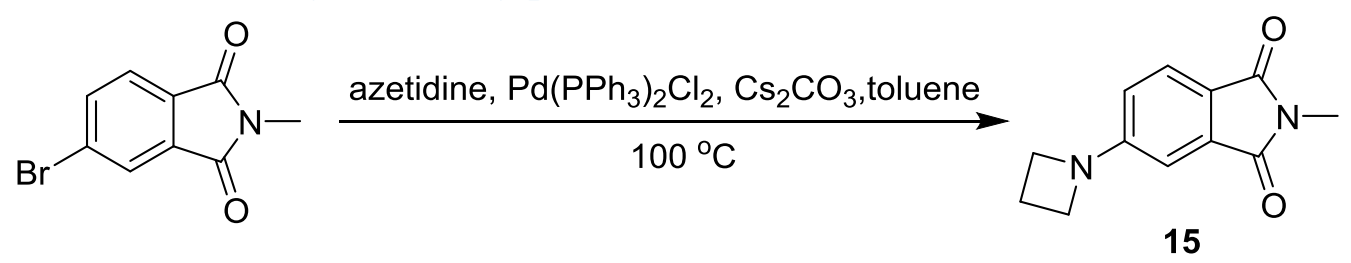

4-Br-N-methylphthalimide (100 mg, $0.42 \mathrm{mmol}$ ), $\mathrm{Cs}_{2} \mathrm{CO}_{3}(411 \mathrm{mg}, 1.26 \mathrm{mmol}$ ), $\mathrm{Pd}\left(\mathrm{PPh}_{3}\right)_{2} \mathrm{Cl}_{2}(19 \mathrm{mg}, 5 \% \mathrm{mmol})$, azetidine $(120 \mathrm{mg}, 2.10 \mathrm{mmol})$ were dissolved in 5 $\mathrm{mL}$ dry toluene under $\mathrm{N}_{2}$. The mixture was heated to $100{ }^{\circ} \mathrm{C}$ and stirred for $10 \mathrm{~h}$. The solvent was removed under reduced pressure, and the residue was further purified by column chromatography $\left(\mathrm{SiO}_{2}, \mathrm{DCM} / \mathrm{MeOH}, 200: 1, \mathrm{~V} / \mathrm{V}\right)$ to give $65 \mathrm{mg}$ light yellow powder, yield $72 \% .{ }^{1} \mathrm{H}$ NMR $\left(400 \mathrm{MHz}, \mathrm{CDCl}_{3}\right) \delta 7.60(\mathrm{~d}, J=8.2 \mathrm{~Hz}, 1 \mathrm{H}), 6.75(\mathrm{~d}, J$ $=2.0 \mathrm{~Hz}, 1 \mathrm{H}), 6.46(\mathrm{dd}, J=8.2,2.0 \mathrm{~Hz}, 1 \mathrm{H}), 4.04(\mathrm{t}, J=7.4 \mathrm{~Hz}, 4 \mathrm{H}), 3.12(\mathrm{~s}, 3 \mathrm{H})$, $2.54-2.36(\mathrm{~m}, 2 \mathrm{H}) .{ }^{13} \mathrm{C}$ NMR $\left(101 \mathrm{MHz}, \mathrm{CDCl}_{3}\right) \delta 169.16,168.97,155.10,134.73$, $124.59,118.41,113.25,104.48,51.70,23.74,16.50$. Analytical HPLC: $99.40 \%$ purity (4.6 mm $\times 150 \mathrm{~mm} 5 \mu \mathrm{m} \mathrm{C18} \mathrm{column;} 10 \mu \mathrm{L}$ injection; 70-30\% $\mathrm{MeOH} / \mathrm{H}_{2} \mathrm{O}$, linear gradient; $30 \mathrm{~min}$ run; $1 \mathrm{~mL} / \mathrm{min}$ flow; detection at $254 \mathrm{~nm}$ ). HRMS (ESI) calcd for $\mathrm{C}_{12} \mathrm{H}_{13} \mathrm{~N}_{2} \mathrm{O}_{2}\left[\mathrm{MH}^{+}\right]$217.0977, found 217.0977.

\subsubsection{4-(aziridin-1-yl)-7-nitrobenzofurazan (16)}

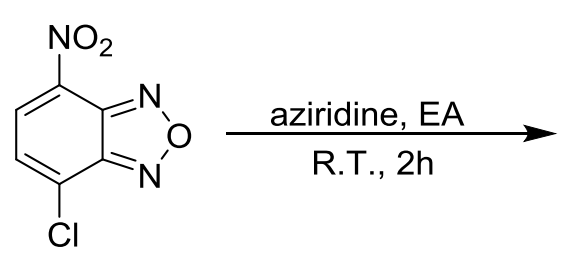<smiles>O=[N+]([O-])c1ccc(N2CC2)c2nonc12</smiles>

16

Aziridine (108 mg, $2.50 \mathrm{mmol})$ was slowly added into the solution of 4-chloro-7nitrobenzofurazan $(100 \mathrm{mg}, 0.50 \mathrm{mmol})$ in $10 \mathrm{~mL}$ EA at room temperature. The mixture was stirred for $4 \mathrm{~h}$, and the precipitate was collected and washed with EA. The product was obtained as $60 \mathrm{mg}$ yellow powder, yield 58\%. ${ }^{1} \mathrm{H}$ NMR (400 MHz, $\left.\mathrm{CDCl}_{3}\right) \delta 8.46(\mathrm{~d}, J=8.1 \mathrm{~Hz}, 1 \mathrm{H}), 6.86(\mathrm{~d}, J=8.1 \mathrm{~Hz}, 1 \mathrm{H}), 2.64(\mathrm{~s}, 4 \mathrm{H}) .{ }^{13} \mathrm{C} \mathrm{NMR}$ $\left(101 \mathrm{MHz}, \mathrm{CDCl}_{3}\right) \delta 151.41,146.84,143.62,133.30,130.03,113.44,29.23$. Analytical HPLC: $97.31 \%$ purity $(4.6 \mathrm{~mm} \times 150 \mathrm{~mm} 5 \mu \mathrm{m} \mathrm{C} 18$ column; $10 \mu \mathrm{L}$ injection; 45-55\% MeOH/ $\mathrm{H}_{2} \mathrm{O}$, linear gradient; $30 \mathrm{~min}$ run; $1 \mathrm{~mL} / \mathrm{min}$ flow; detection at $254 \mathrm{~nm}$ ). HRMS (ESI) calcd for $\mathrm{C}_{8} \mathrm{H}_{7} \mathrm{~N}_{4} \mathrm{O}_{3}\left[\mathrm{MH}^{+}\right]$207.0518, found 207.0516. 


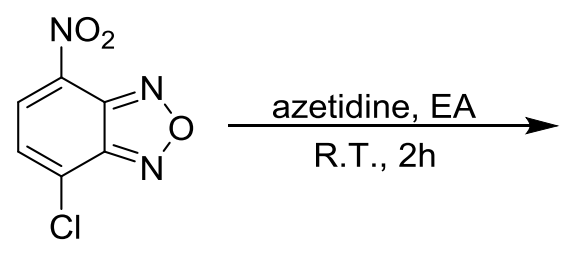<smiles>O=[N+]([O-])c1ccc(N2CCC2)c2nonc12</smiles>

17

Azetidine (143 mg, $2.50 \mathrm{mmol}$ ) was slowly added into the solution of 4-chloro-7nitrobenzofurazan $(100 \mathrm{mg}, 0.50 \mathrm{mmol})$ in $10 \mathrm{~mL}$ EA at room temperature. The mixture was stirred for $2 \mathrm{~h}$, and the precipitate was collected and washed with EA. The product was obtained as $90 \mathrm{mg}$ red powder, yield $82 \% .{ }^{1} \mathrm{H}$ NMR (400 MHz, $\left.\mathrm{CDCl}_{3}\right) \delta 8.40(\mathrm{~d}, J=8.7 \mathrm{~Hz}, 1 \mathrm{H}), 5.77(\mathrm{~d}, J=8.8 \mathrm{~Hz}, 1 \mathrm{H}), 4.84(\mathrm{~s}, 2 \mathrm{H}), 4.39(\mathrm{~s}, 2 \mathrm{H})$, $2.87-2.49(\mathrm{~m}, 2 \mathrm{H}) .{ }^{13} \mathrm{C}$ NMR (101 MHz, DMSO) $\delta 145.63,145.04,144.12,136.88$, $119.58,99.92,56.89,53.47,17.00$. Analytical HPLC: $98.90 \%$ purity $(4.6 \mathrm{~mm} \times 150$ $\mathrm{mm} 5 \mu \mathrm{m} \mathrm{C} 18$ column; $10 \mu \mathrm{L}$ injection; $45-55 \% \mathrm{MeOH} / \mathrm{H}_{2} \mathrm{O}$, linear gradient; $30 \mathrm{~min}$ run; $1 \mathrm{~mL} / \mathrm{min}$ flow; detection at $254 \mathrm{~nm}$ ). HRMS (ESI) calcd for $\mathrm{C}_{9} \mathrm{H}_{9} \mathrm{~N}_{4} \mathrm{O}_{3}\left[\mathrm{MH}^{+}\right]$ 221.0675 , found 221.0670 . 
$2.3{ }^{1} \mathrm{H}-\mathrm{NMR},{ }^{13} \mathrm{C}-\mathrm{NMR}, \mathrm{HRMS}$ and analytical HPLC spectra of $\mathbf{1}-\mathbf{1 7}$ and other intermediate products

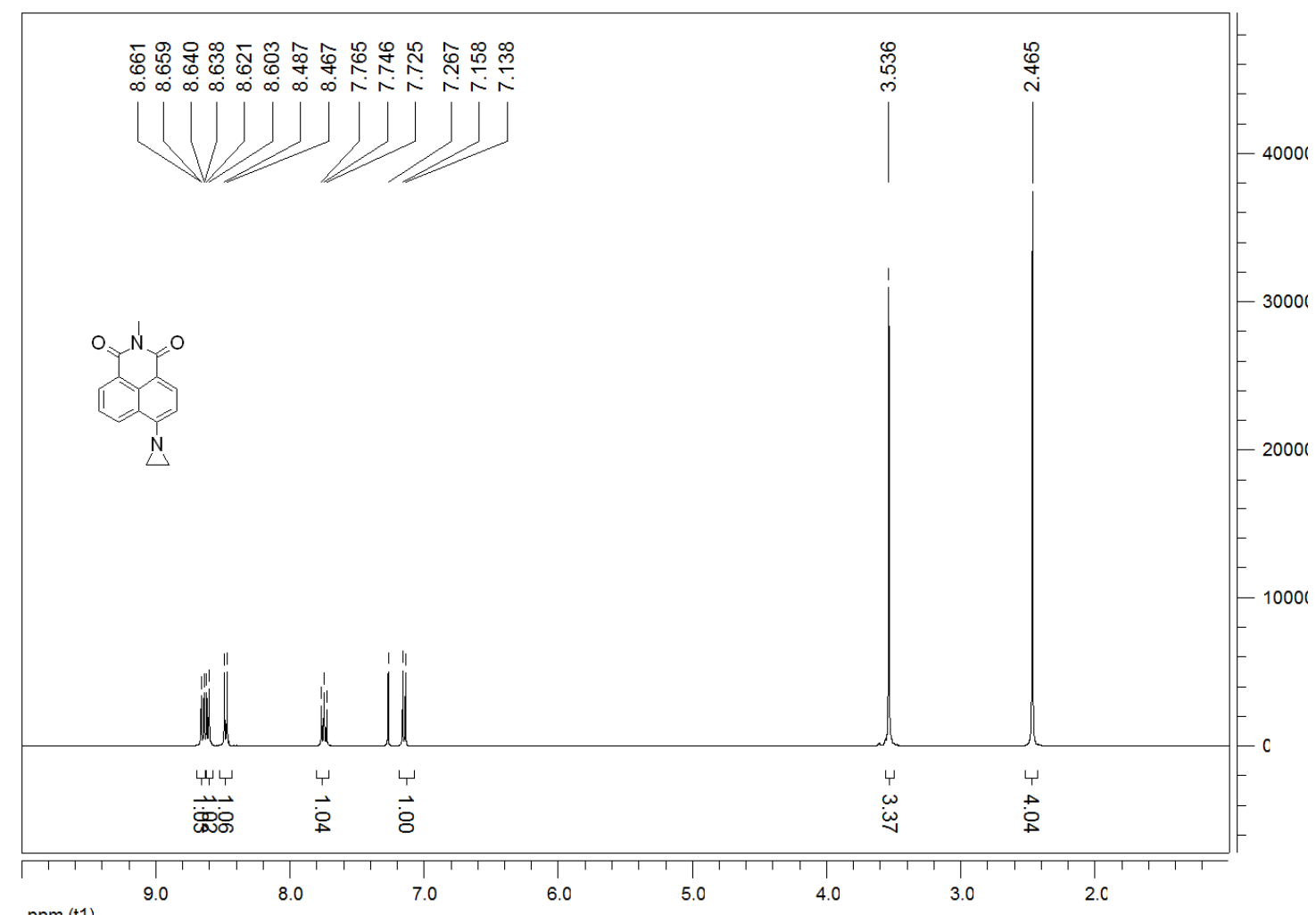

Figure S16. 1H-NMR spectrum of $\mathbf{1}$ in $\mathrm{CDCl} 3$.

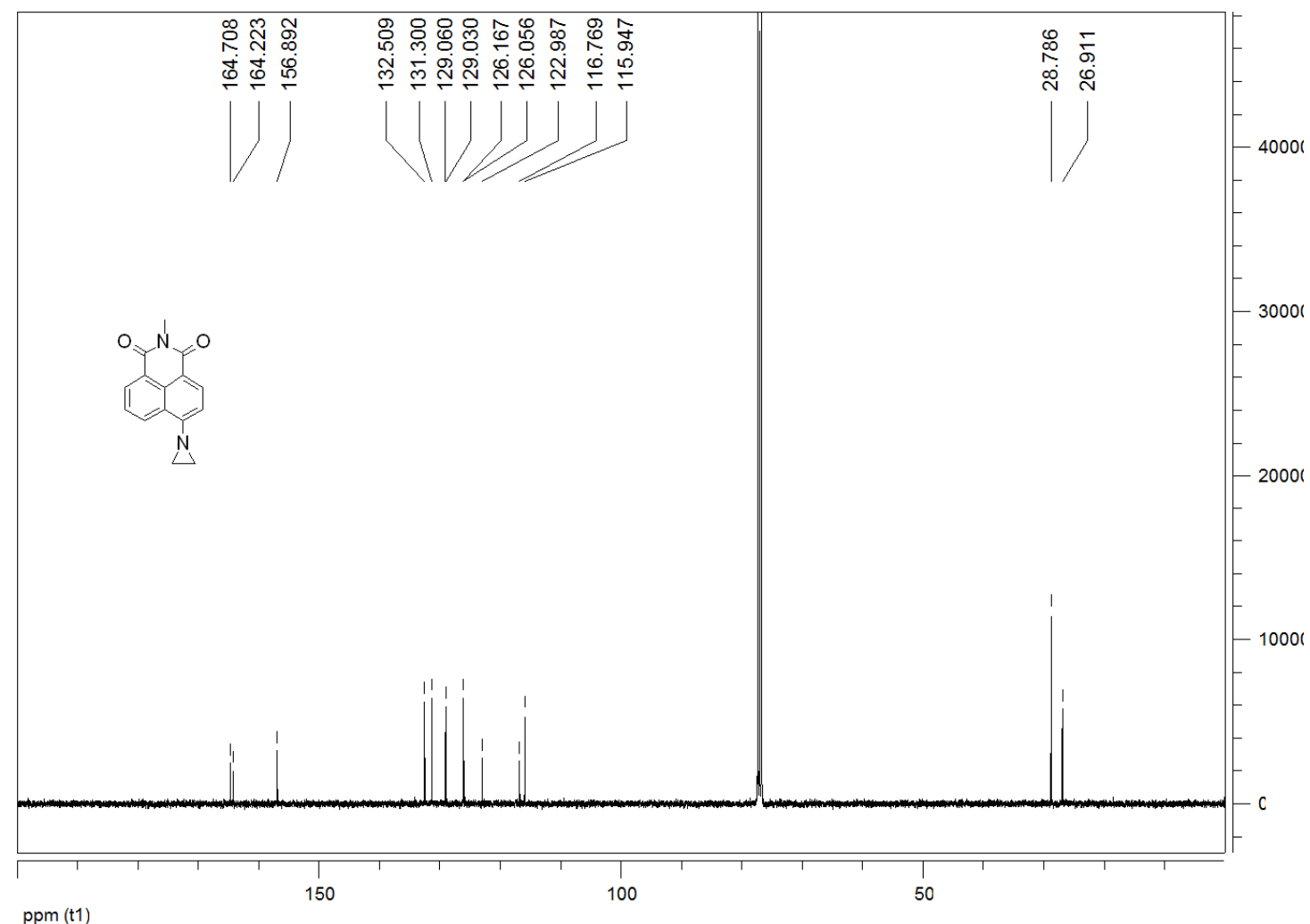

Figure S17. ${ }^{13} \mathrm{C}$-NMR spectrum of $\mathbf{1}$ in $\mathrm{CDCl}_{3}$. 


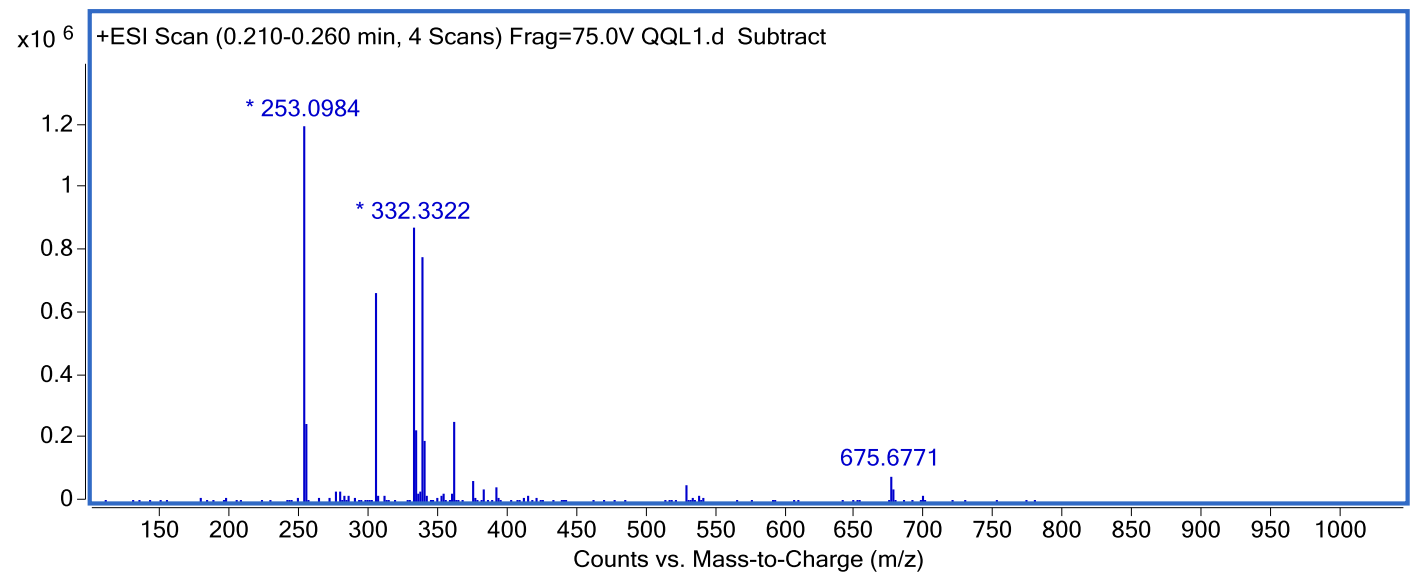

Figure S18. HRMS spectrum of $\mathbf{1}$.

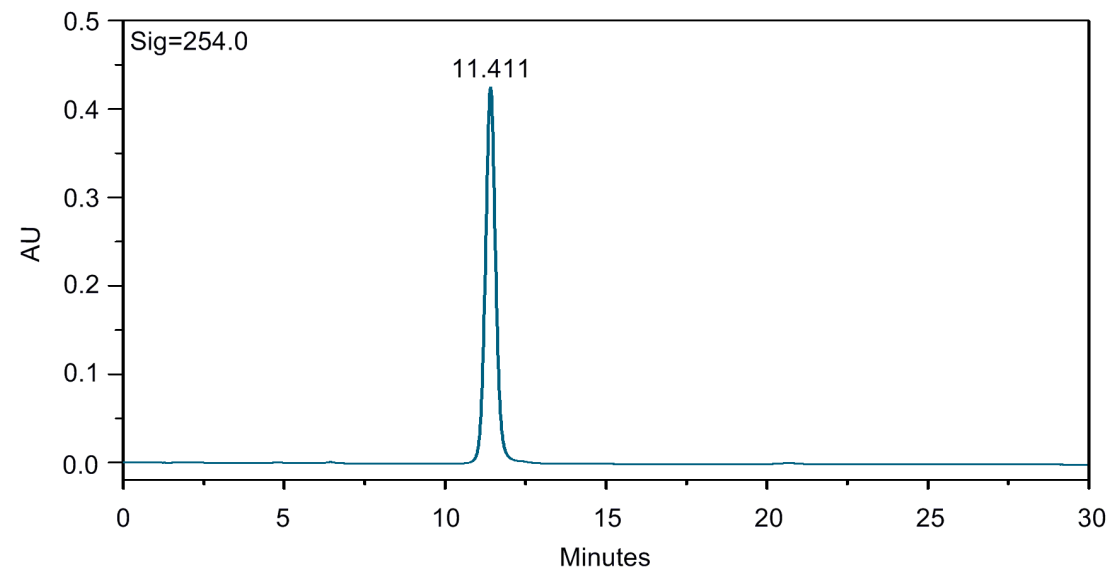

Figure S19. Analytical HPLC spectrum of $\mathbf{1}$. 


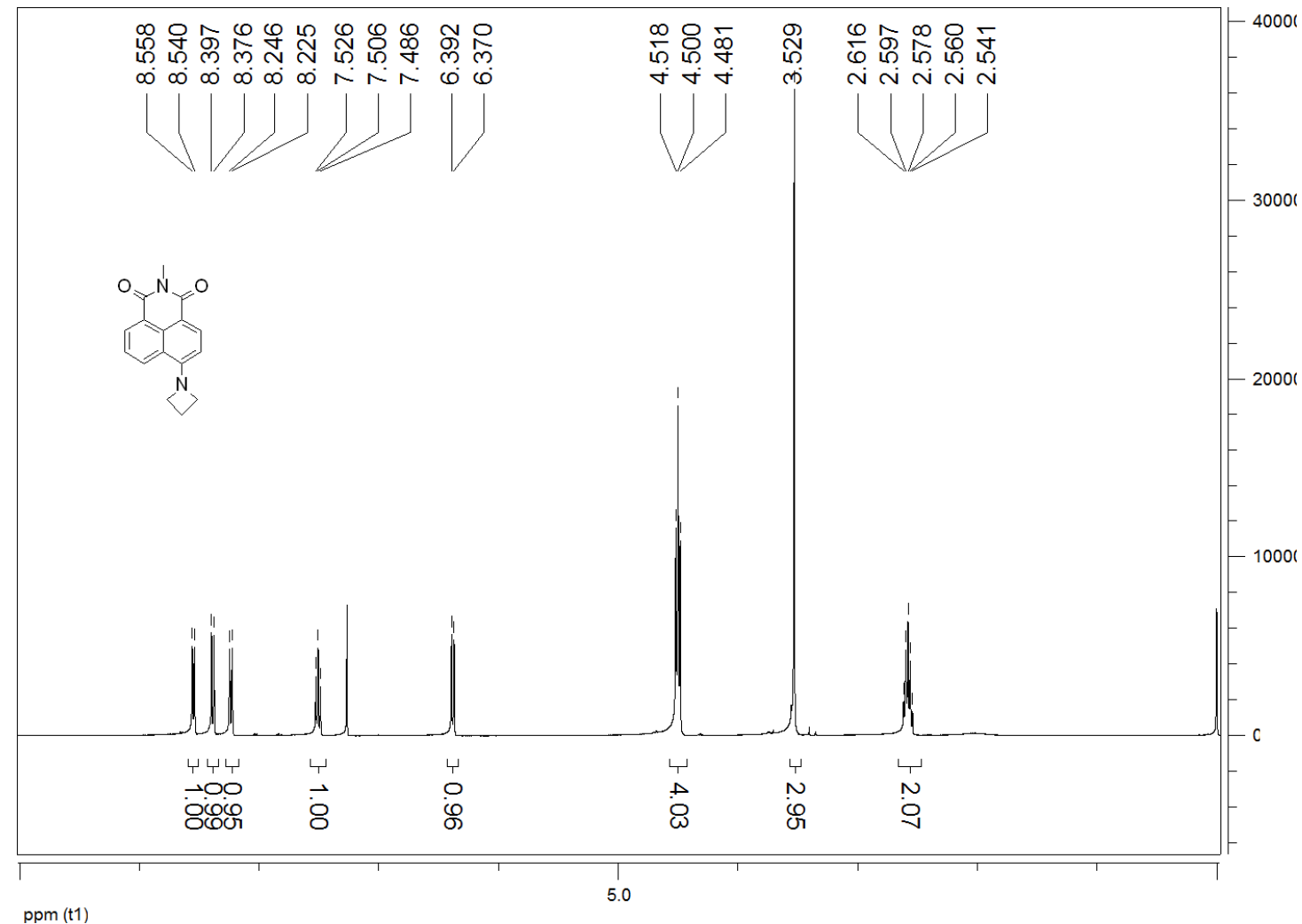

Figure S20. ${ }^{1} \mathrm{H}-\mathrm{NMR}$ spectrum of 2 in $\mathrm{CDCl}_{3}$.

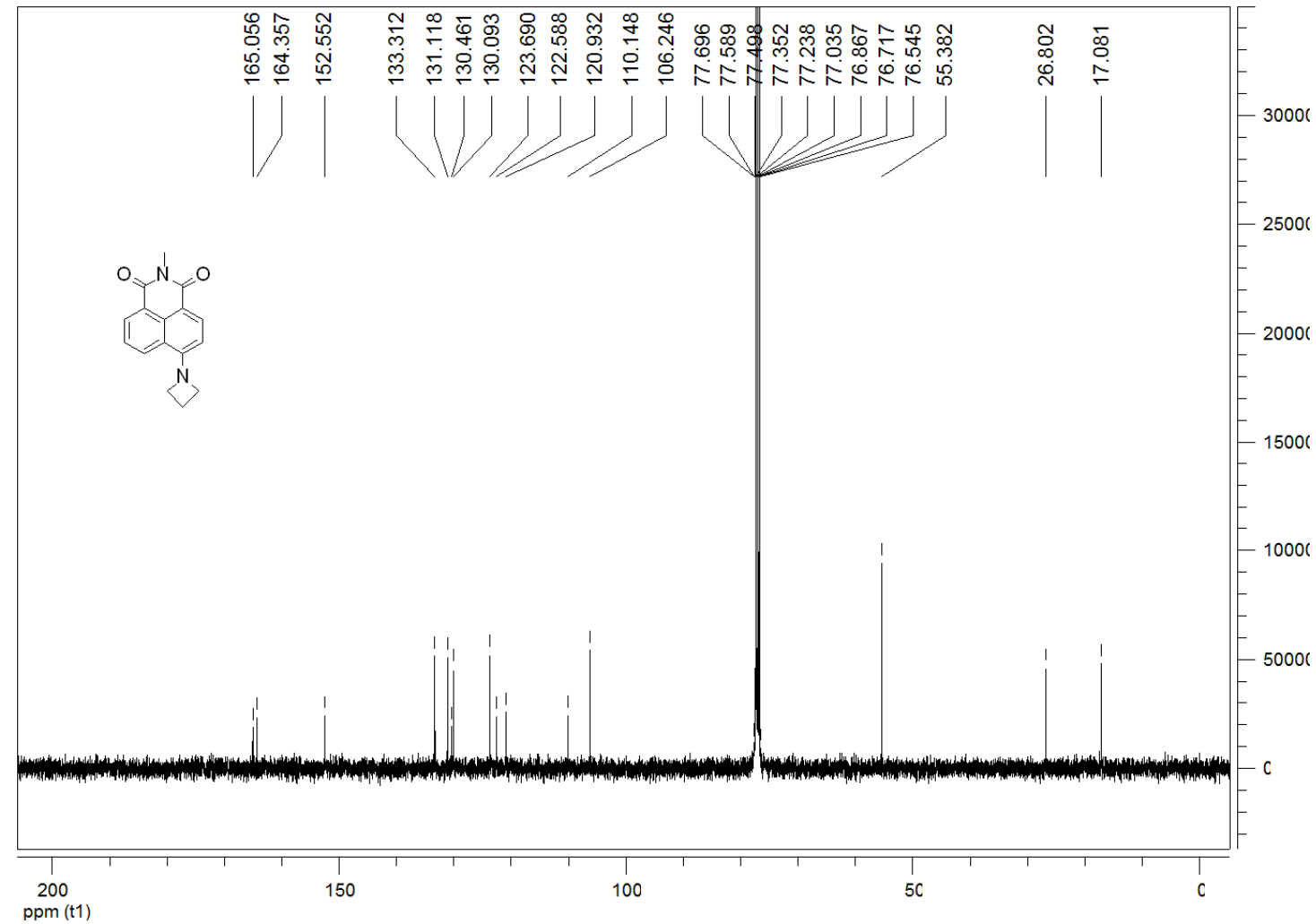

Figure S21. ${ }^{13} \mathrm{C}-\mathrm{NMR}$ spectrum of $\mathbf{2}$ in $\mathrm{CDCl}_{3}$. 


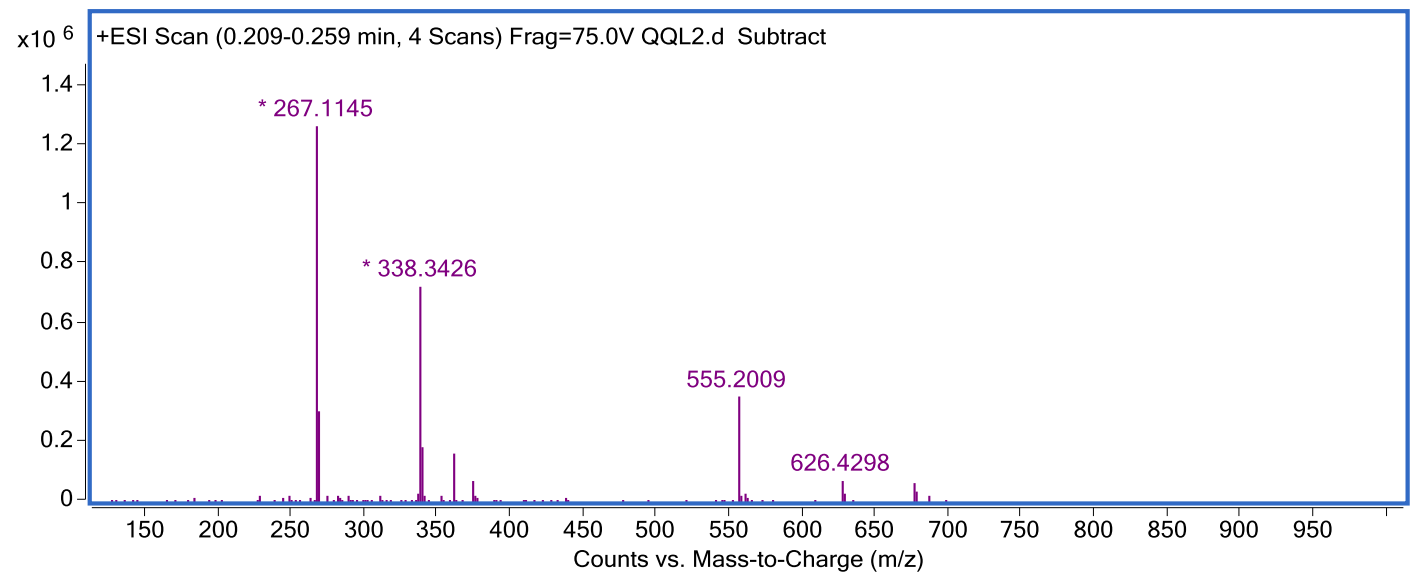

Figure S22. HRMS spectrum of 2.

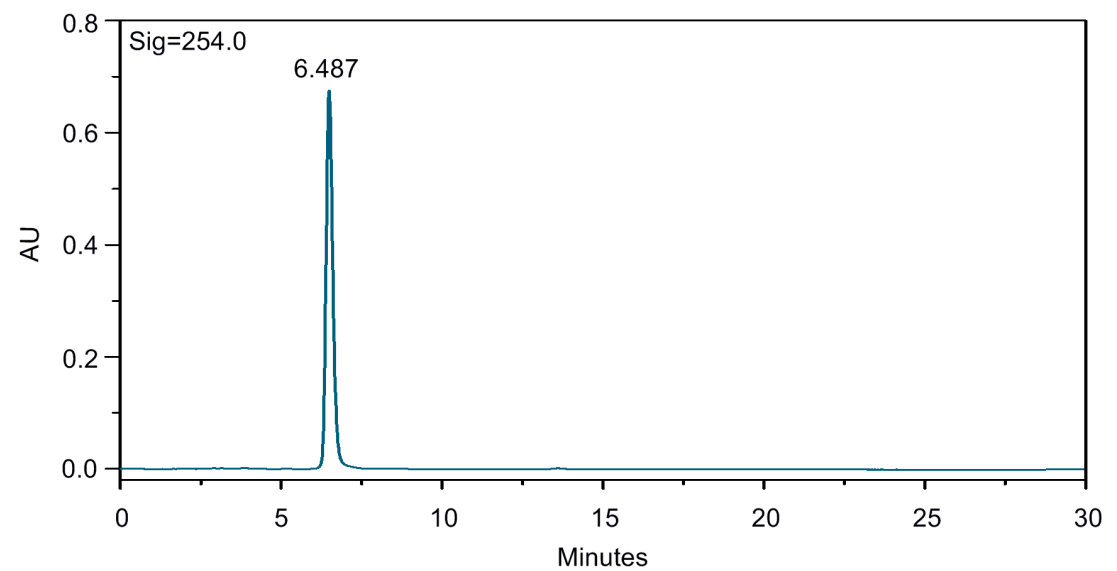

Figure S23. Analytical HPLC spectrum of 2. 


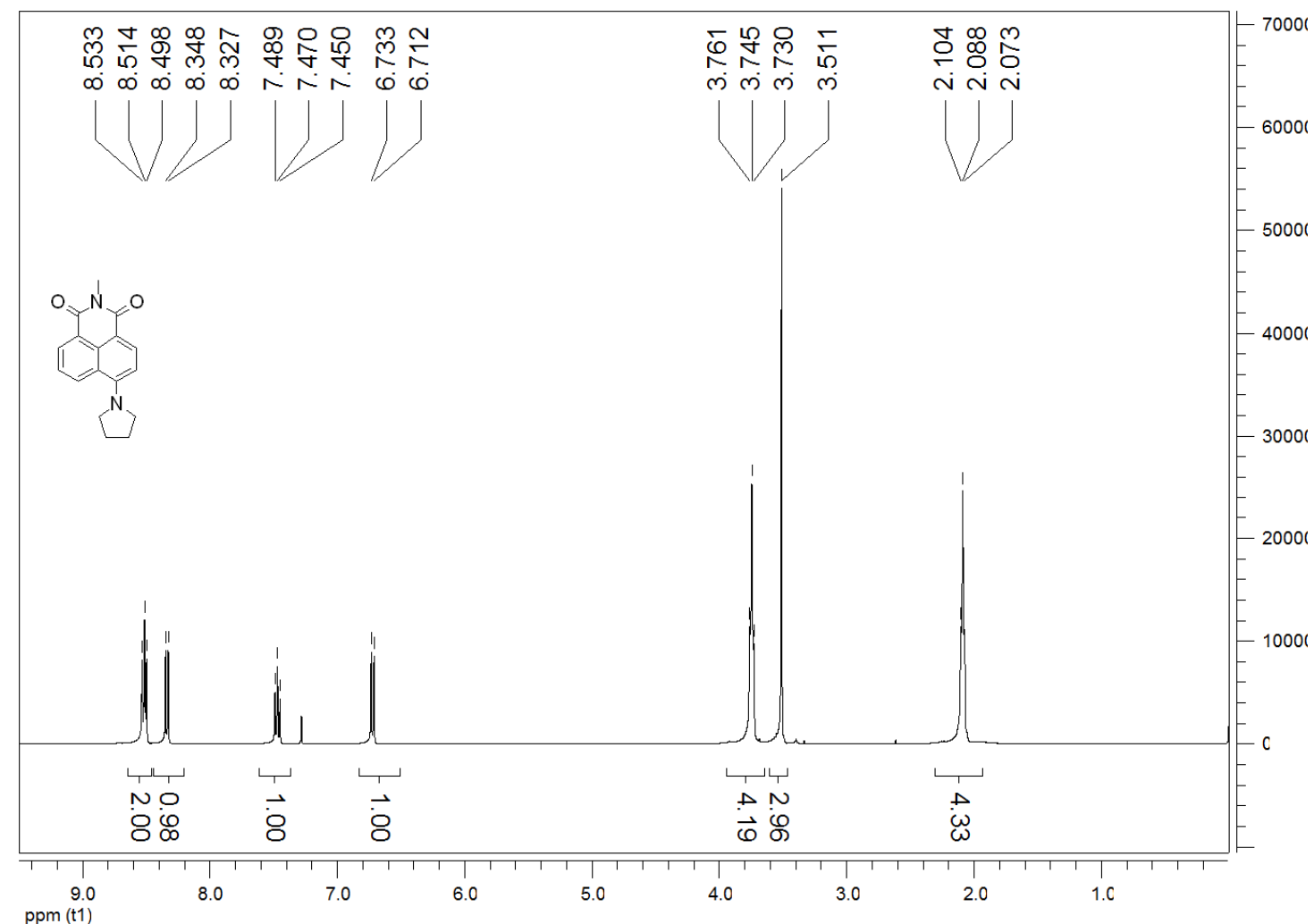

Figure S24. ${ }^{1} \mathrm{H}-\mathrm{NMR}$ spectrum of $\mathbf{3}$ in $\mathrm{CDCl}_{3}$.

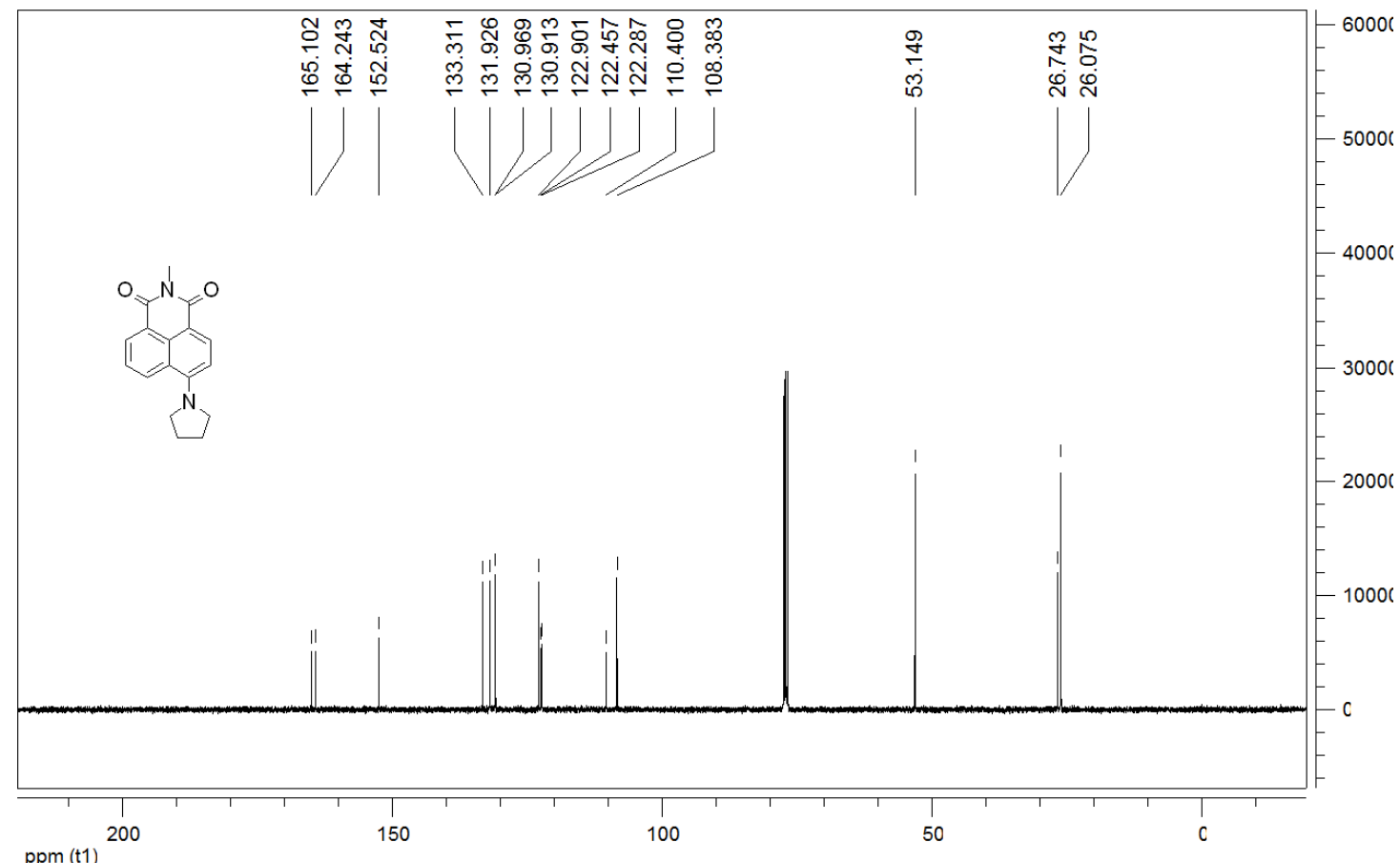

Figure S25. ${ }^{13} \mathrm{C}-\mathrm{NMR}$ spectrum of $\mathbf{3}$ in $\mathrm{CDCl}_{3}$. 


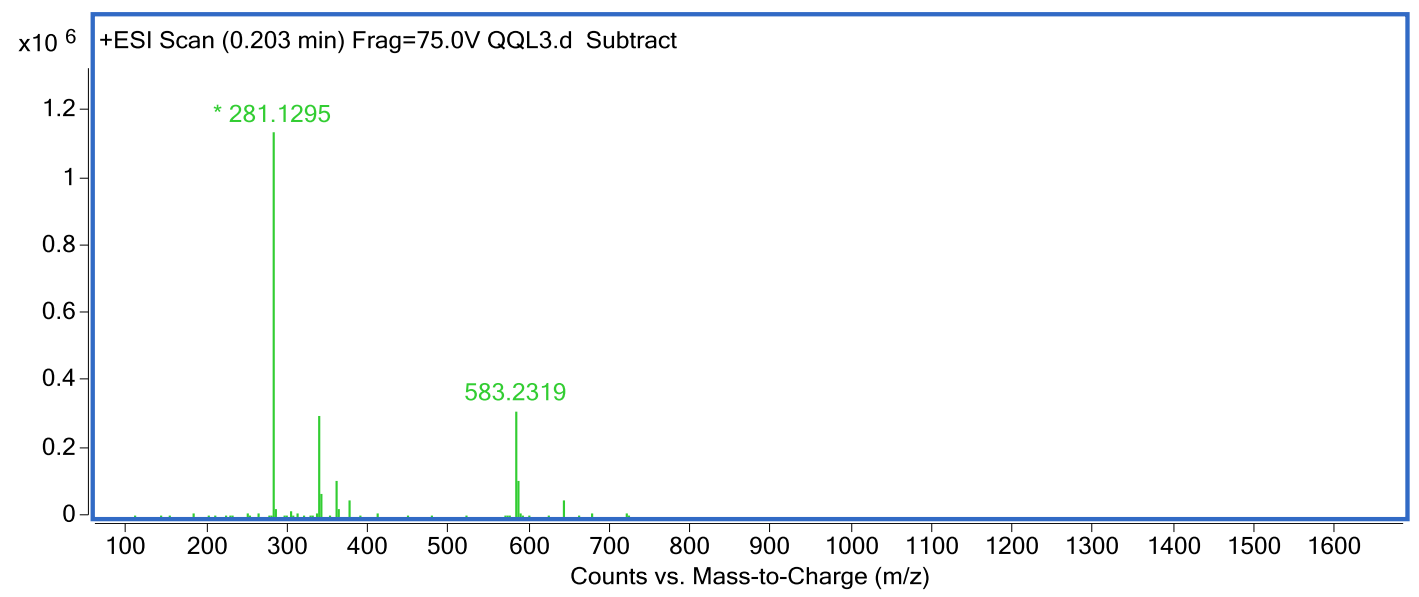

Figure S26. HRMS spectrum of $\mathbf{3}$.

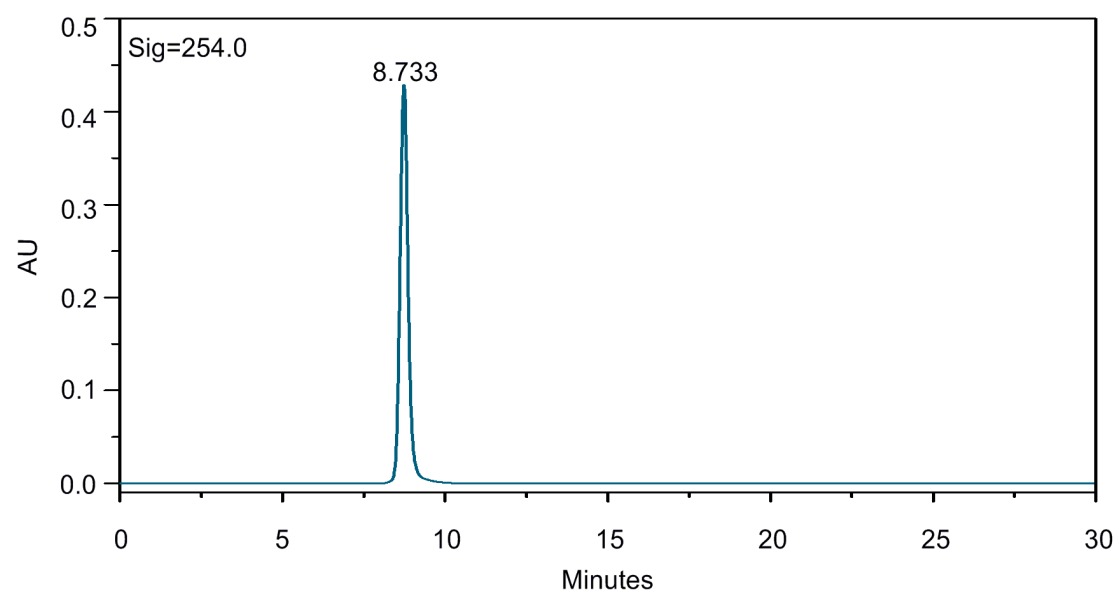

Figure S27. Analytical HPLC spectrum of 3. 


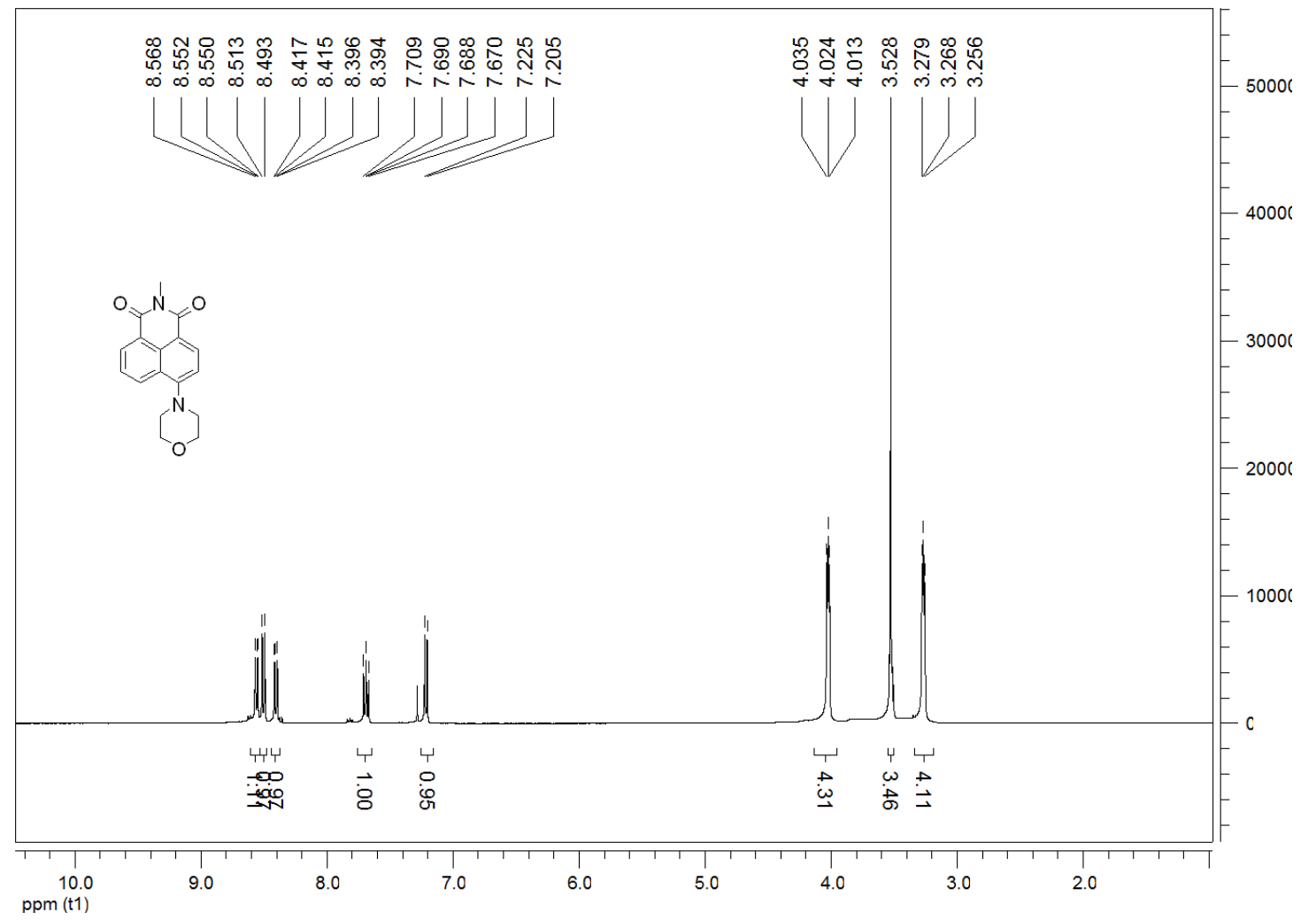

Figure S28. ${ }^{1} \mathrm{H}-\mathrm{NMR}$ spectrum of $\mathbf{4}$ in $\mathrm{CDCl}_{3}$.

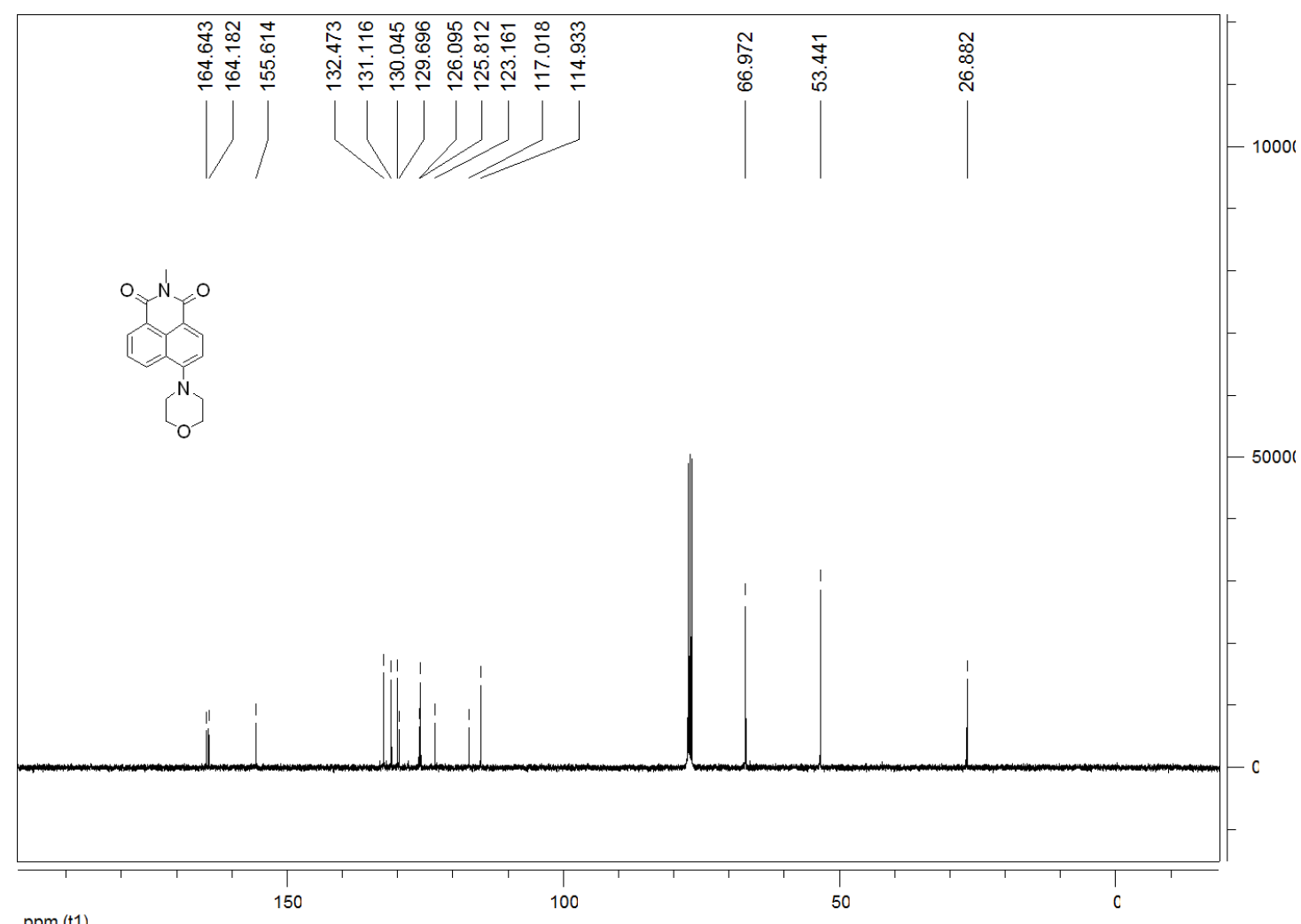

Figure S29. ${ }^{13} \mathrm{C}-\mathrm{NMR}$ spectrum of $\mathbf{4}$ in $\mathrm{CDCl}_{3}$. 


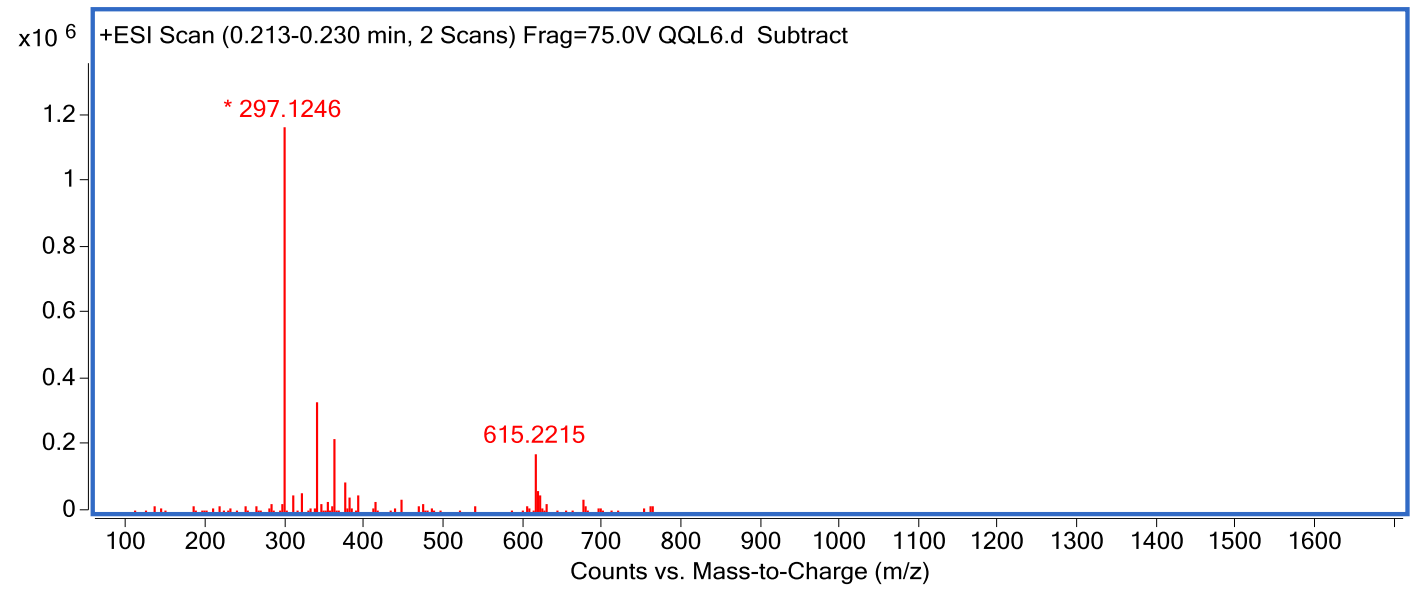

Figure S30. HRMS spectrum of 4 .

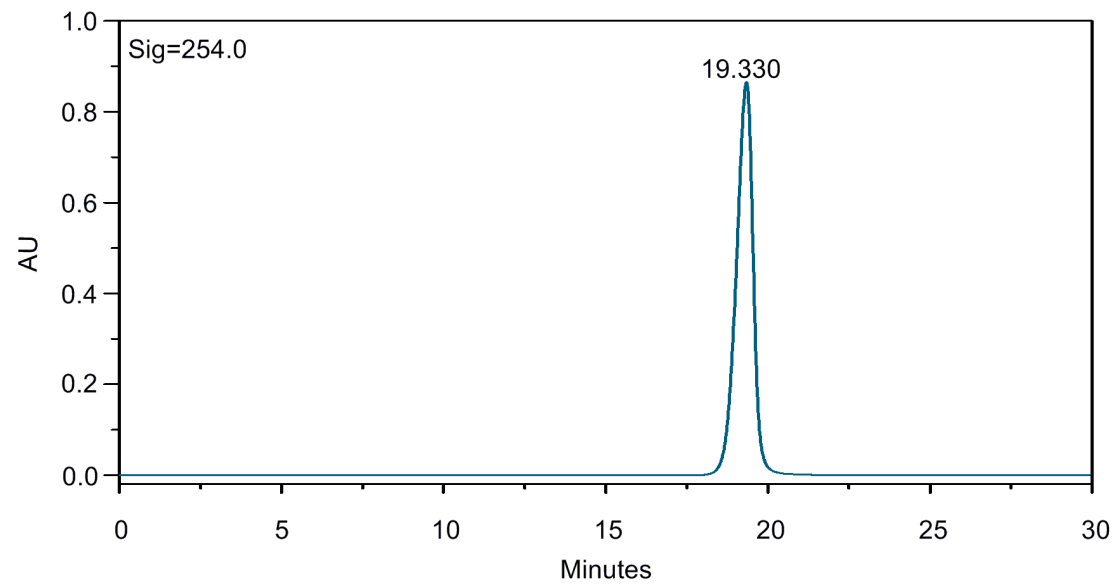

Figure S31. Analytical HPLC spectrum of 4. 


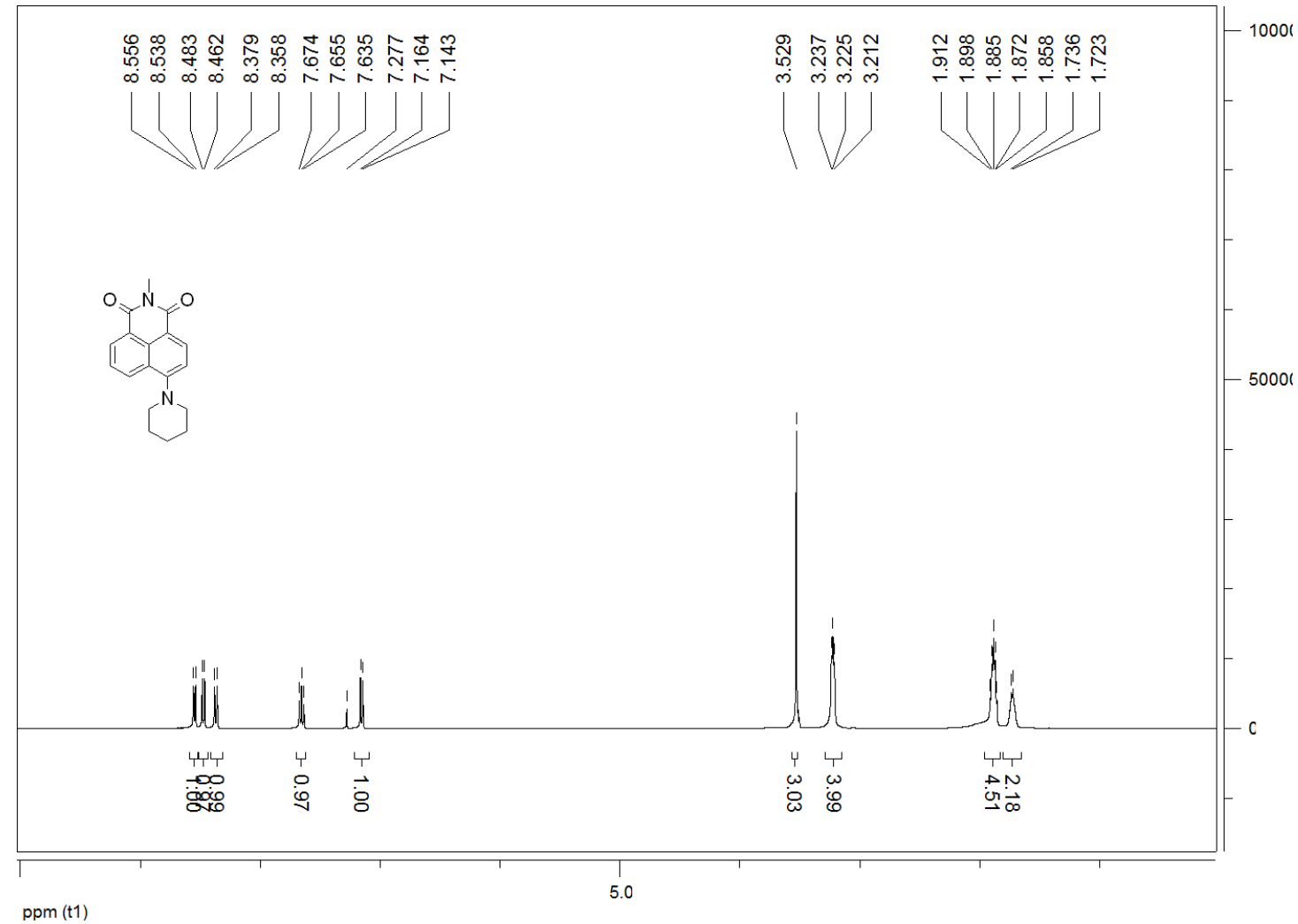

Figure S32. ${ }^{1} \mathrm{H}-\mathrm{NMR}$ spectrum of 5 in $\mathrm{CDCl}_{3}$.

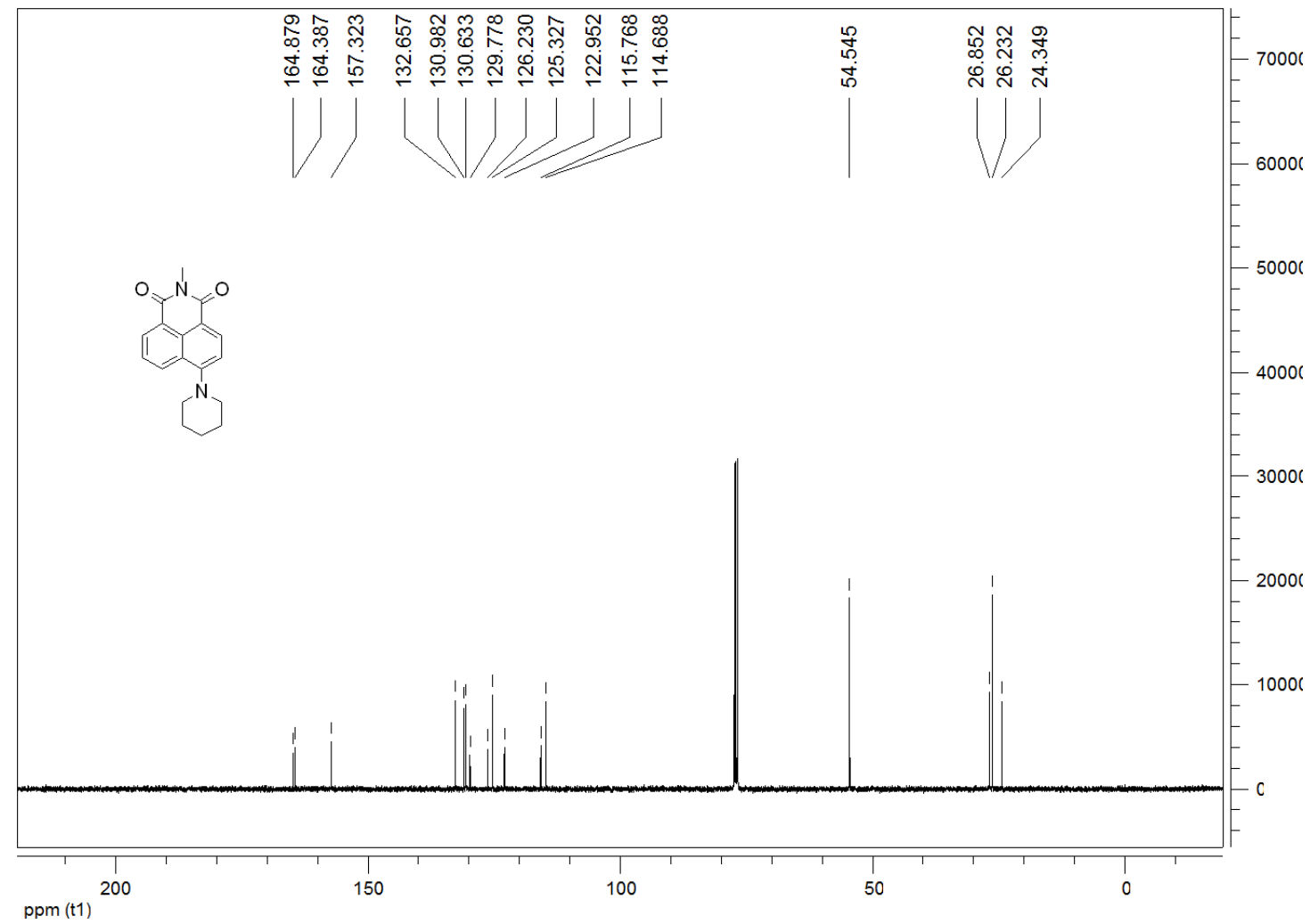

Figure $\mathrm{S} 33 .{ }^{13} \mathrm{C}$-NMR spectrum of $\mathbf{5}$ in $\mathrm{CDCl}_{3}$. 


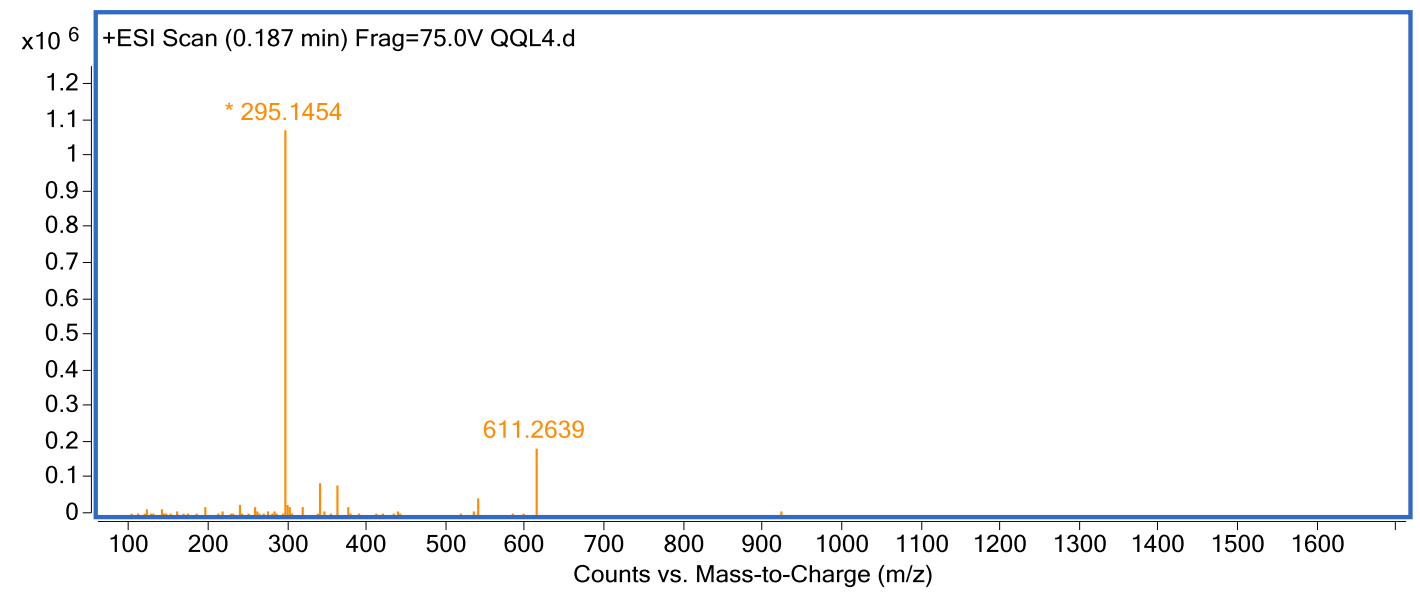

Figure S34. HRMS spectrum of 5.

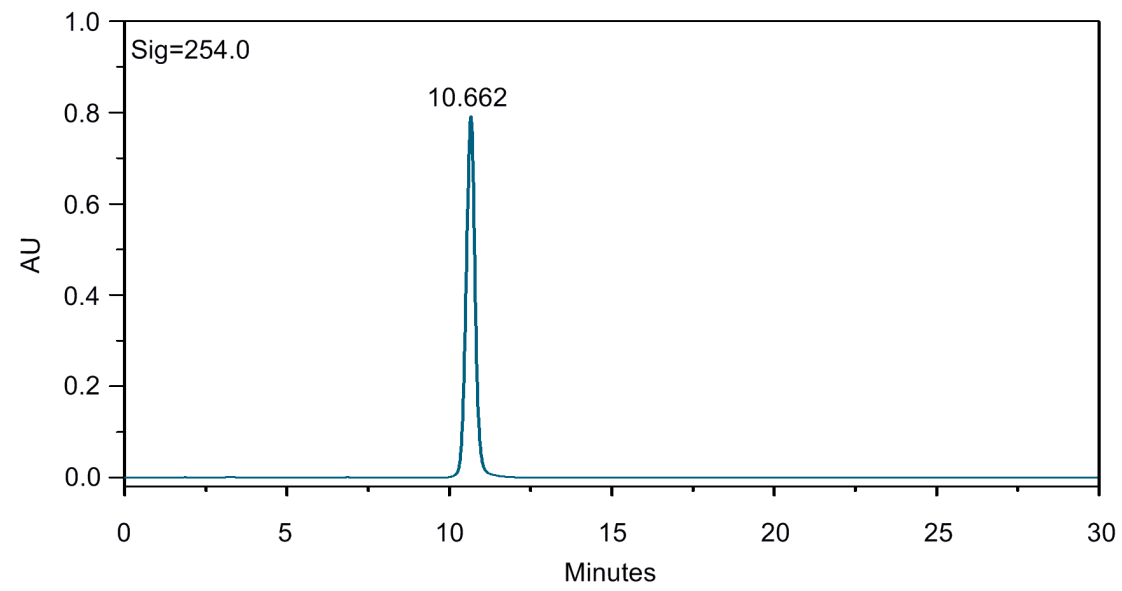

Figure S35. Analytical HPLC spectrum of 5. 


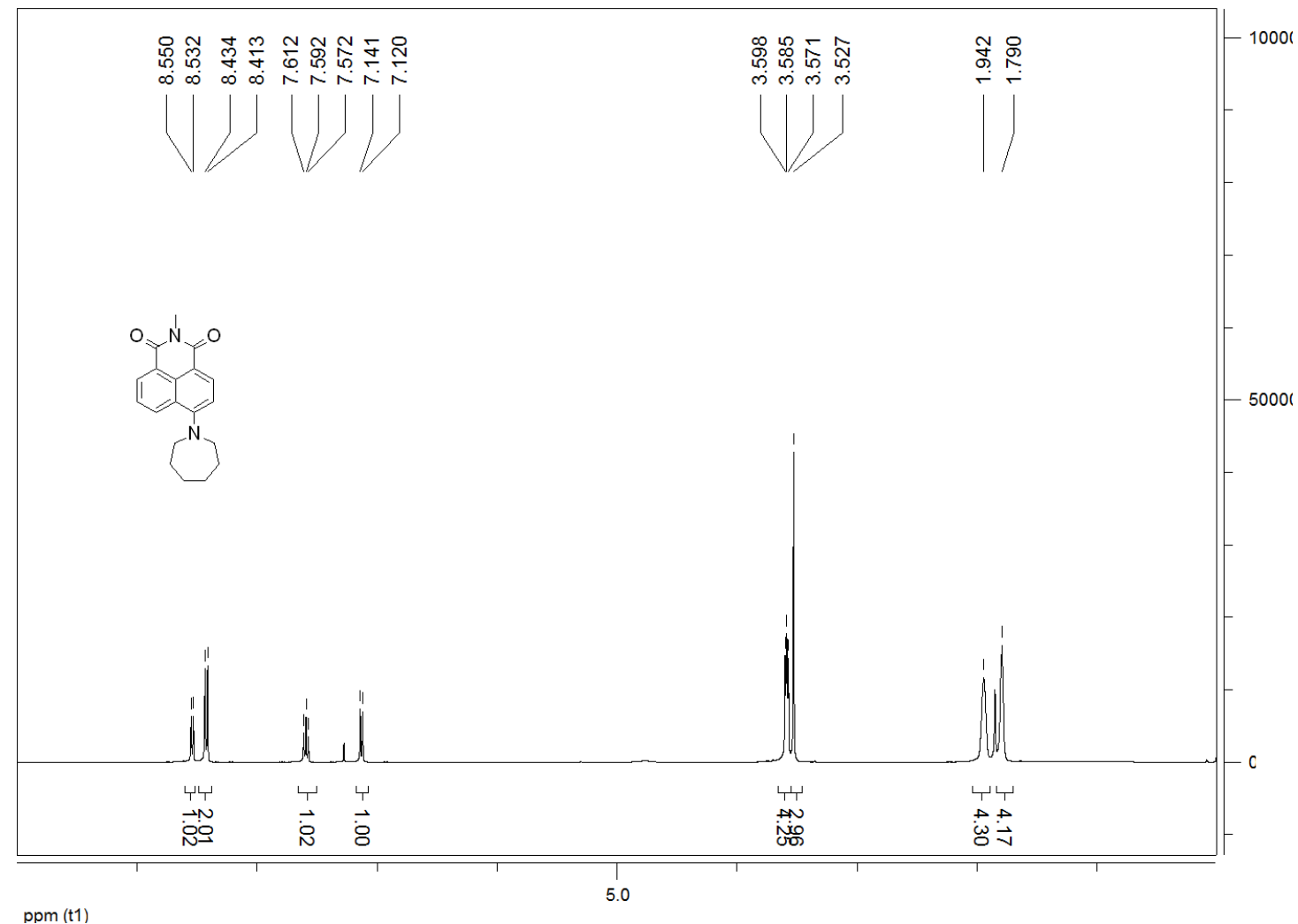

ppm (t1)

Figure S36. ${ }^{1} \mathrm{H}-\mathrm{NMR}$ spectrum of 6 in $\mathrm{CDCl}_{3}$.

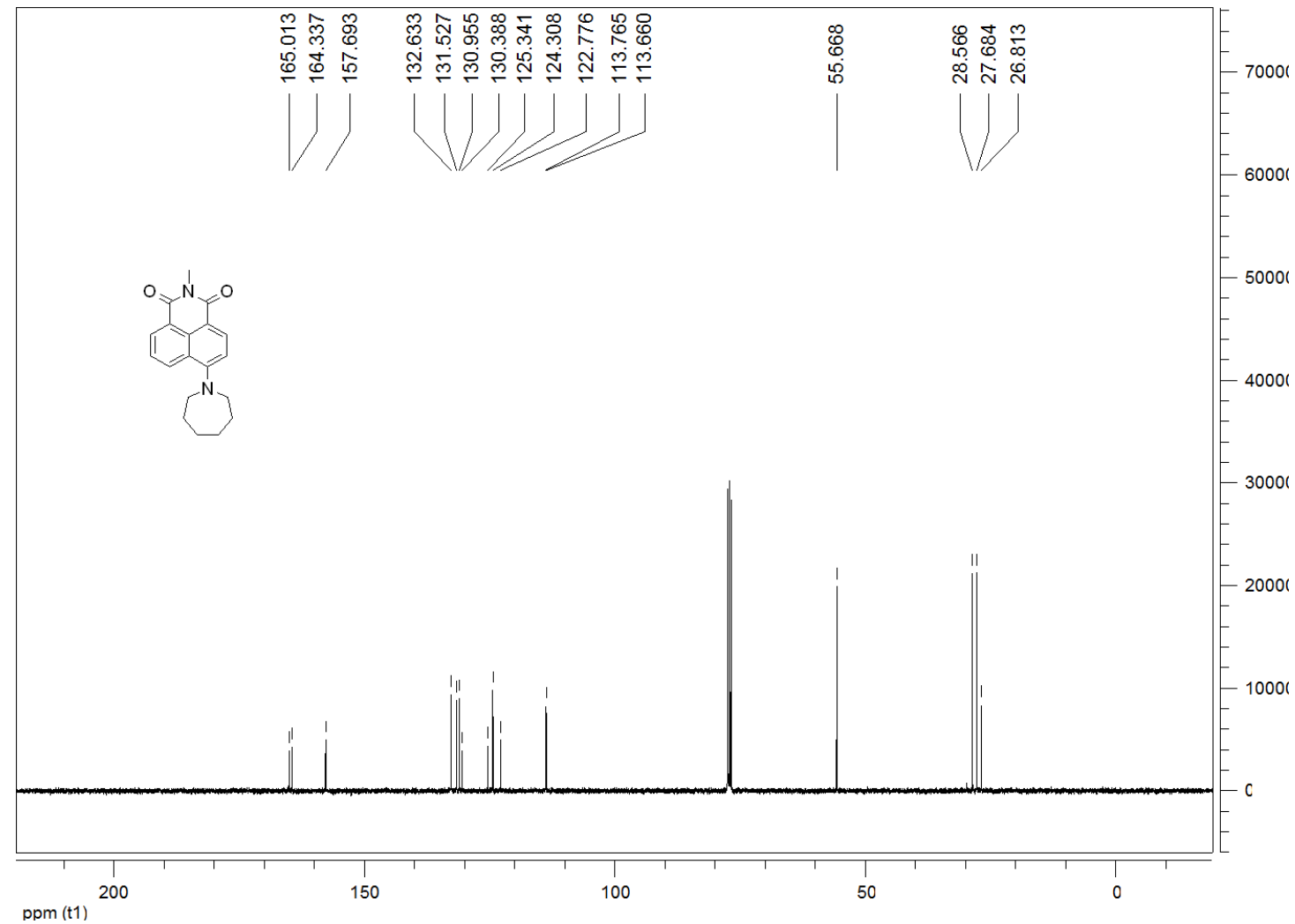

Figure S37. ${ }^{13} \mathrm{C}-\mathrm{NMR}$ spectrum of $\mathbf{6}$ in $\mathrm{CDCl}_{3}$. 


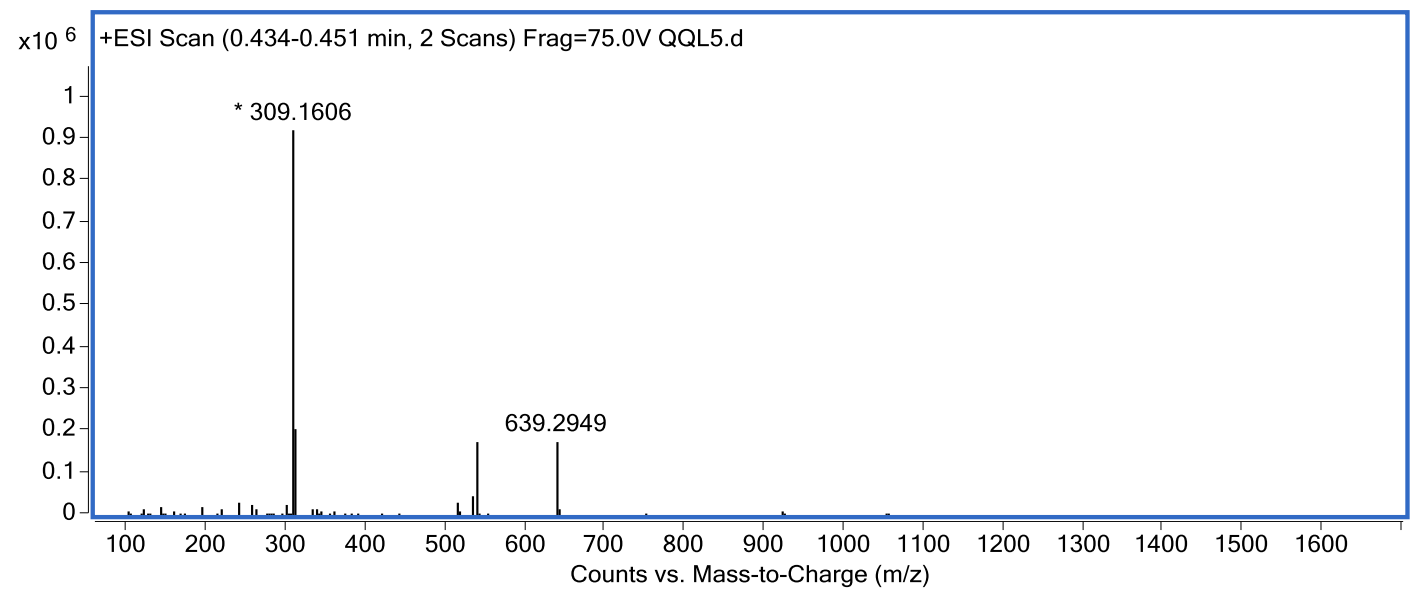

Figure S38. HRMS spectrum of 6.

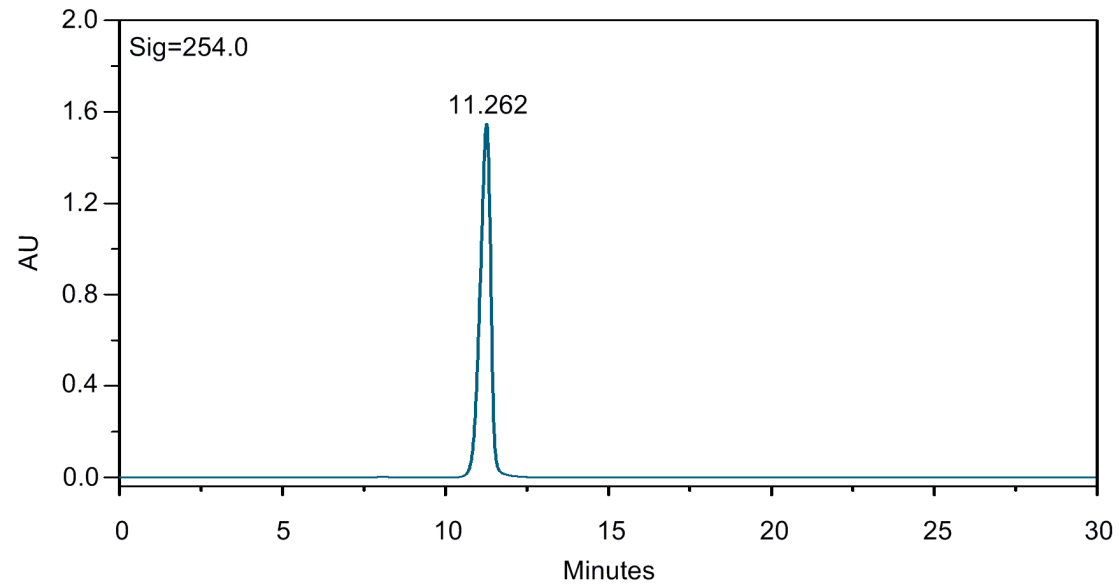

Figure S39. Analytical HPLC spectrum of 6. 


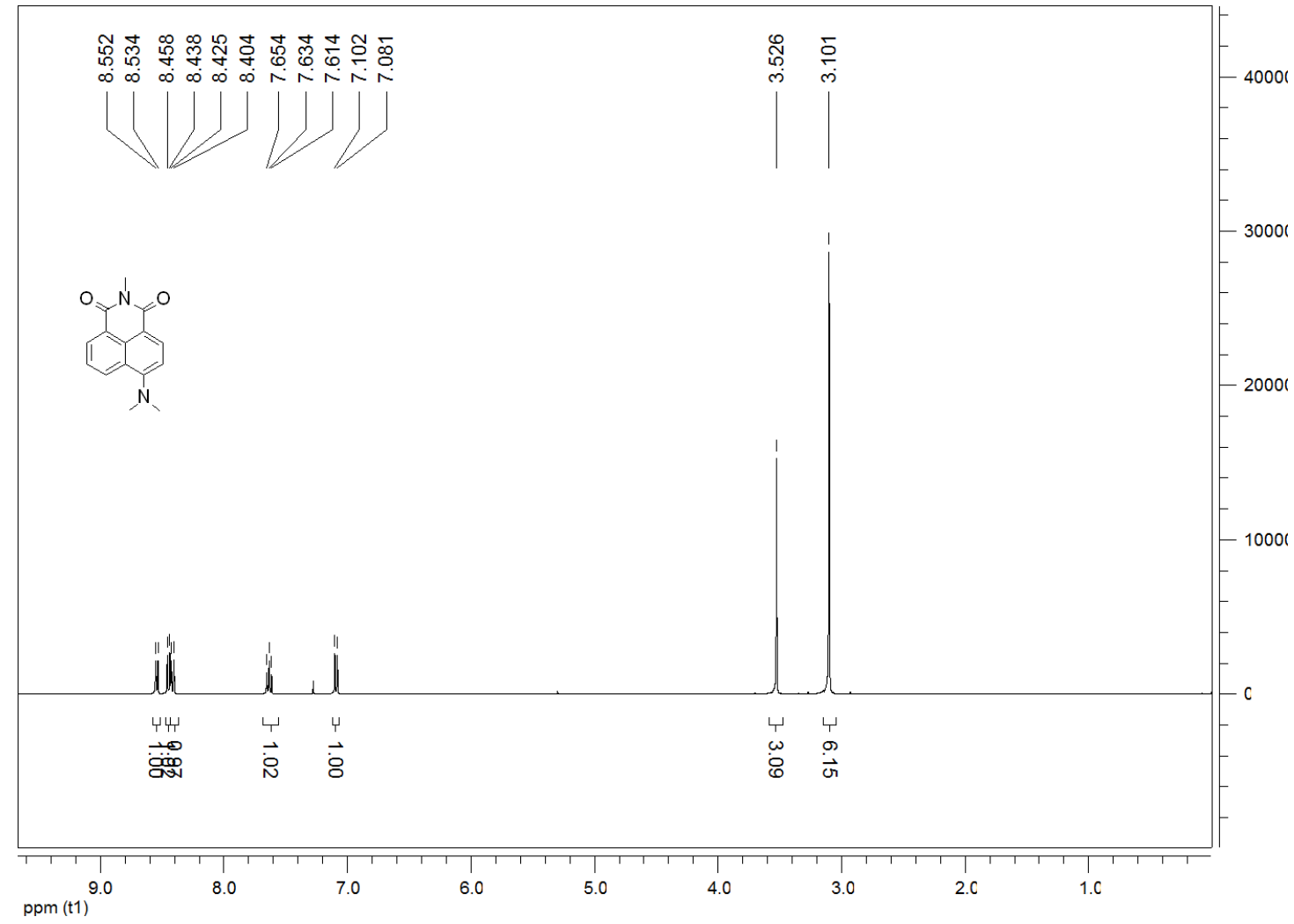

Figure S40. ${ }^{1} \mathrm{H}-\mathrm{NMR}$ spectrum of $\mathbf{7}$ in $\mathrm{CDCl}_{3}$.

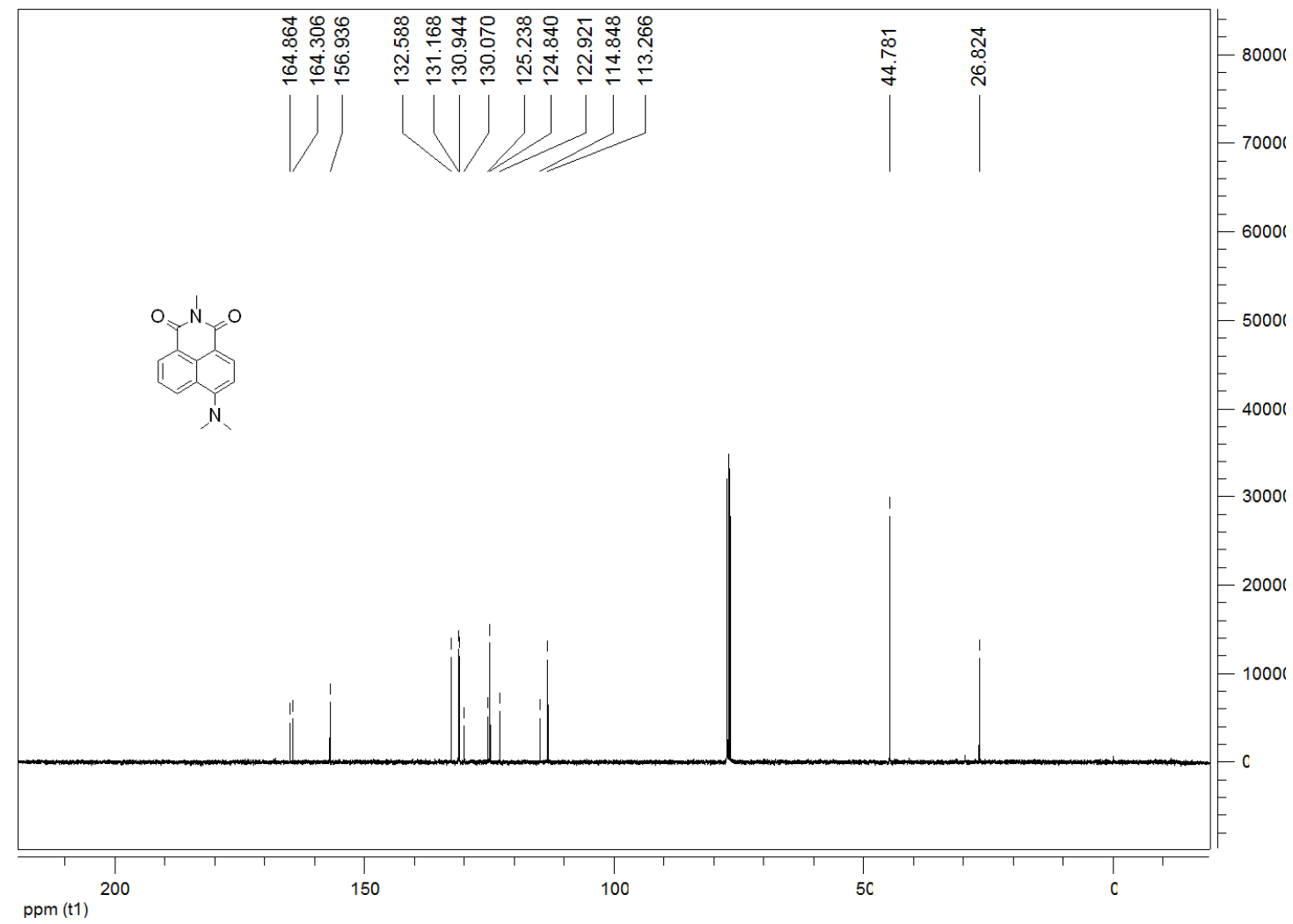

Figure $\mathrm{S} 41 .{ }^{13} \mathrm{C}-\mathrm{NMR}$ spectrum of $\mathbf{7}$ in $\mathrm{CDCl}_{3}$. 


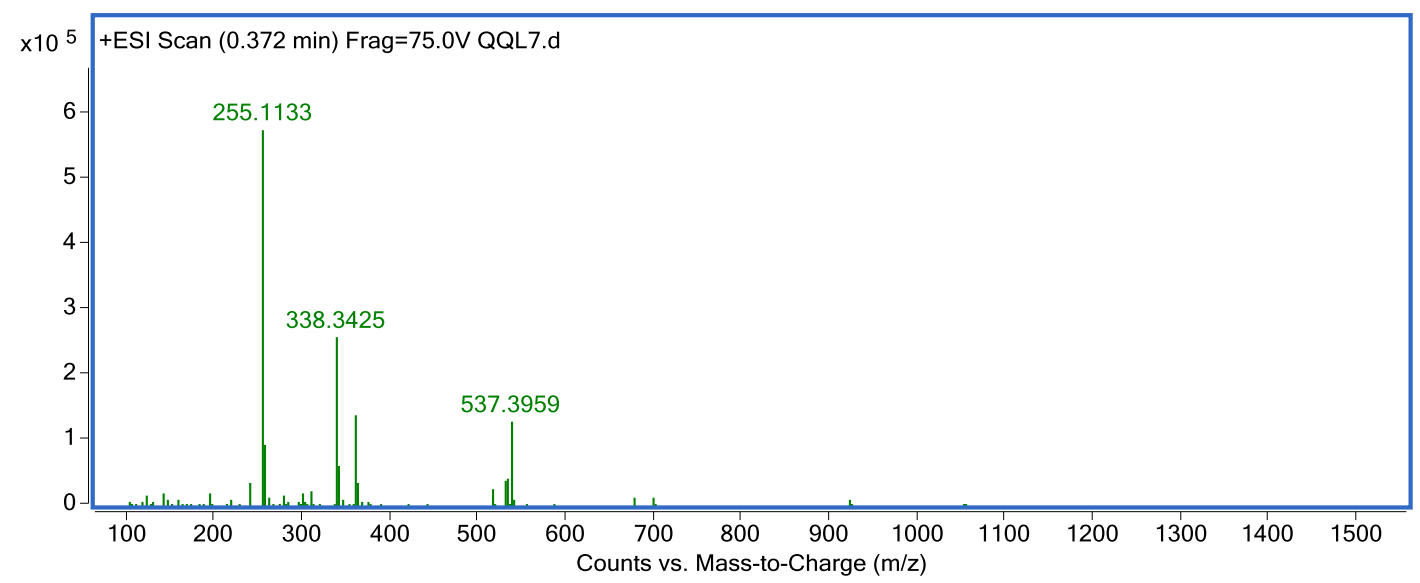

Figure S42. HRMS spectrum of 7.

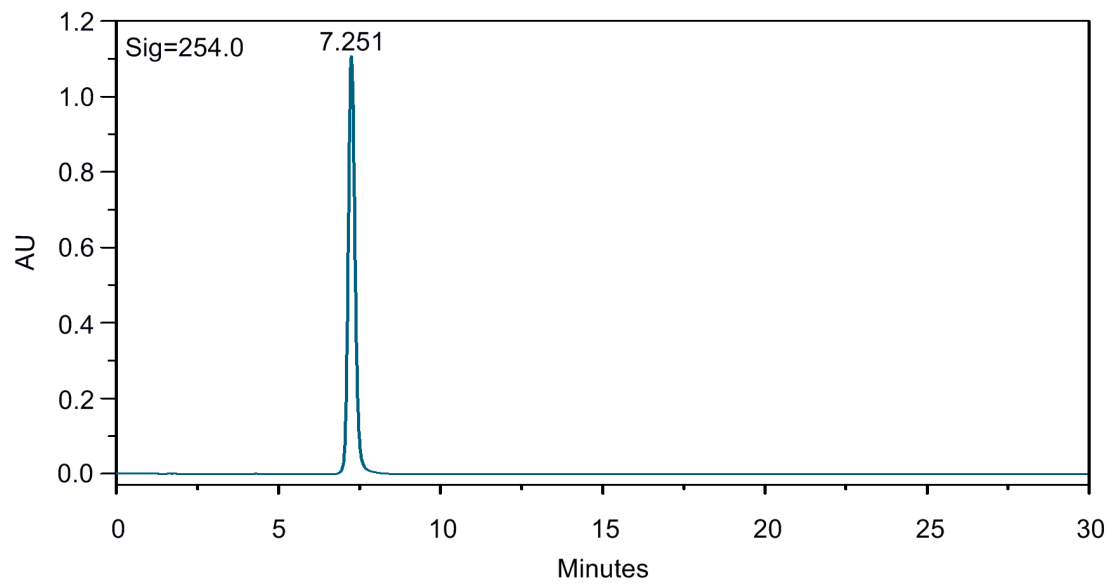

Figure S43. Analytical HPLC spectrum of 7. 


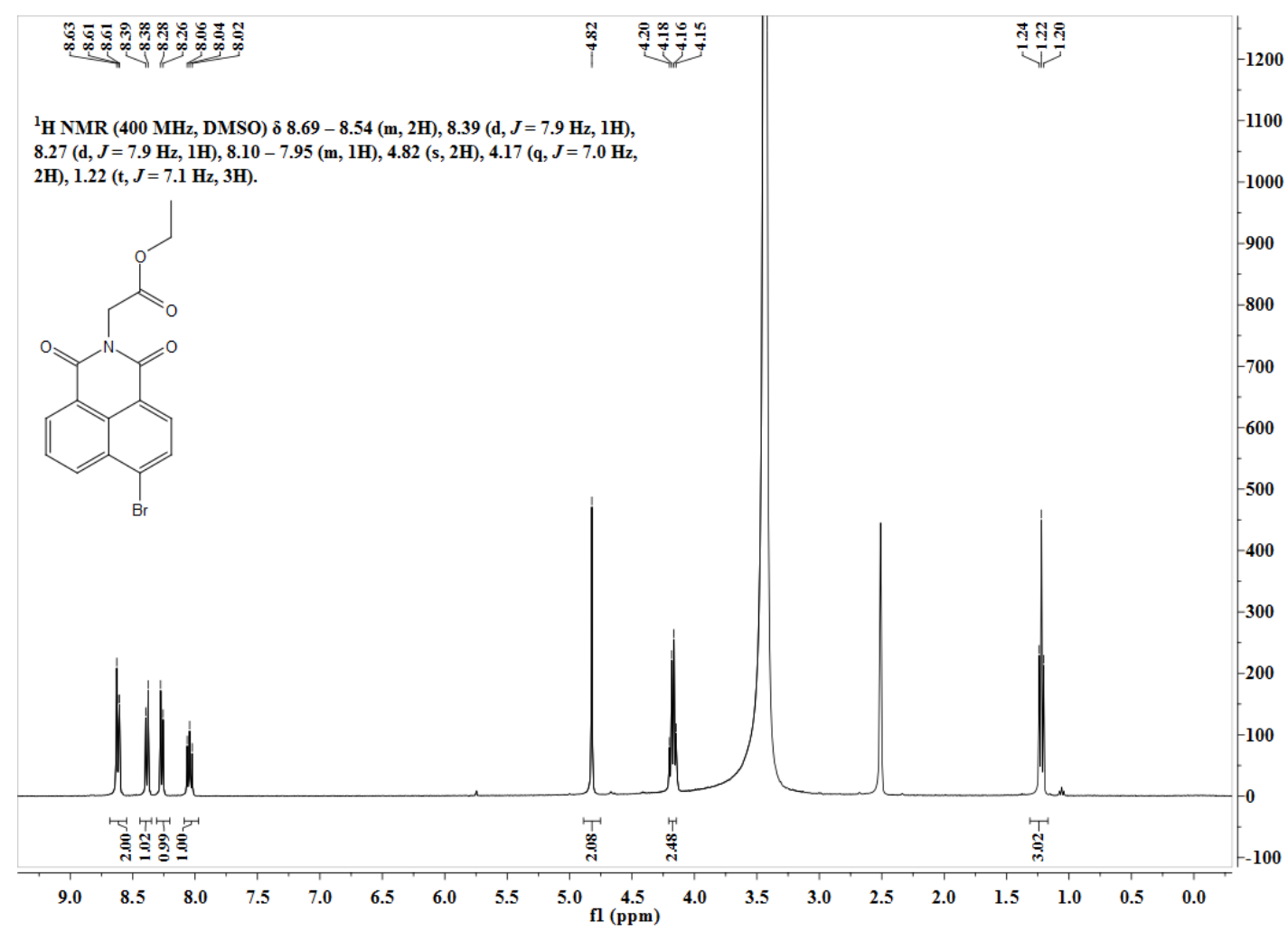

Figure S44. ${ }^{1} \mathrm{H}$ NMR of N-ethoxycarbonylmethyl-4-Bromo-1,8-naphthalimide in DMSO- $d_{6}$.

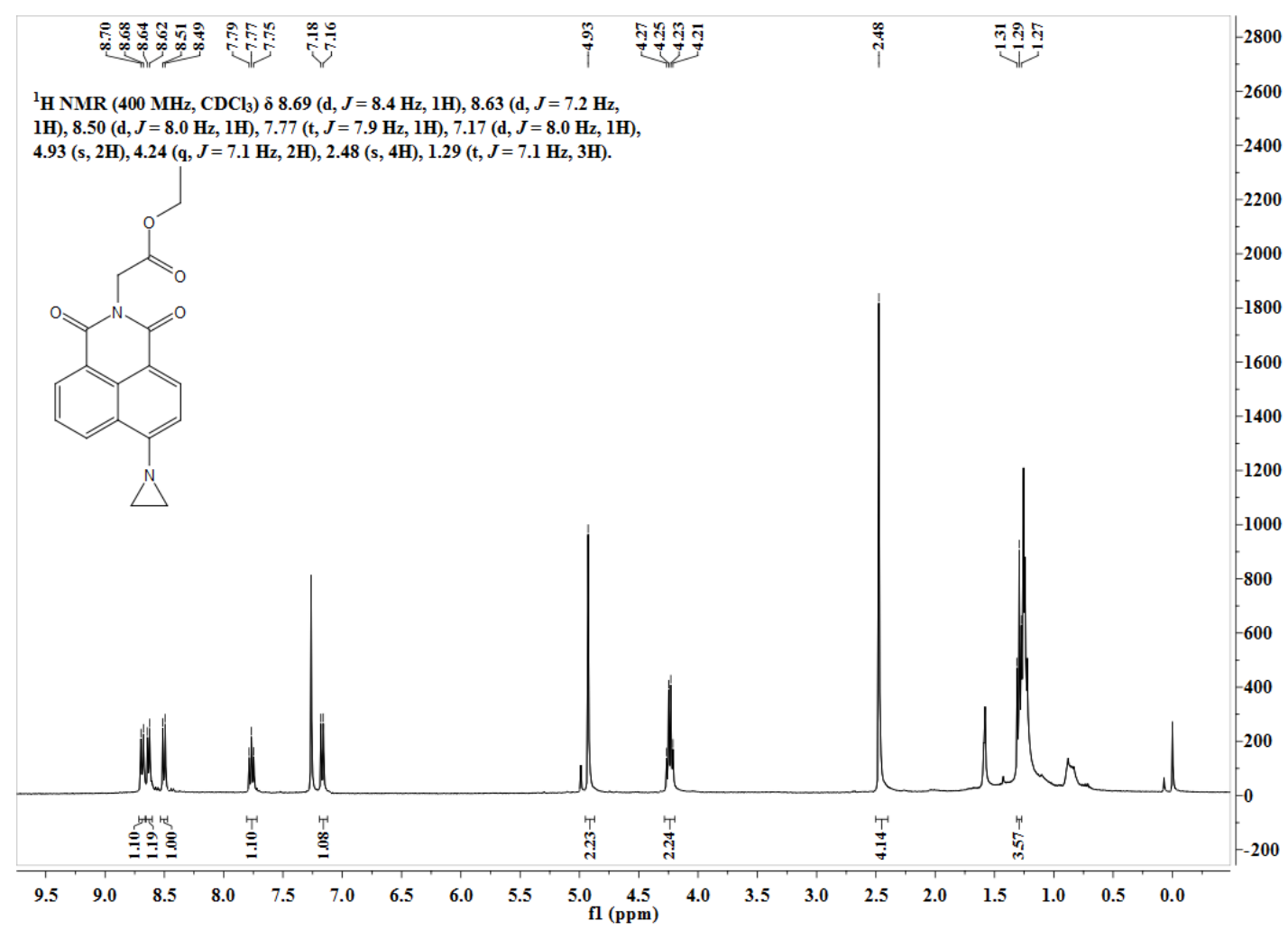

Figure S45. ${ }^{1} \mathrm{H}$ NMR of N-ethoxycarbonylmethyl-4-aziridinly-1,8-naphthalimide 8 in $\mathrm{CDCl}_{3}$. 


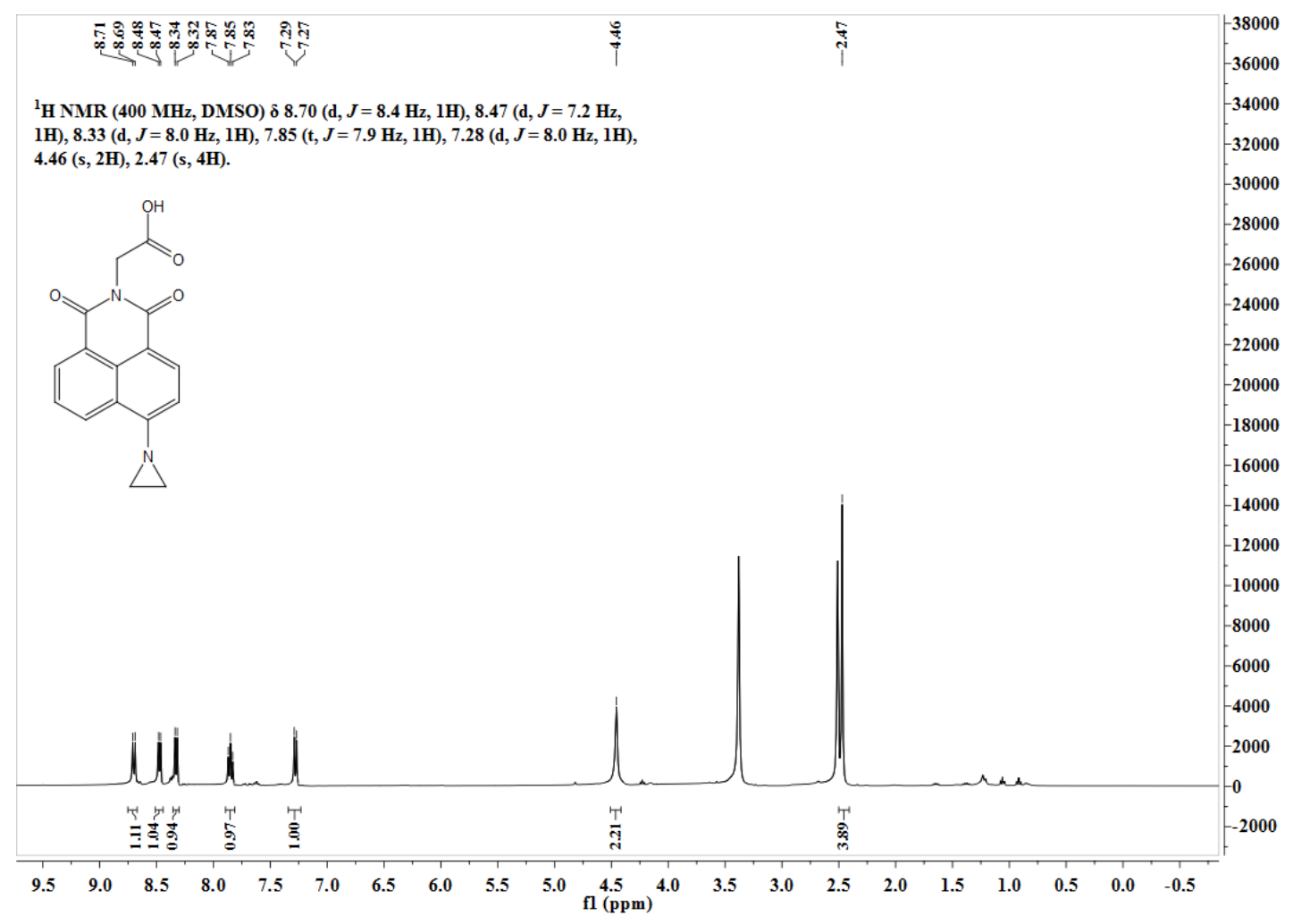

Figure S46. ${ }^{1} \mathrm{H}$ NMR of 8 in DMSO- $d_{6}$.

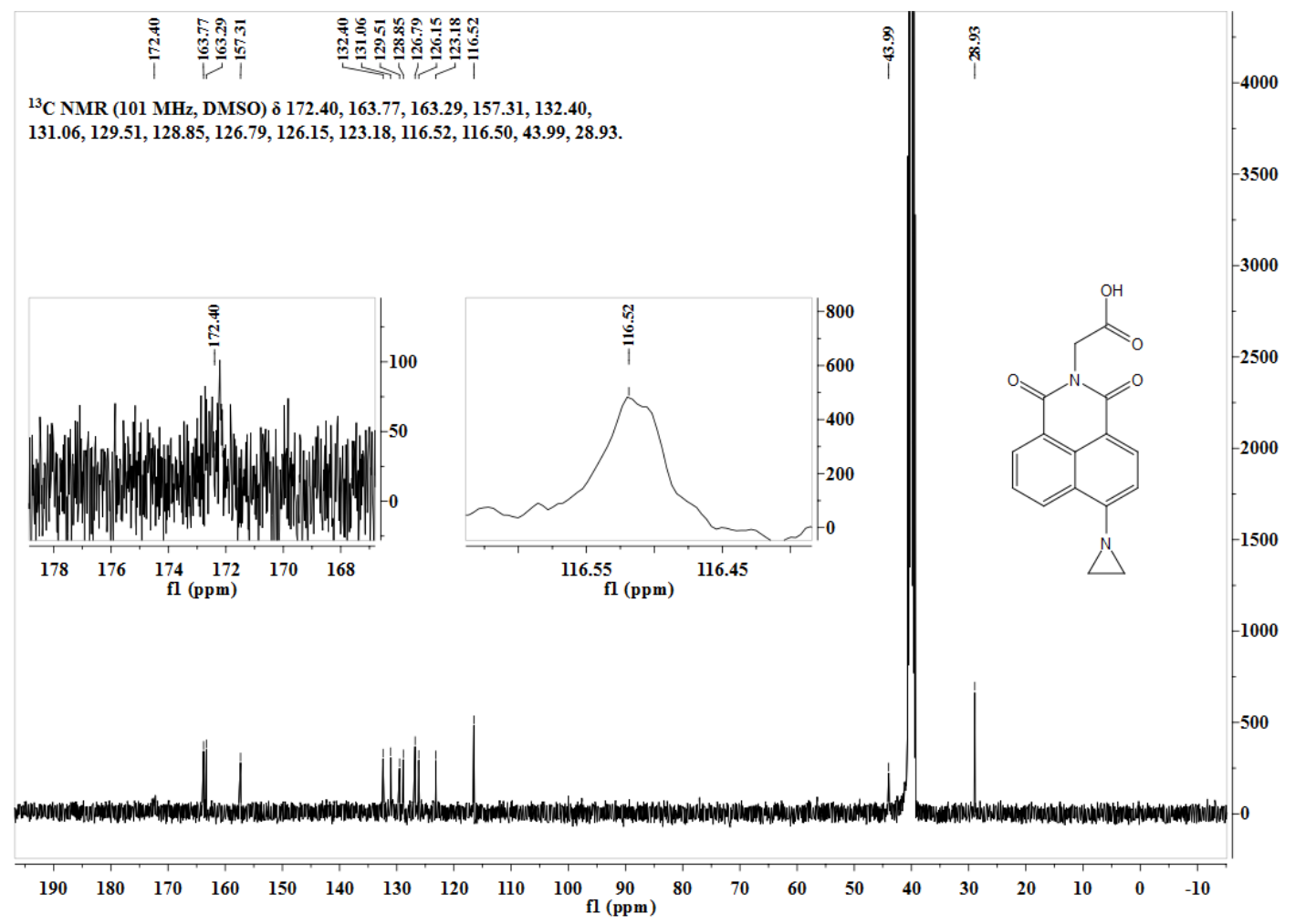

Figure S47. ${ }^{13} \mathrm{C}$ NMR of 8 in DMSO- $d_{6}$. 


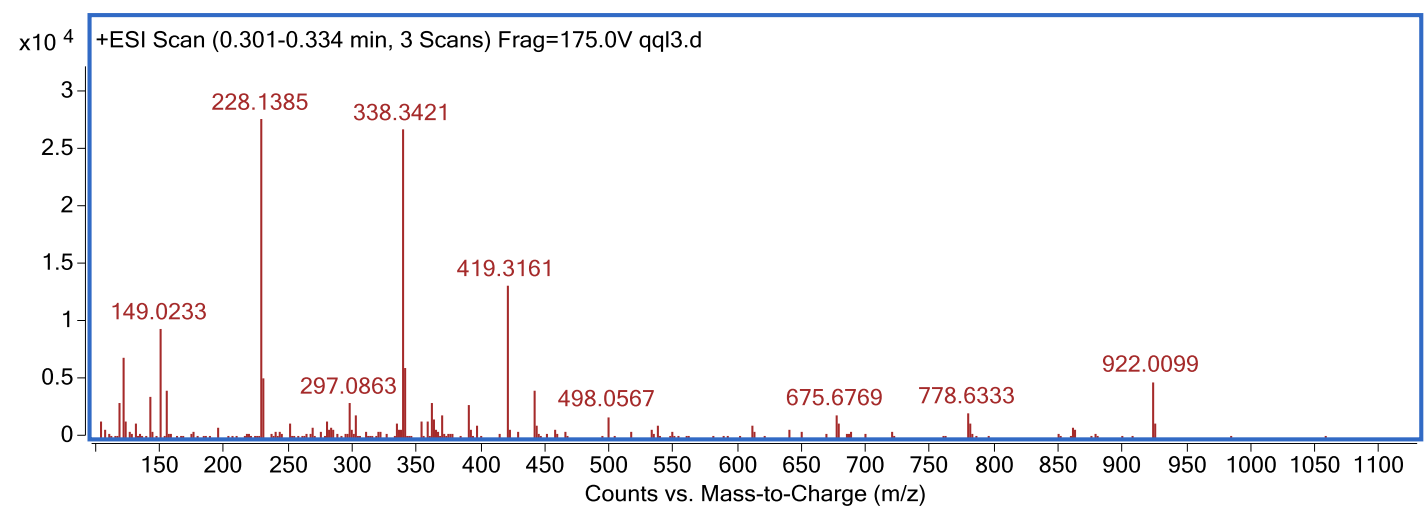

Figure S48. HRMS spectrum of $\mathbf{8}$.

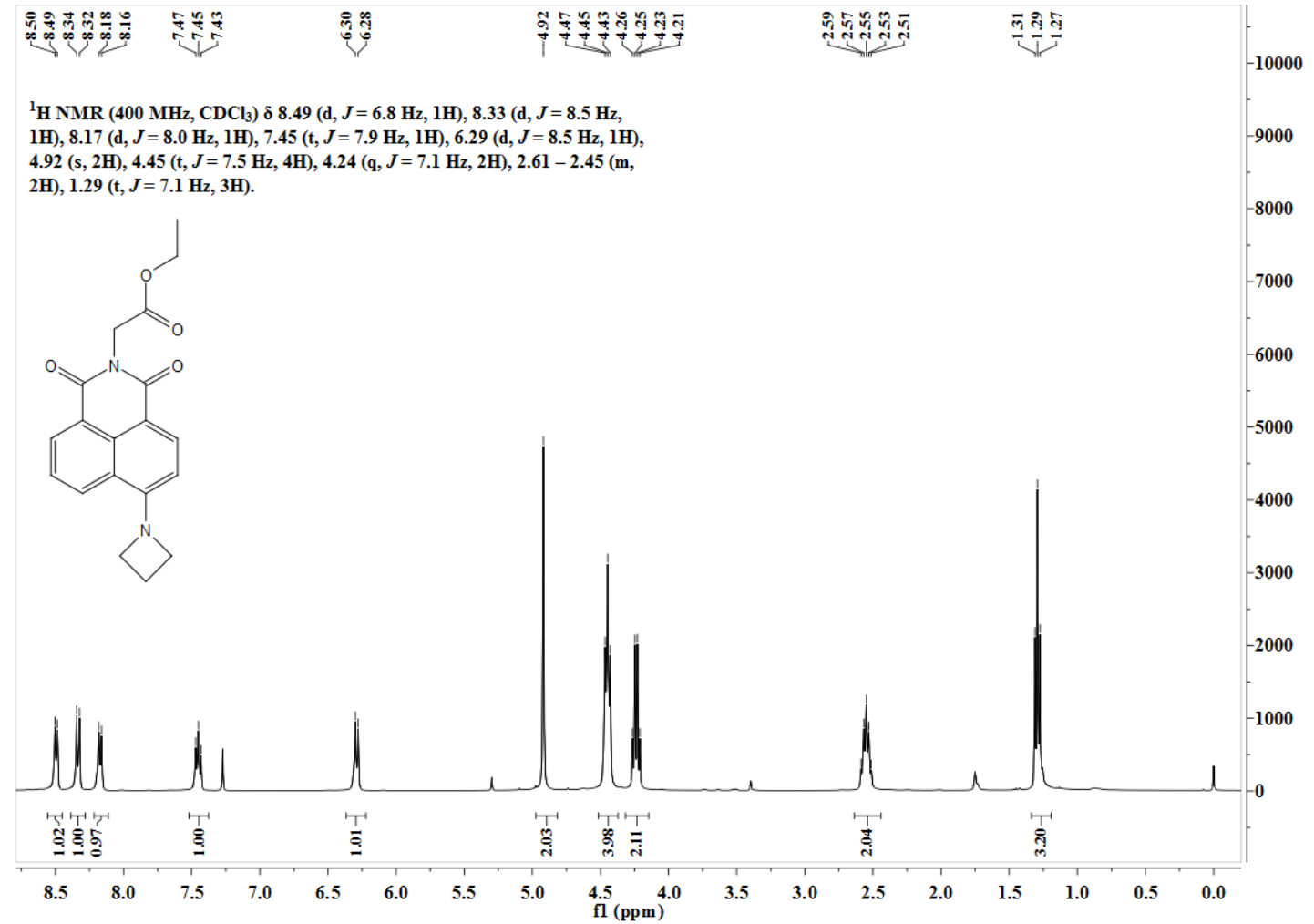

Figure S49. ${ }^{1} \mathrm{H}$ NMR of N-ethoxycarbonylmethyl-4-azetidinly-1,8-naphthalimide 9 in $\mathrm{CDCl}_{3}$. 


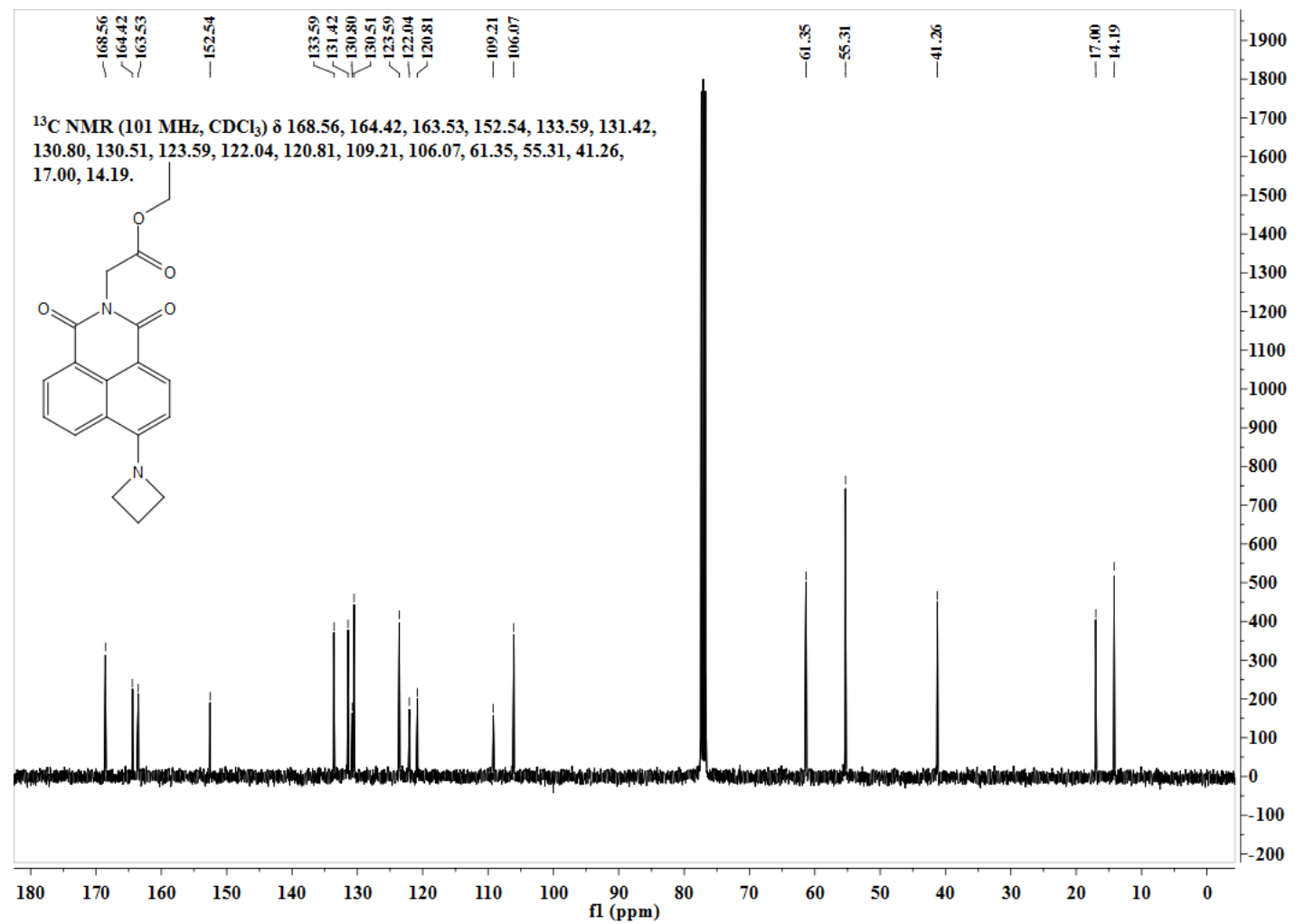

Figure S50. ${ }^{13} \mathrm{C}$ NMR of N-ethoxycarbonylmethyl-4-azetidinly-1,8-naphthalimide 9 in $\mathrm{CDCl}_{3}$.

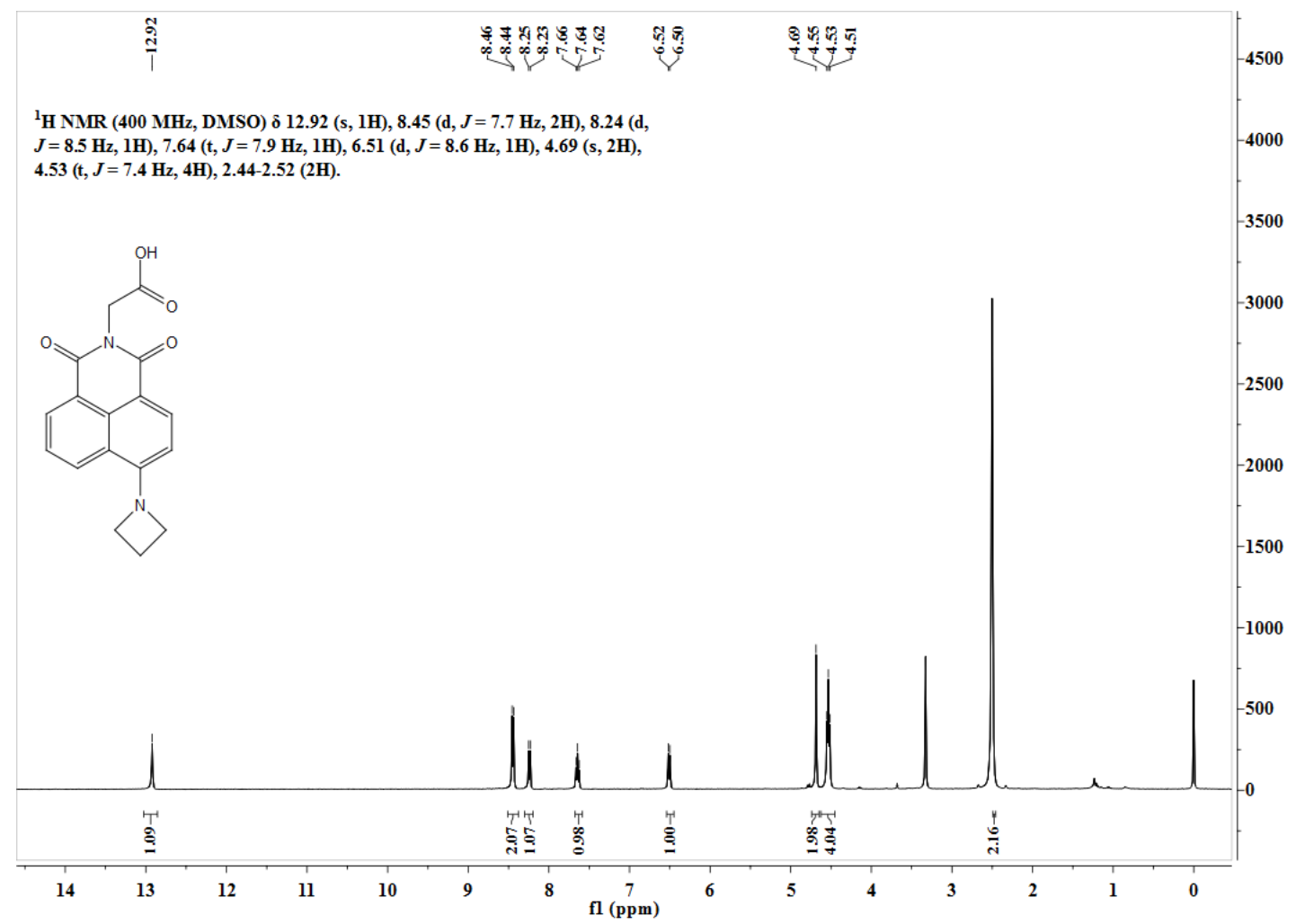

Figure S51. ${ }^{1} \mathrm{H}$ NMR of 9 in DMSO- $d_{6}$. 


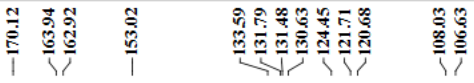

${ }^{13} \mathrm{C}$ NMR (101 MHz, DMSO) $\delta 170.12,163.94,162.92,153.02,133.59$,

$131.79,131.48,130.63,124.45,121.71,120.68,108.03,106.63,55.79,41.34$,

16.91.
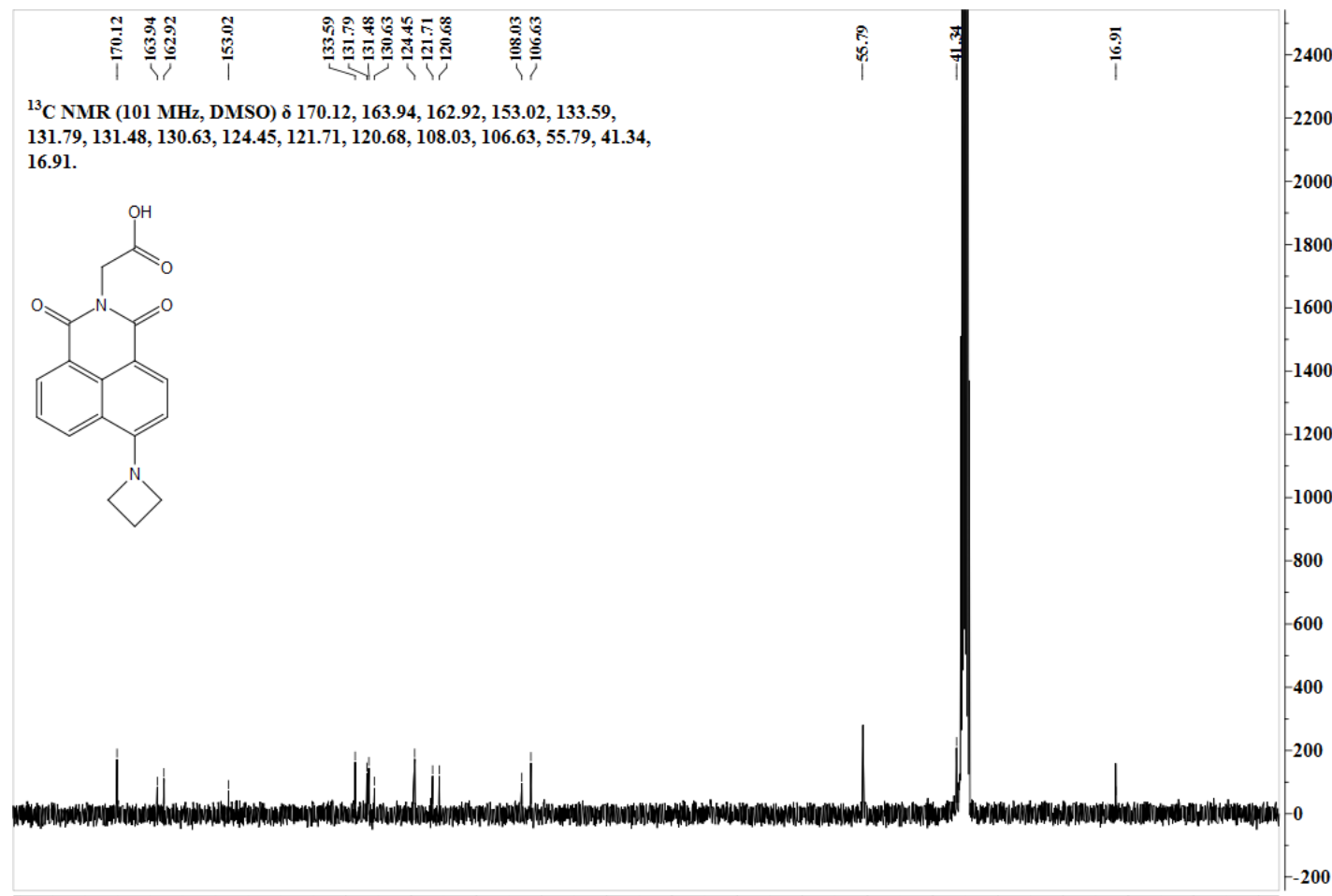

$\begin{array}{lllllllllllllllllll}180 & 170 & 160 & 150 & 140 & 130 & 120 & 110 & 100 & \underset{\mathrm{fl}}{(\mathrm{ppm})} & 80 & 70 & 60 & 50 & 40 & 30 & 20 & 10 & 0\end{array}$

Figure S52. ${ }^{13} \mathrm{C}$ NMR of 9 in DMSO- $d_{6}$.

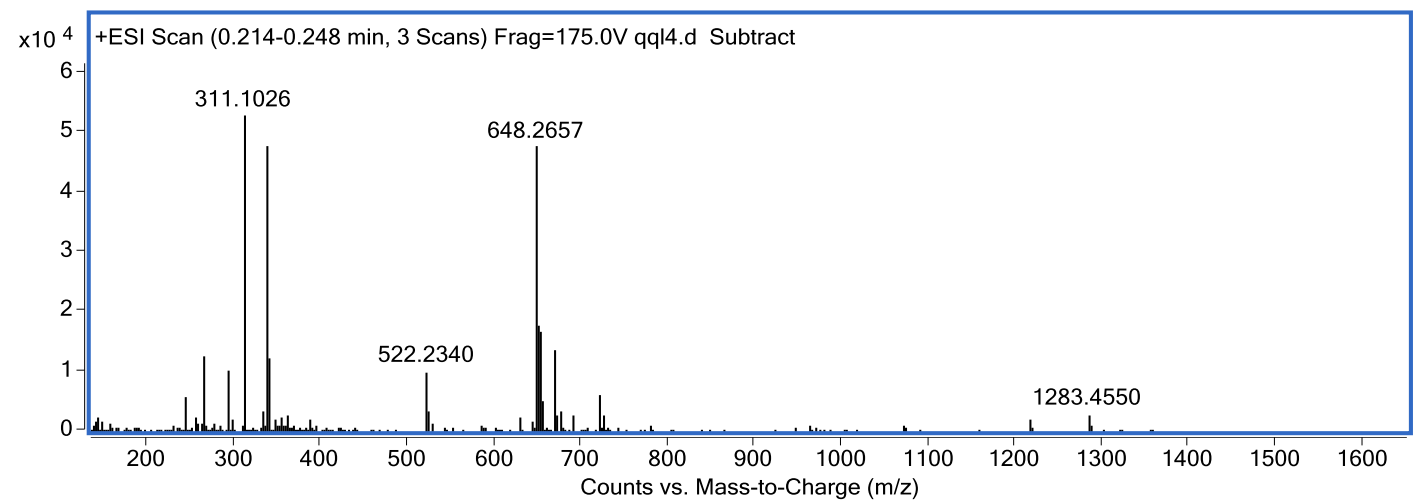

Figure S53. HRMS of 9. 


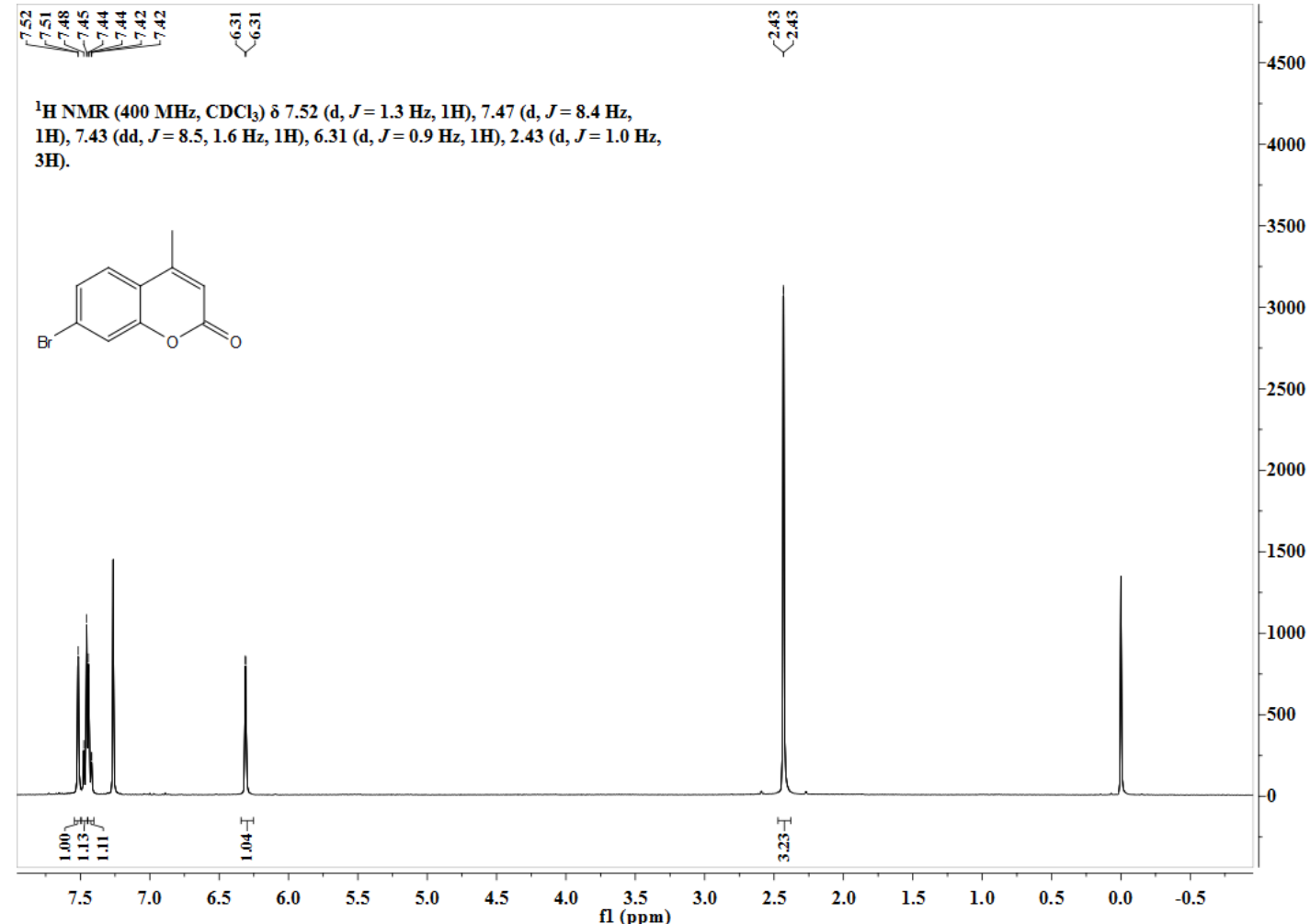

Figure S54. ${ }^{1} \mathrm{H}$ NMR of 7-Br-4-methylcoumarin in $\mathrm{CDCl}_{3}$.

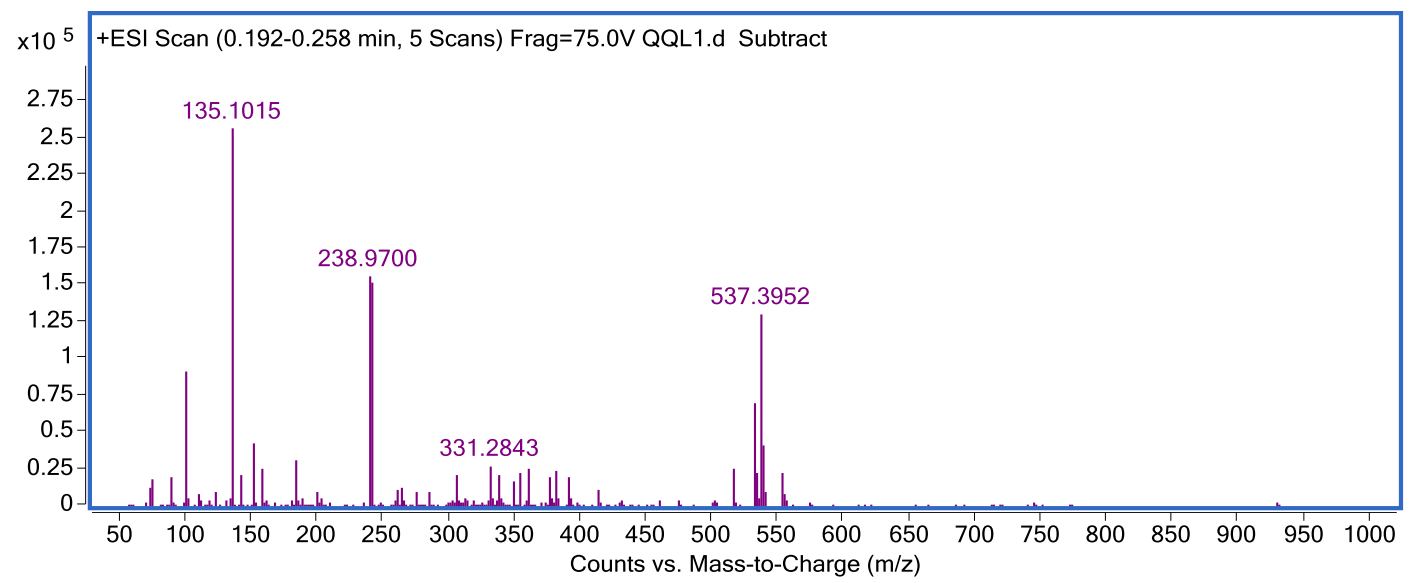

Figure S55. HRMS of 7-bromo-4-methylcoumarin. 


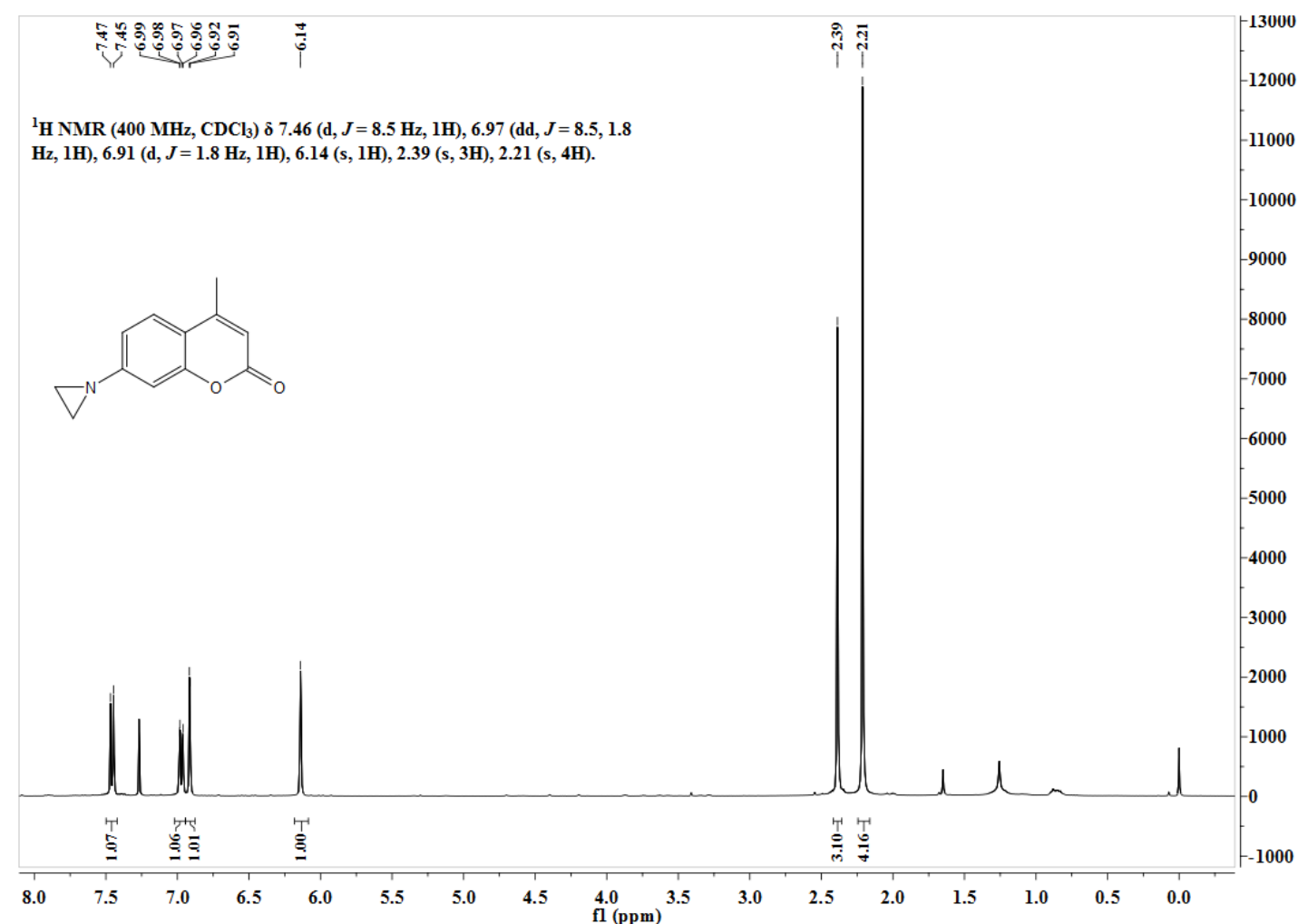

Figure S56. ${ }^{1} \mathrm{H}$ NMR of 7-aziridinyl-4-methylcoumarin $\mathbf{1 0}$ in $\mathrm{CDCl}_{3}$.

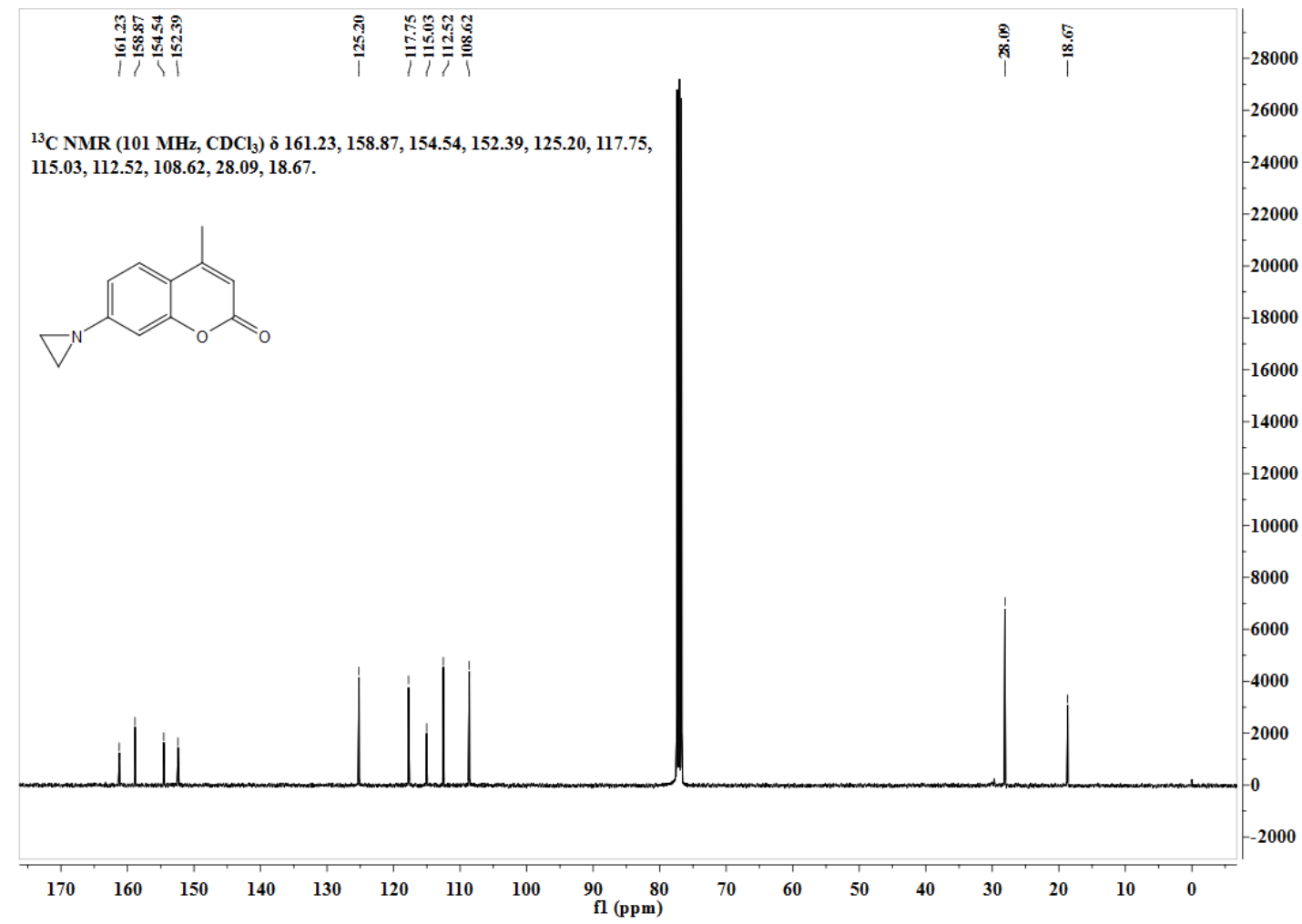

Figure S57. ${ }^{13} \mathrm{C}$ NMR of 7-aziridinyl-4-methylcoumarin $\mathbf{1 0}$ in $\mathrm{CDCl}_{3}$. 


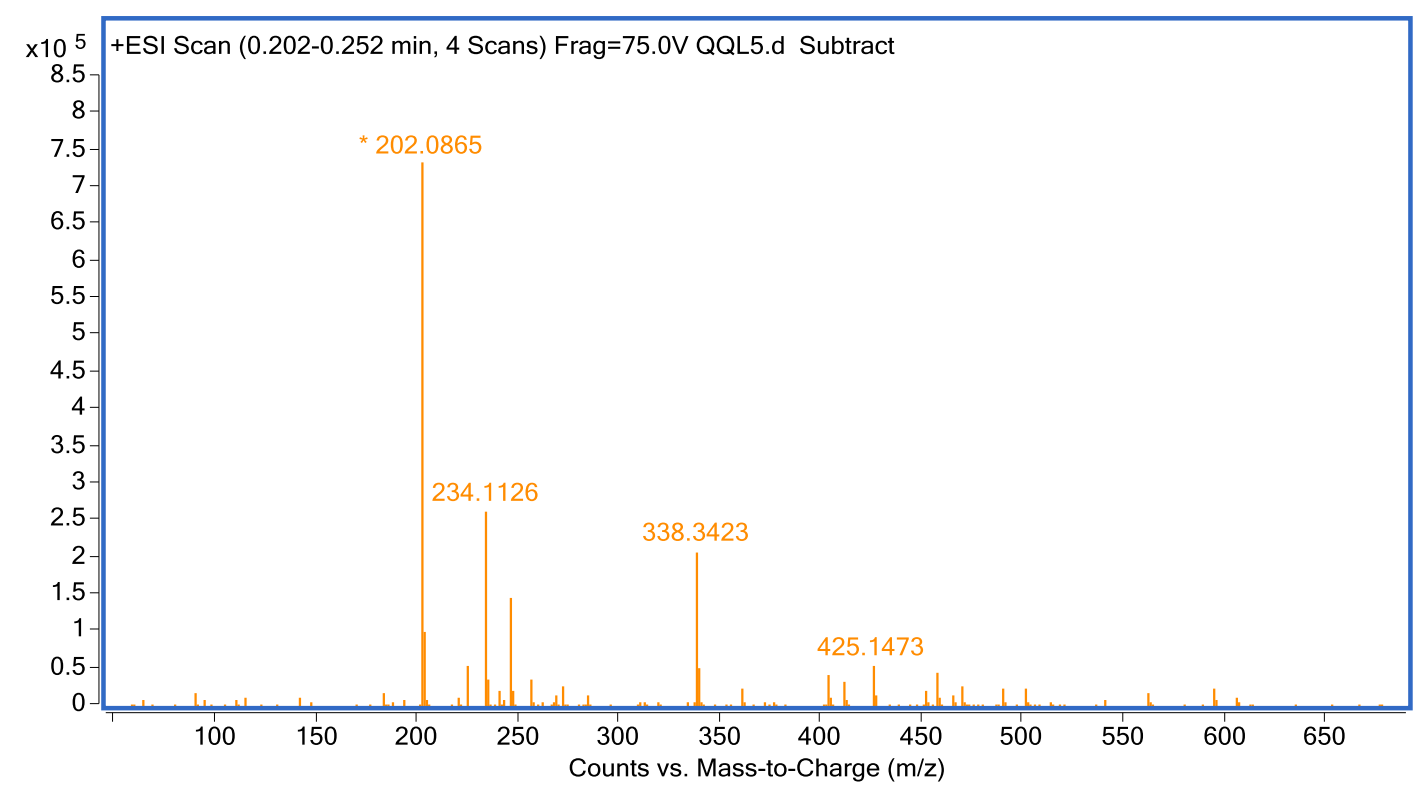

Figure S58. HRMS of 7-aziridinyl-4-methylcoumarin $\mathbf{1 0 .}$

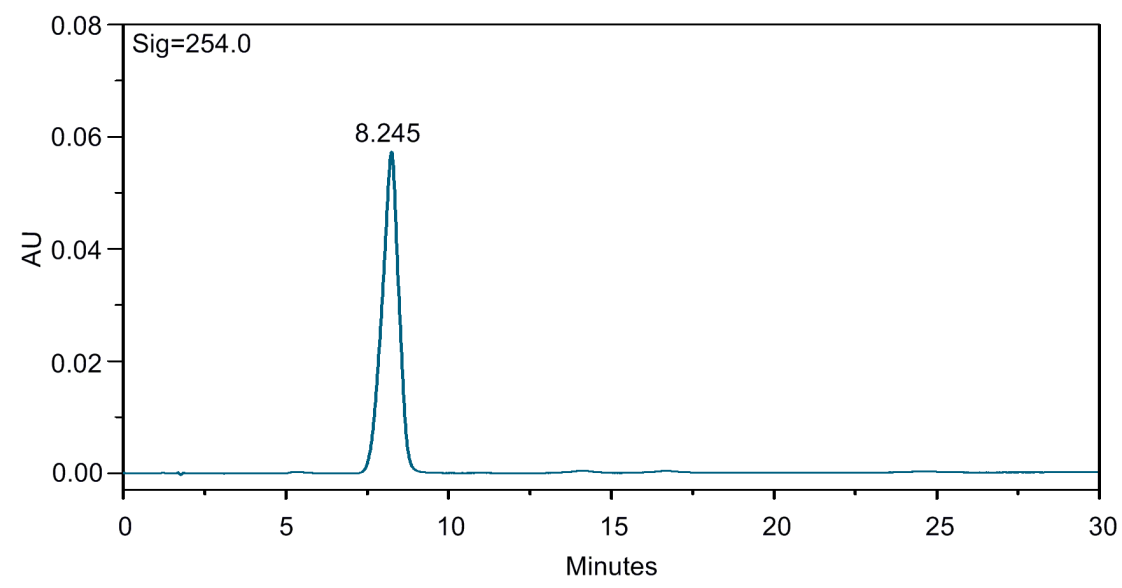

Figure S59. Analytical HPLC spectrum of 7-aziridinyl-4-methylcoumarin 10. 


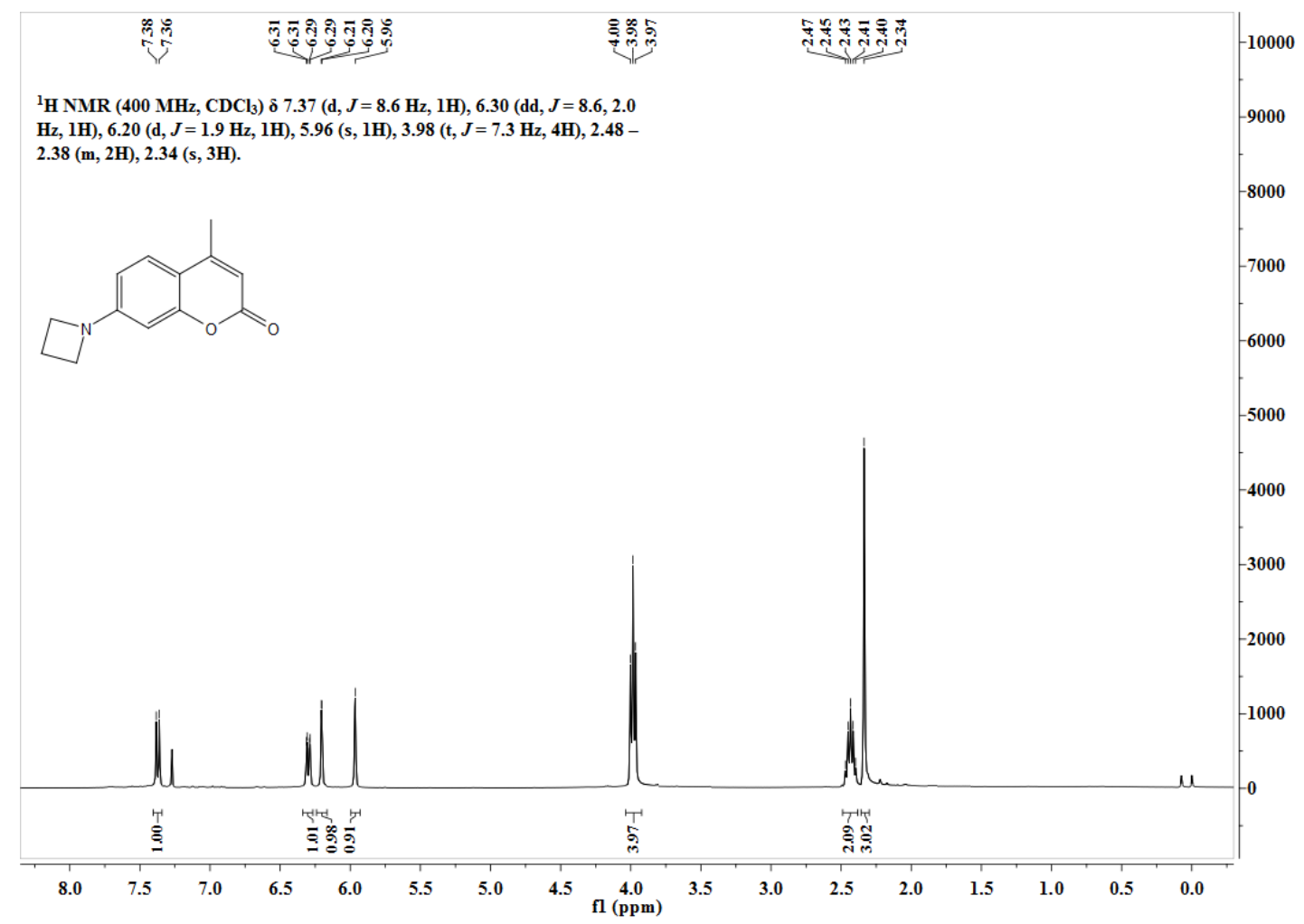

Figure S60. ${ }^{1} \mathrm{H}$ NMR of 7-azetidinyl-4-methylcoumarin 11 in $\mathrm{CDCl}_{3}$.

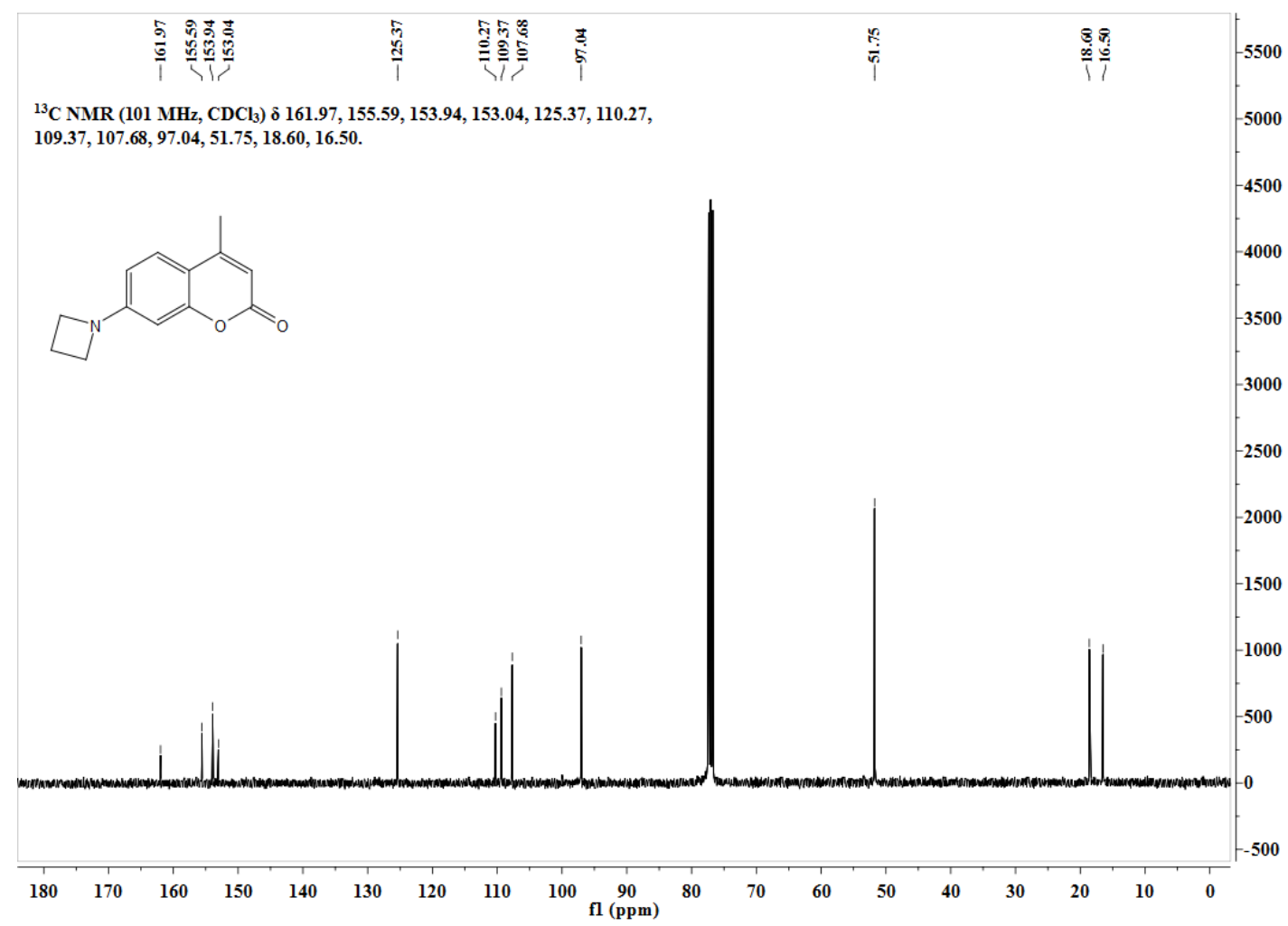

Figure S61. ${ }^{13} \mathrm{C}$ NMR of 7-azetidinyl-4-methylcoumarin 11 in $\mathrm{CDCl}_{3}$. 


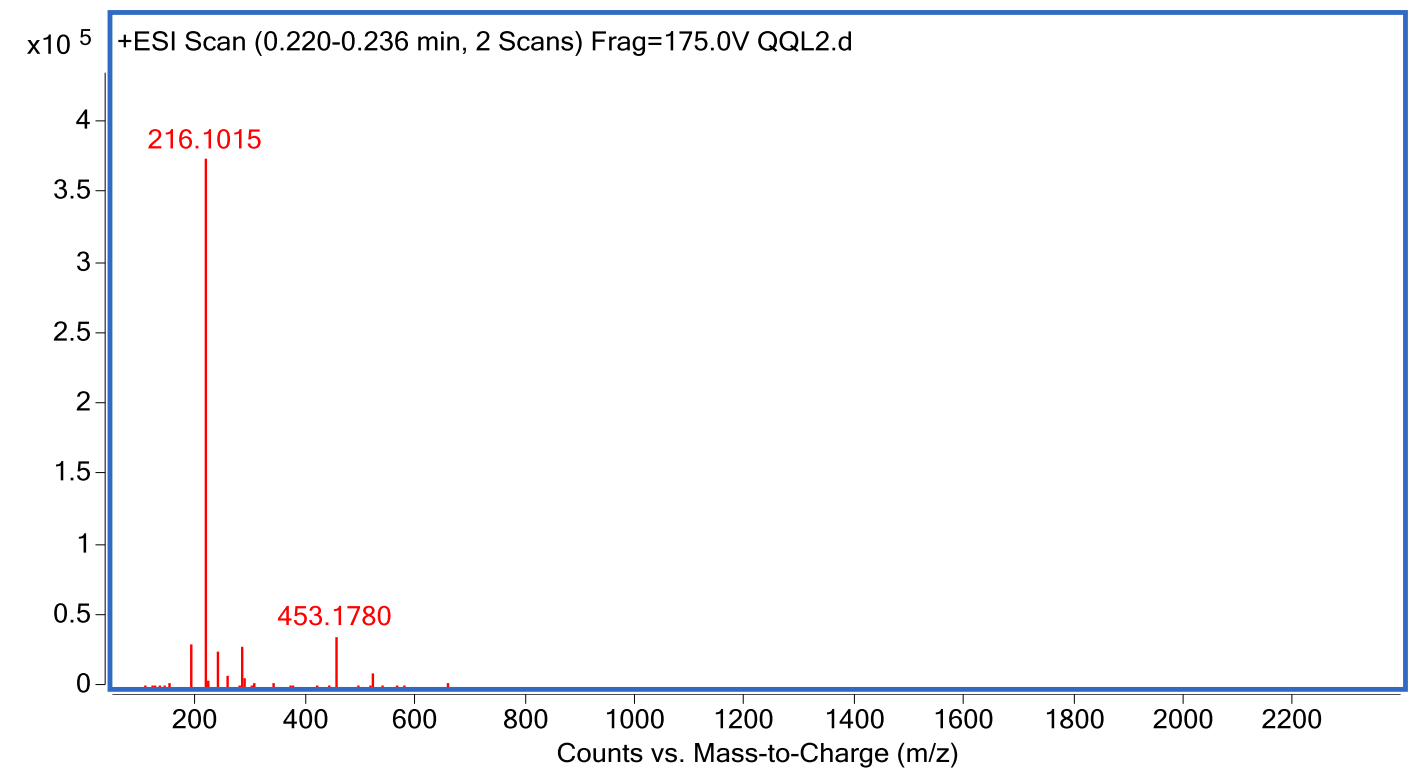

Figure S62. HRMS of 7-azetidinyl-4-methylcoumarin 11.

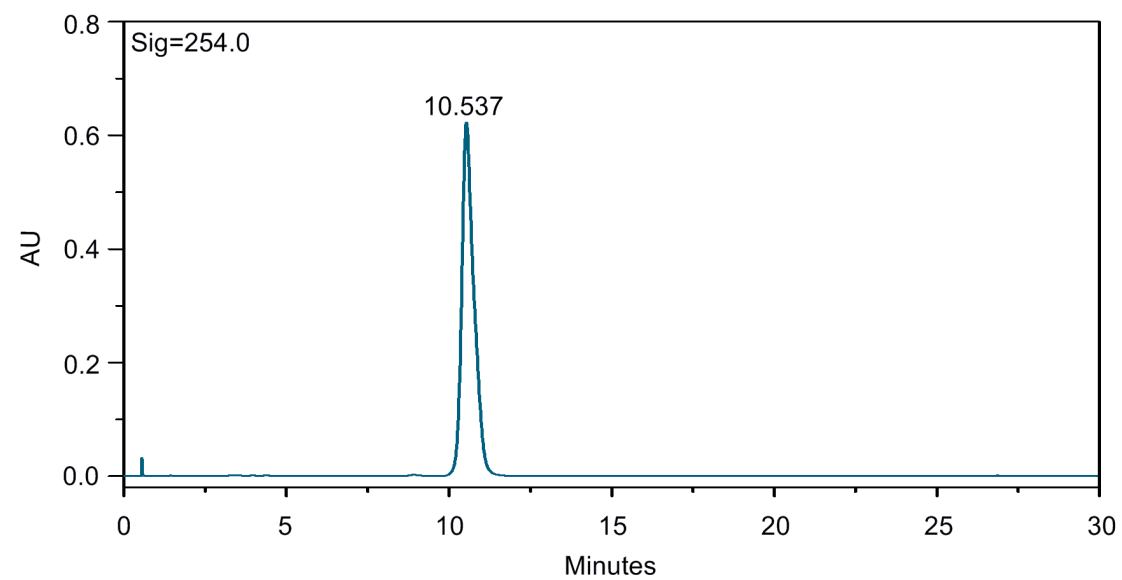

Figure S63. Analytical HPLC spectrum of 7-azetidinyl-4-methylcoumarin 11. 


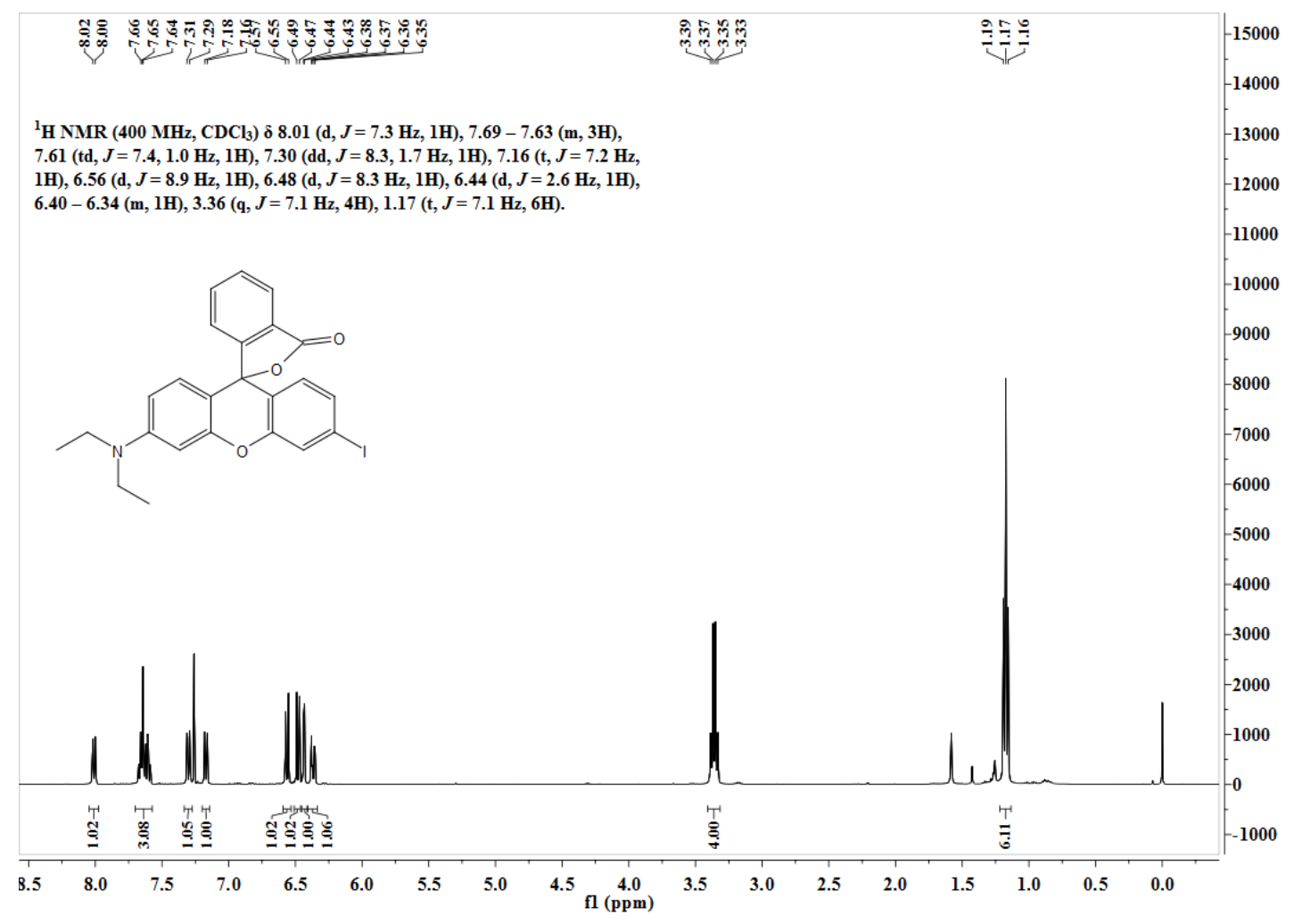

Figure S64. ${ }^{1} \mathrm{H}$ NMR of $\mathbf{R I}$ in $\mathrm{CDCl}_{3}$.

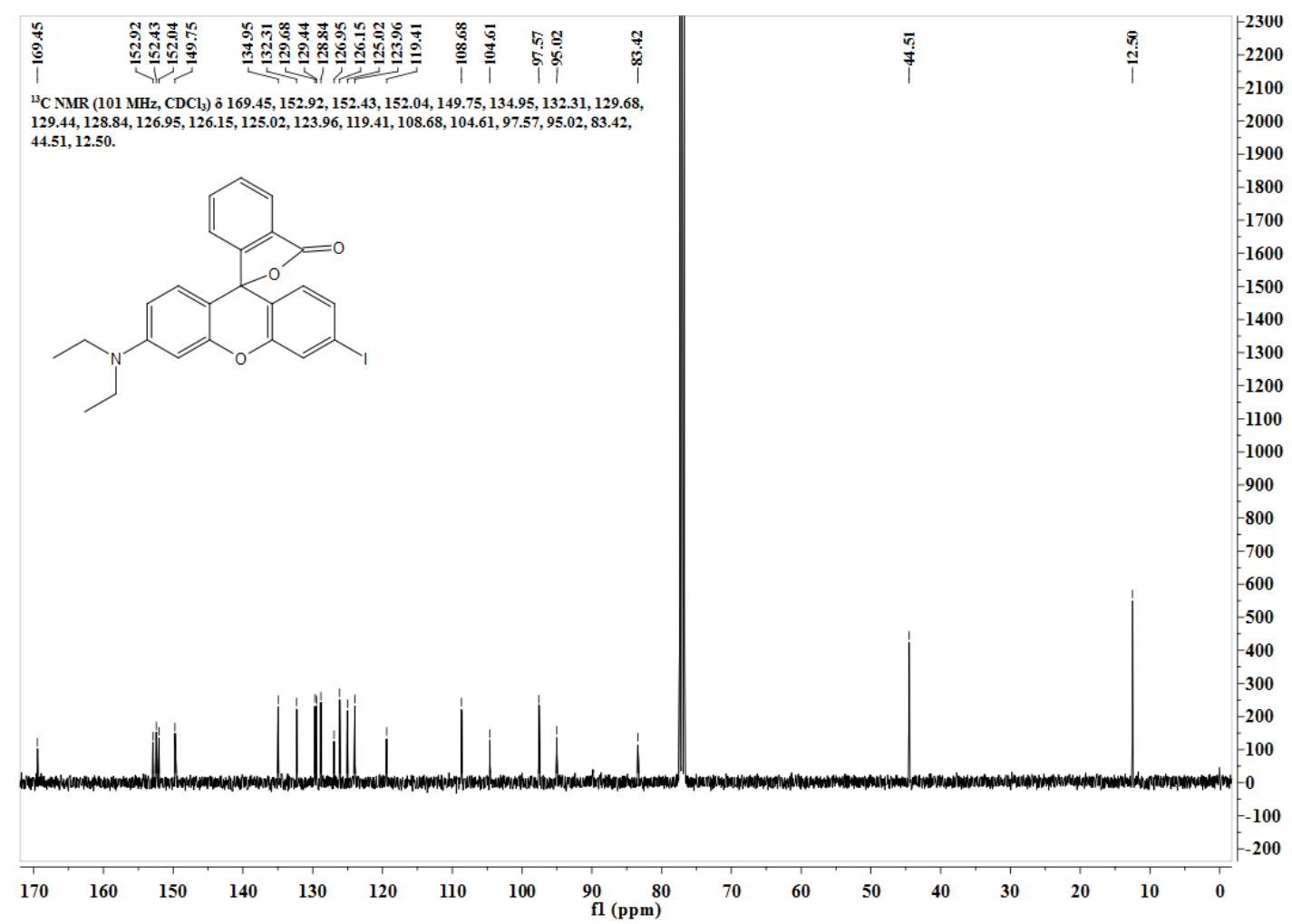

Figure S65. ${ }^{13} \mathrm{C}$ NMR of $\mathbf{R I}$ in $\mathrm{CDCl}_{3}$. 


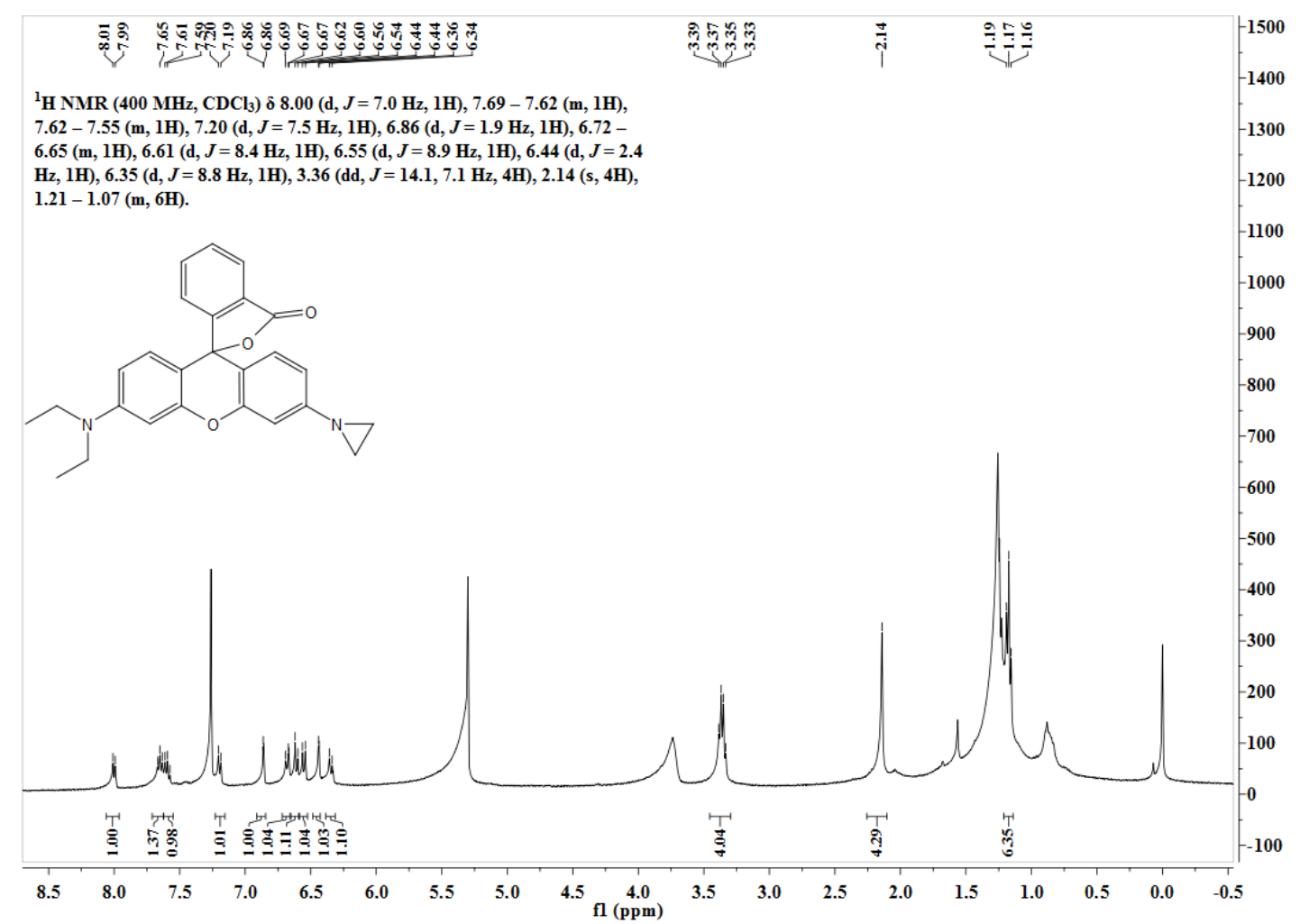

Figure S66. ${ }^{1} \mathrm{H}$ NMR of 12 in $\mathrm{CDCl}_{3}$.

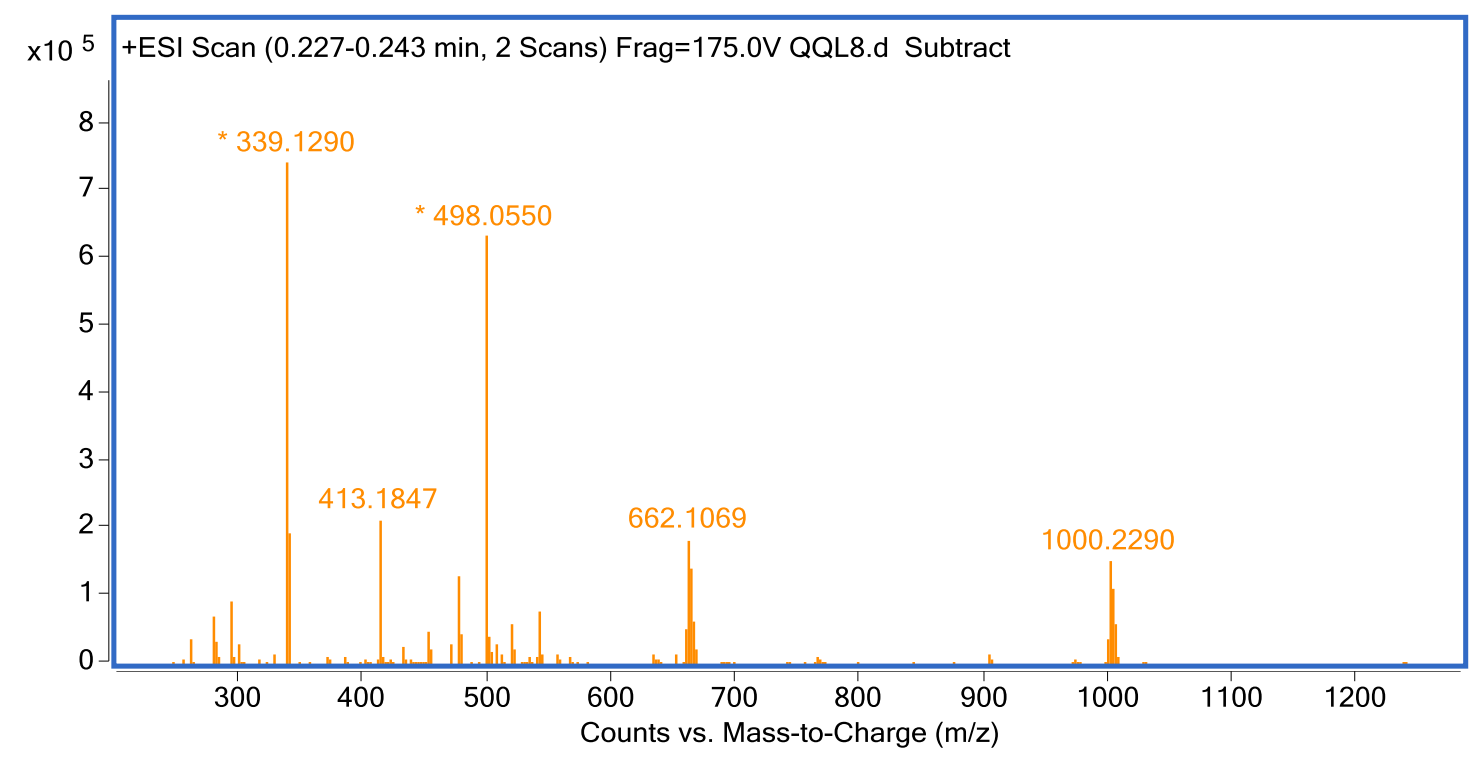

Figure S67. HRMS of $\mathbf{1 2}$. 


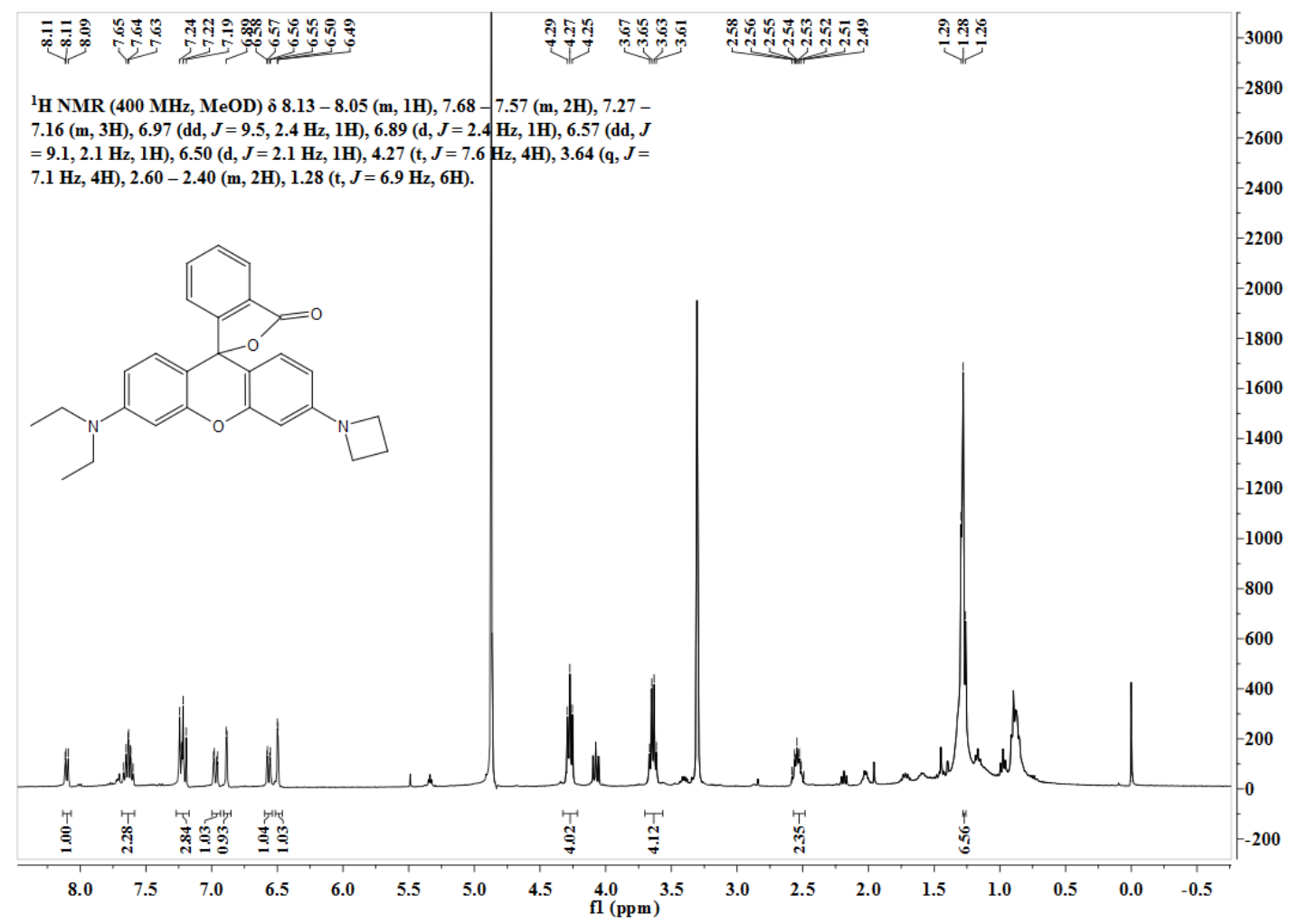

Figure S68. ${ }^{1} \mathrm{H}$ NMR of $\mathbf{1 3}$ in $\mathrm{CD}_{3} \mathrm{OD}$.

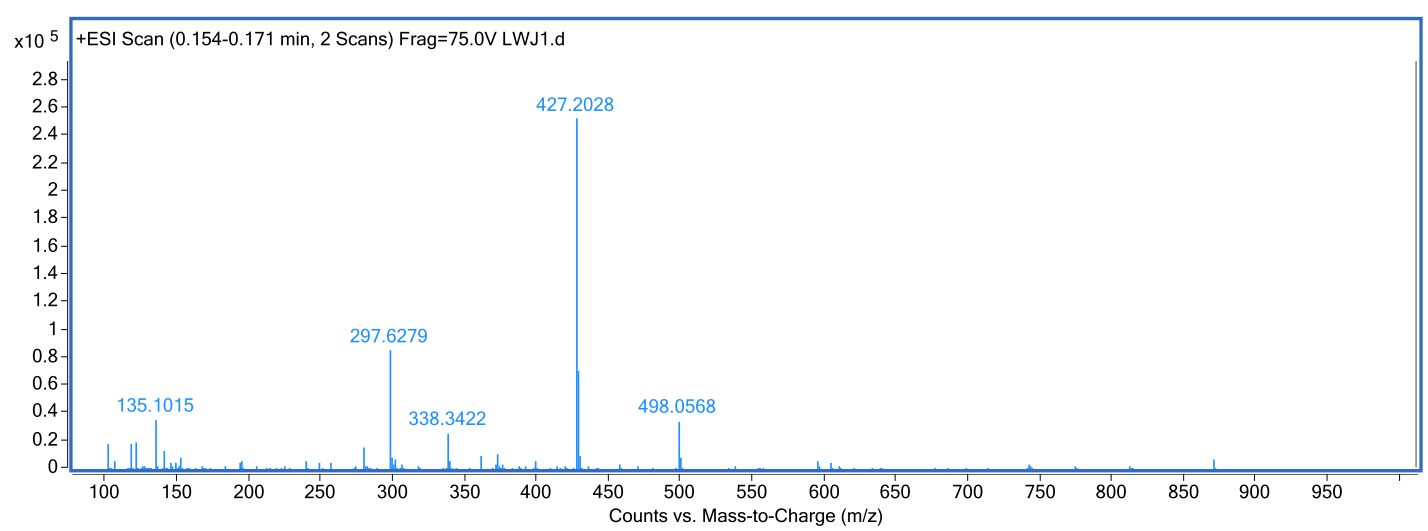

Figure S69. HRMS of 13. 


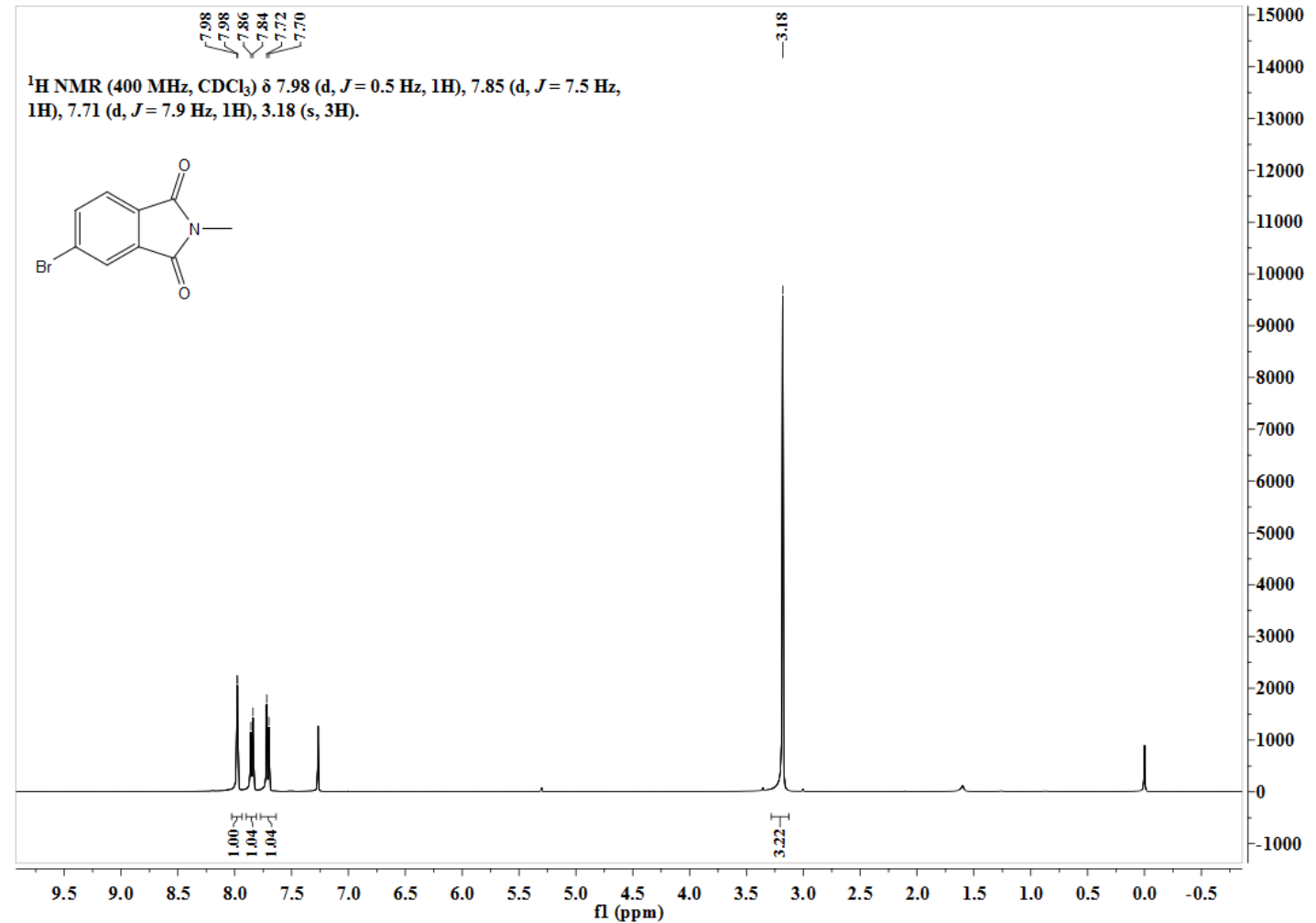

Figure S70. ${ }^{1} \mathrm{H}$ NMR of 4-Br-N-methylphthalimide in $\mathrm{CDCl}_{3}$.

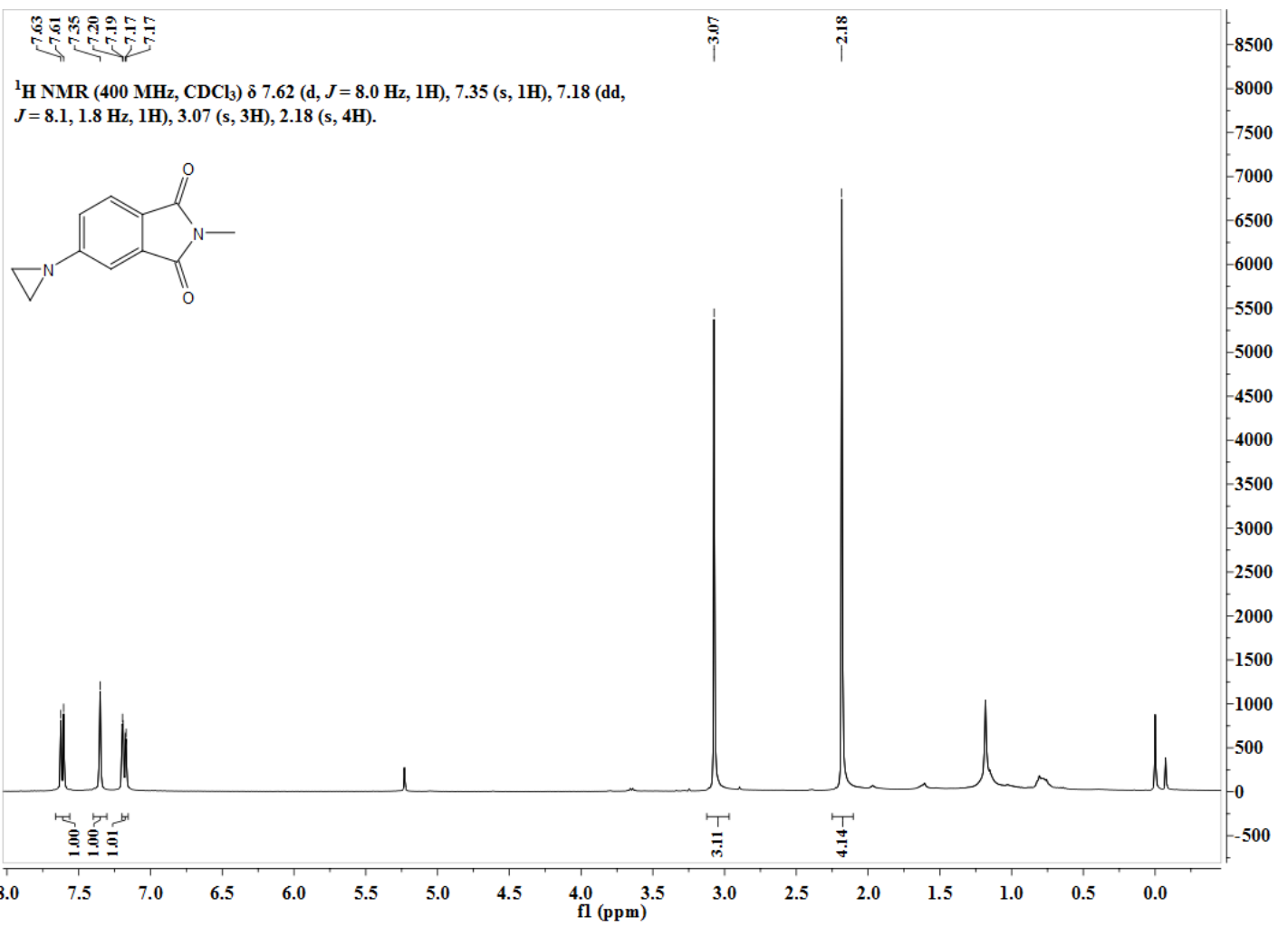

Figure S71. ${ }^{1} \mathrm{H}$ NMR of 4-aziridinly-N-methylphthalimide 14 in $\mathrm{CDCl}_{3}$. 


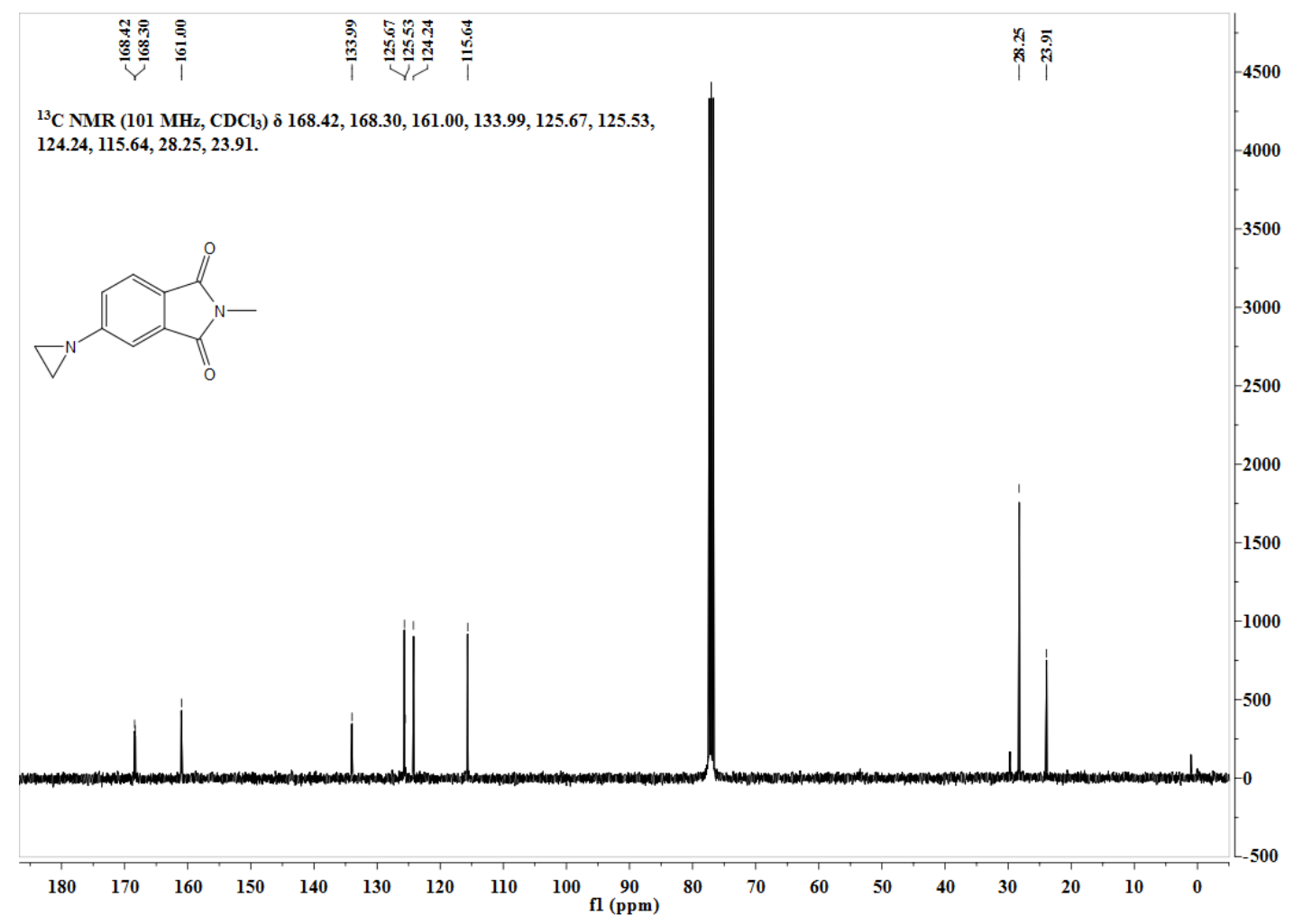

Figure S72. ${ }^{13} \mathrm{C}$ NMR of 4-aziridinly-N-methylphthalimide 14 in $\mathrm{CDCl}_{3}$.

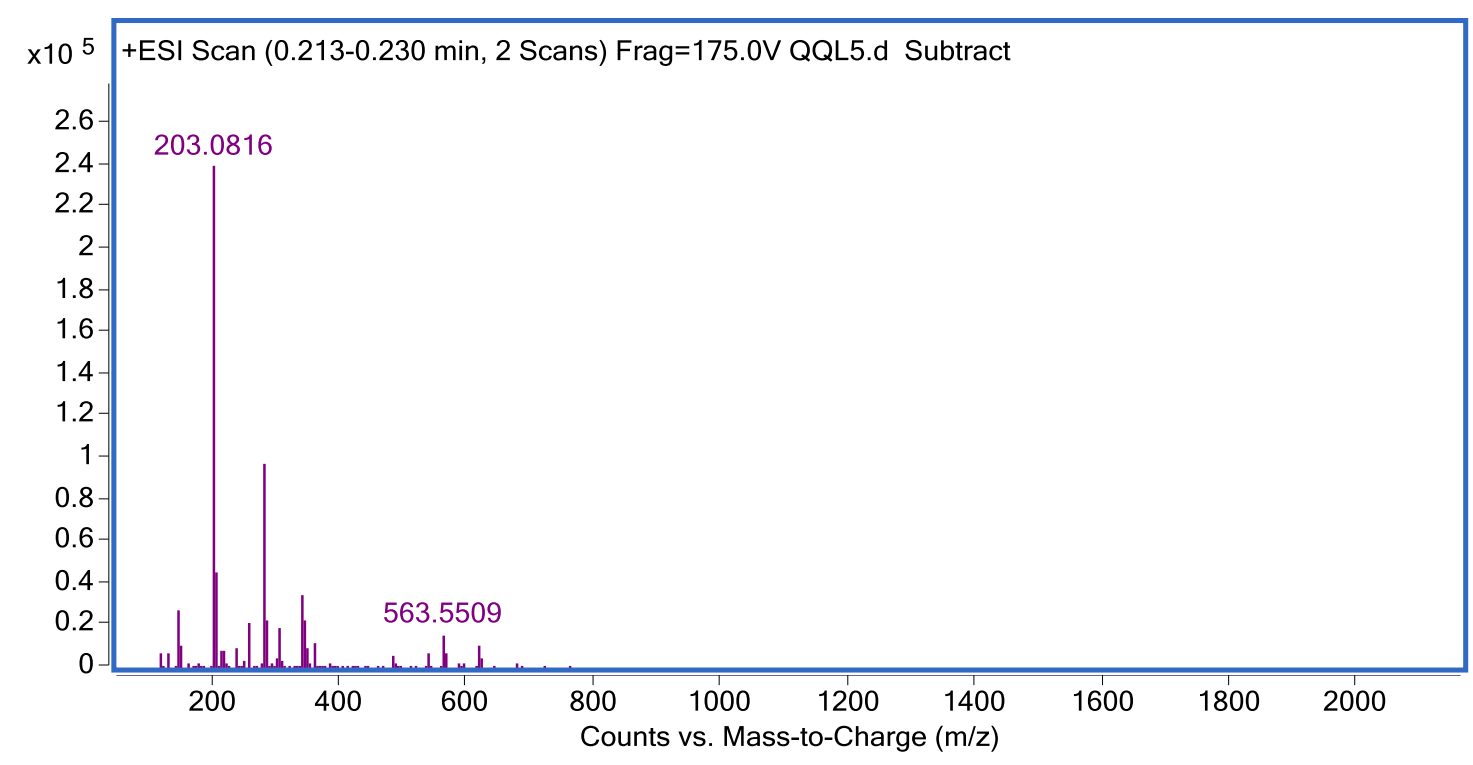

Figure S73. HRMS of 4-aziridinly-N-methylphthalimide 14. 


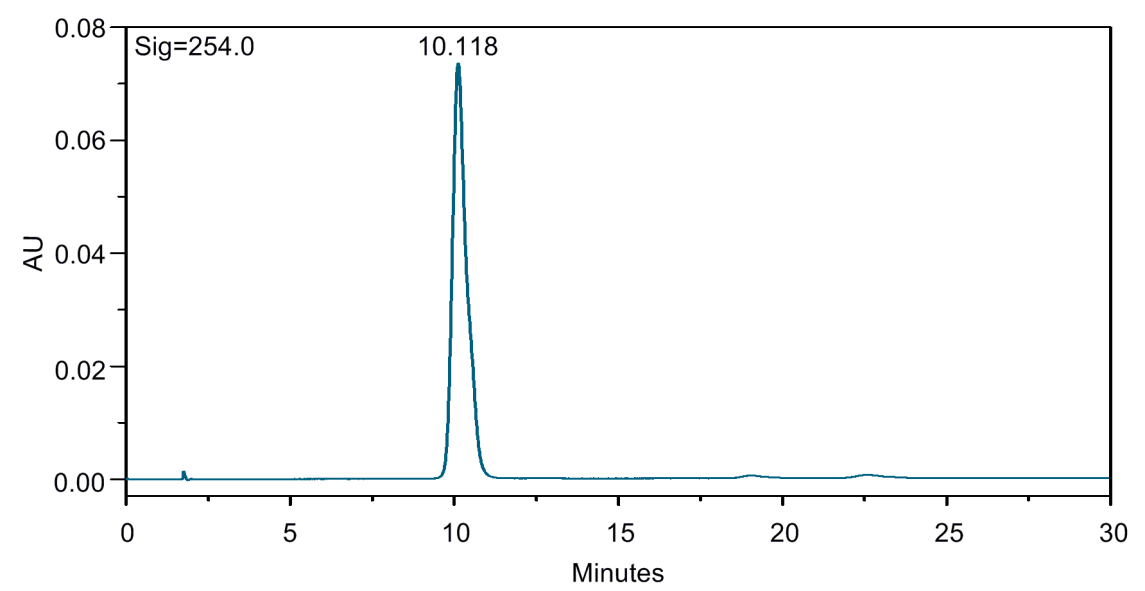

Figure S74. Analytical HPLC spectrum of 4-aziridinly-N-methylphthalimide 14

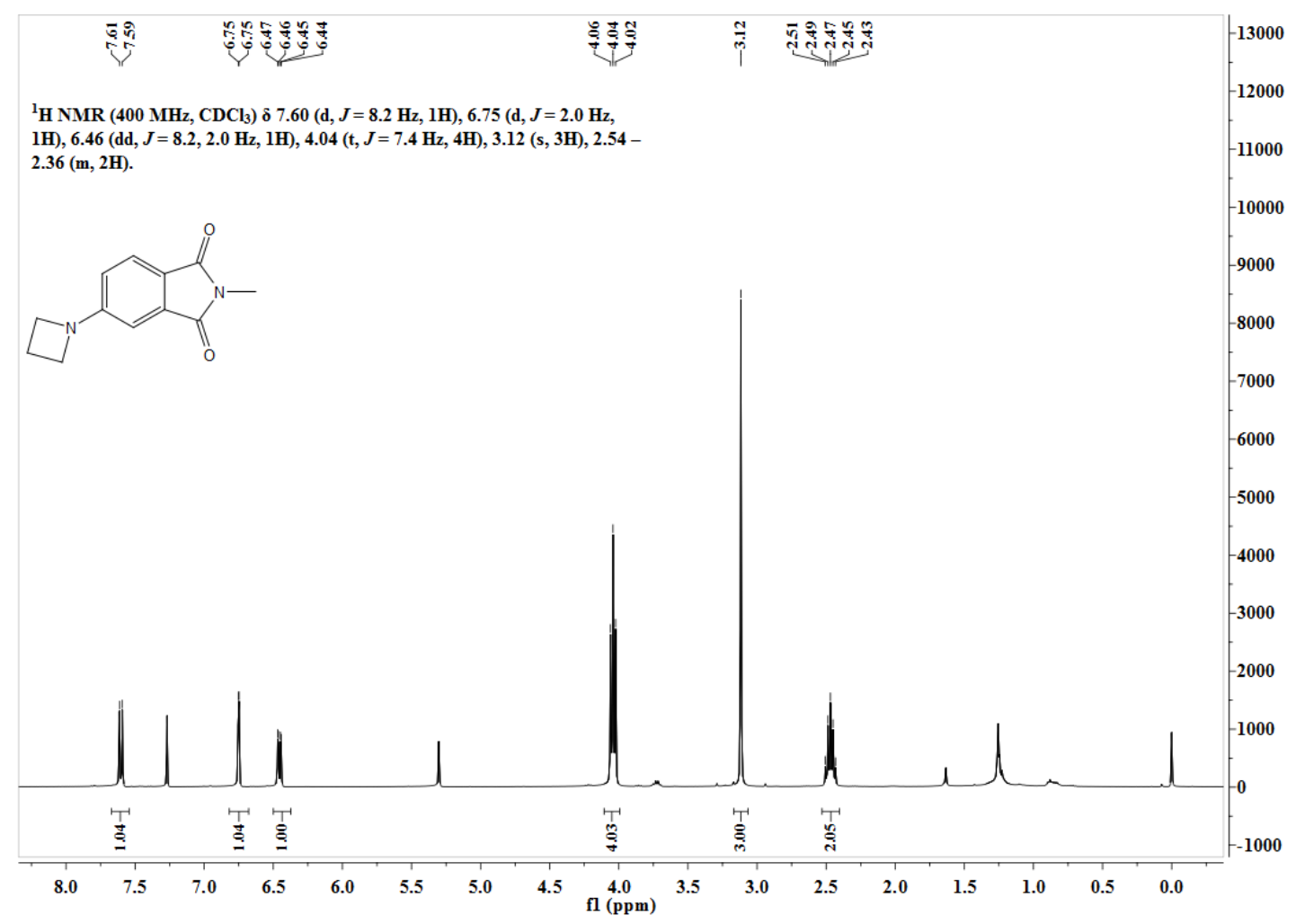

Figure S75. ${ }^{1} \mathrm{H}$ NMR of 4-azetidinly-N-methylphthalimide 15 in $\mathrm{CDCl}_{3}$. 


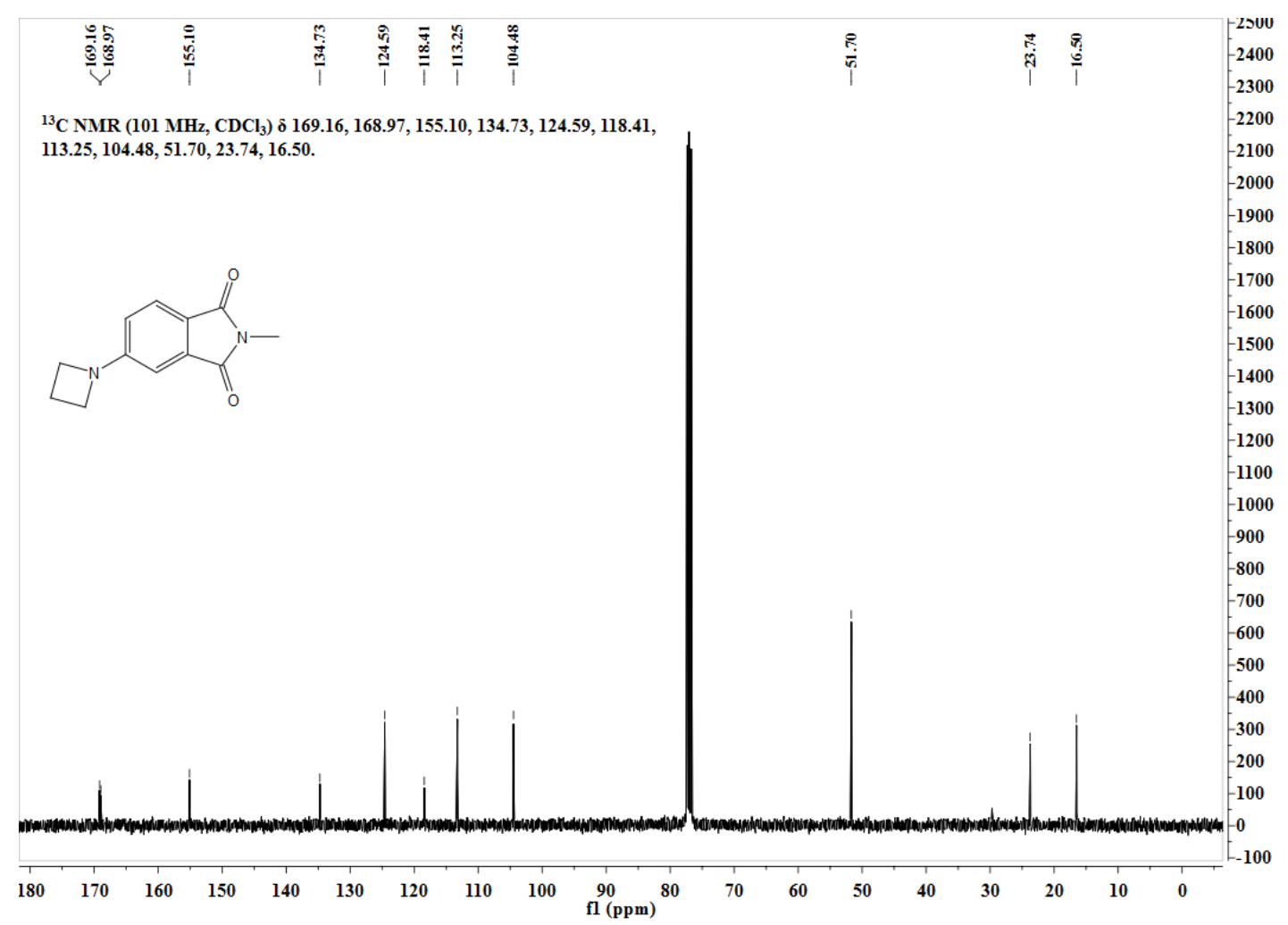

Figure S76. ${ }^{13} \mathrm{C}$ NMR of 4-azetidinly-N-methylphthalimide 15 in $\mathrm{CDCl}_{3}$.

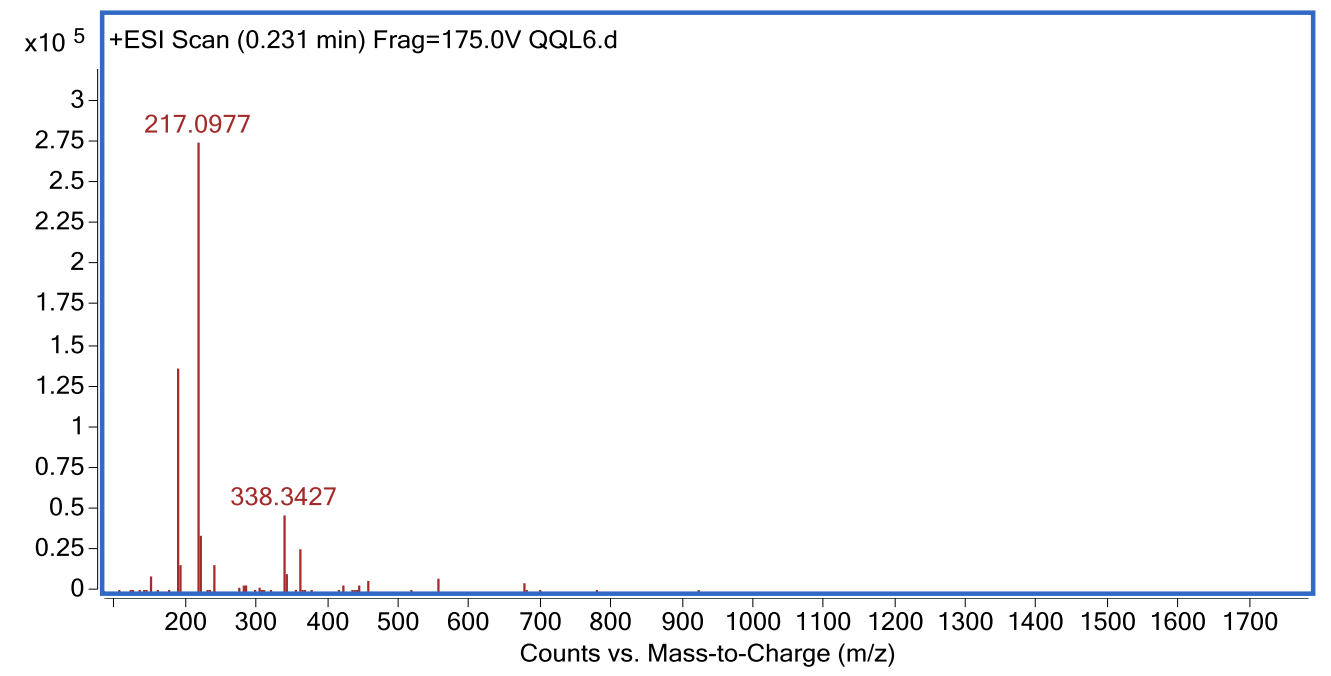

Figure S77. HRMS of 4-azetidinly-N-methylphthalimide 15. 


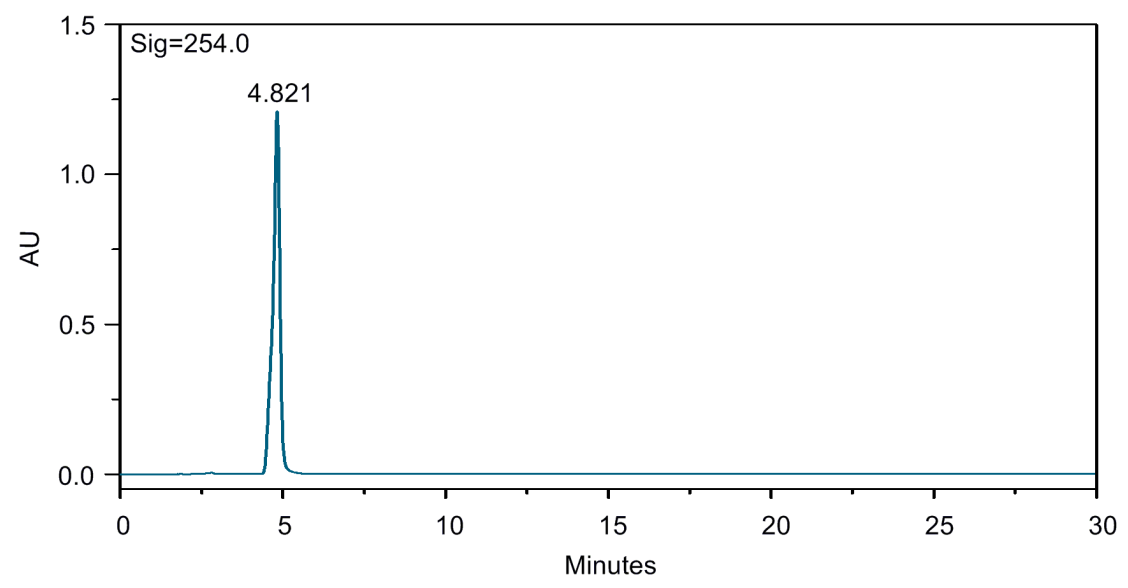

Figure S78. Analytical HPLC spectrum of 4-azetidinly-N-methylphthalimide 15.

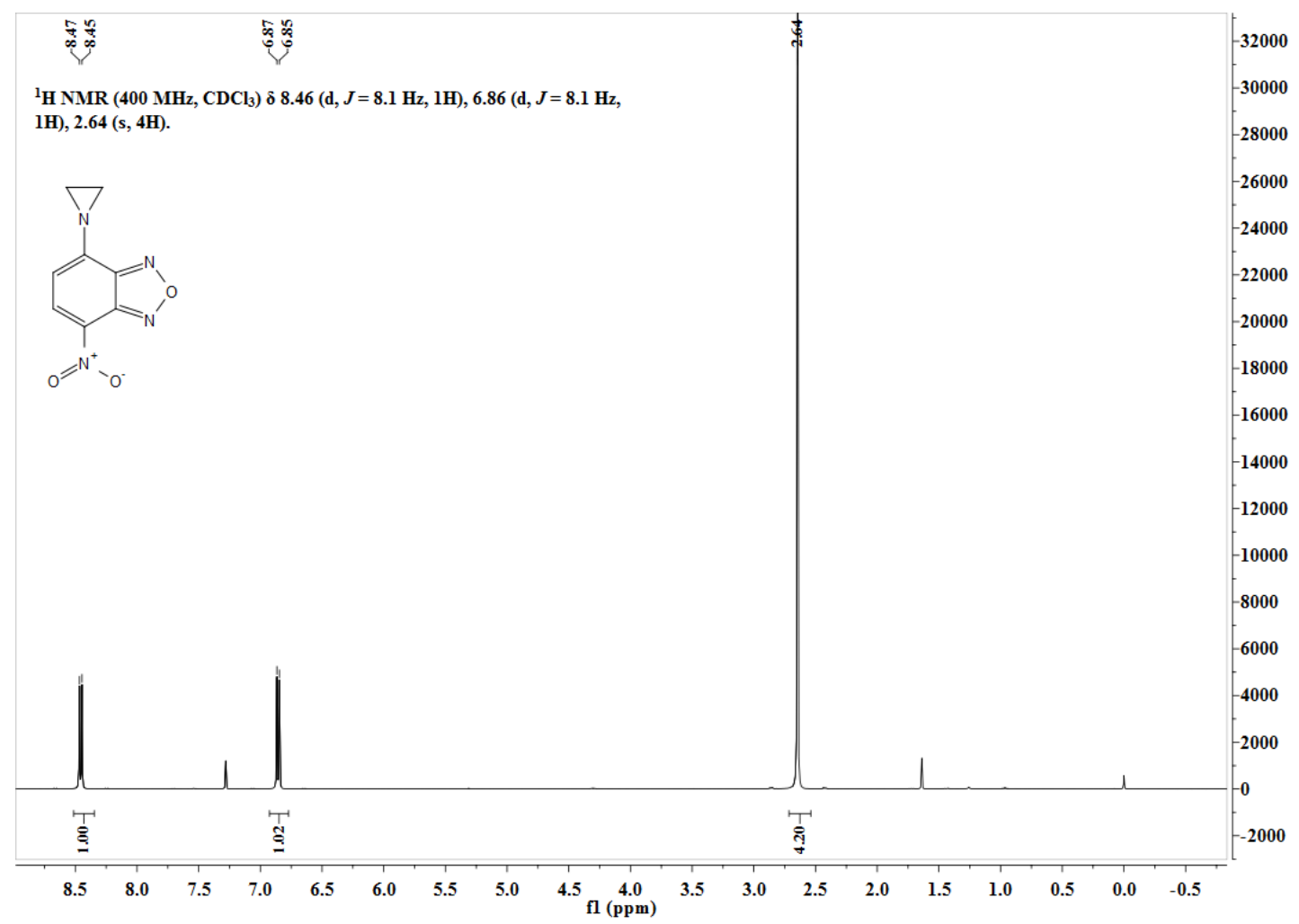

Figure S79. ${ }^{1} \mathrm{H}$ NMR of 4-aziridinly-7-nitrobenzofurazan 16 in $\mathrm{CDCl}_{3}$. 


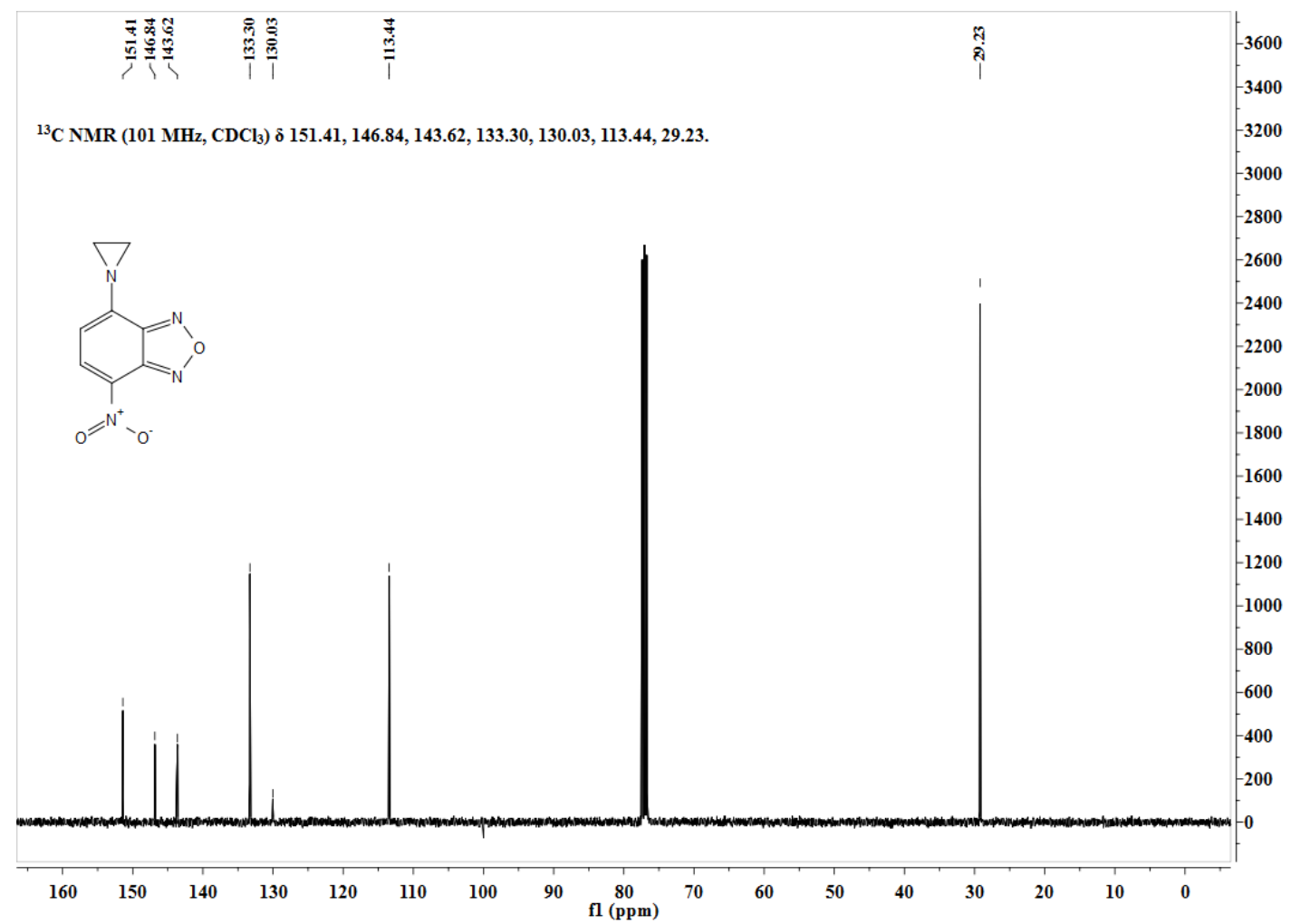

Figure S80. ${ }^{13} \mathrm{C}$ NMR of 4-aziridinly-7-nitrobenzofurazan $\mathbf{1 6}$ in $\mathrm{CDCl}_{3}$.

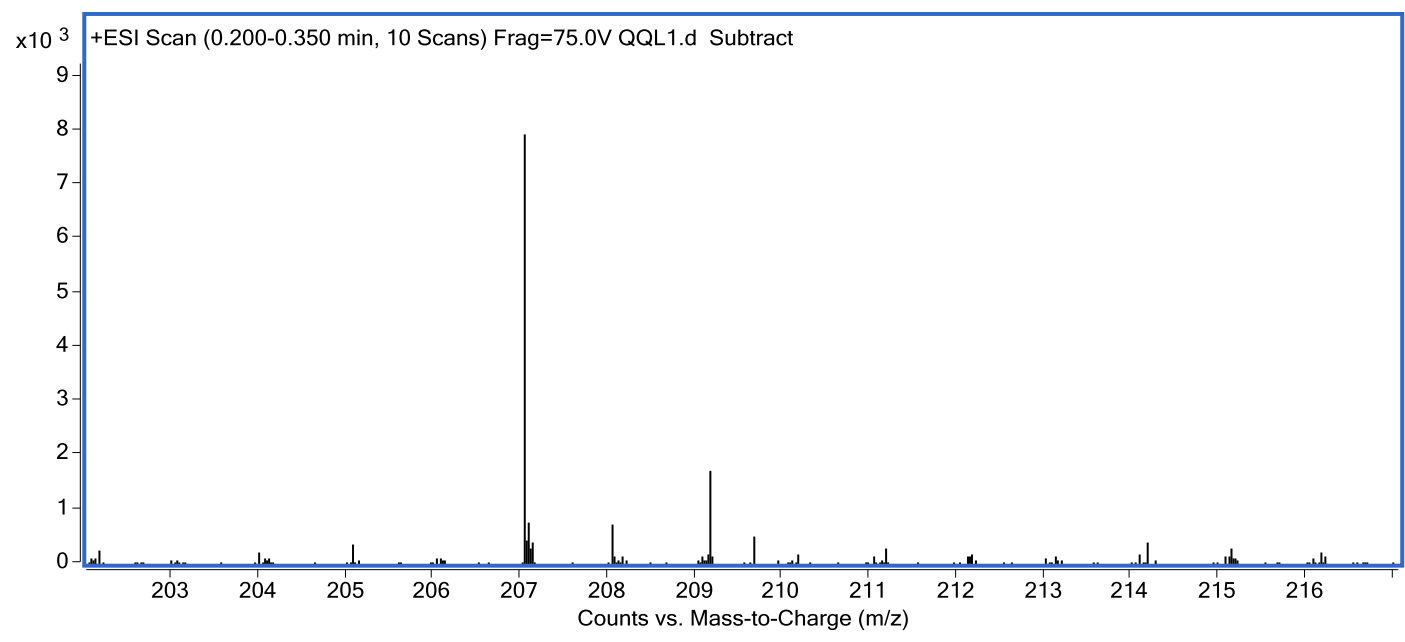

Figure S81. HRMS of 4-aziridinly-7-nitrobenzofurazan 16. 


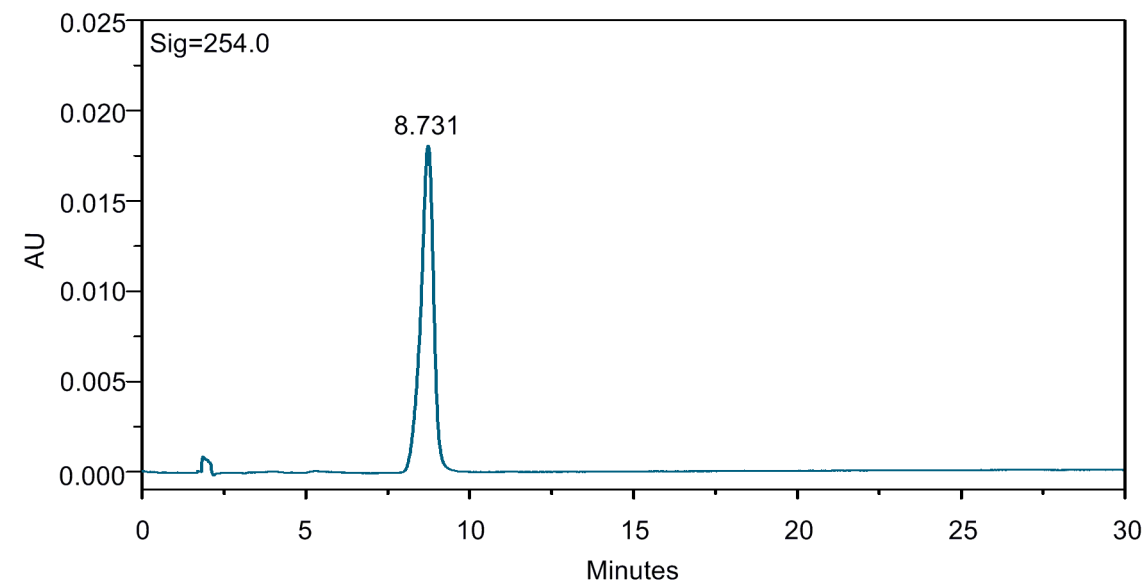

Figure S82. Analytical HPLC spectrum of 4-aziridinly-7-nitrobenzofurazan 16.

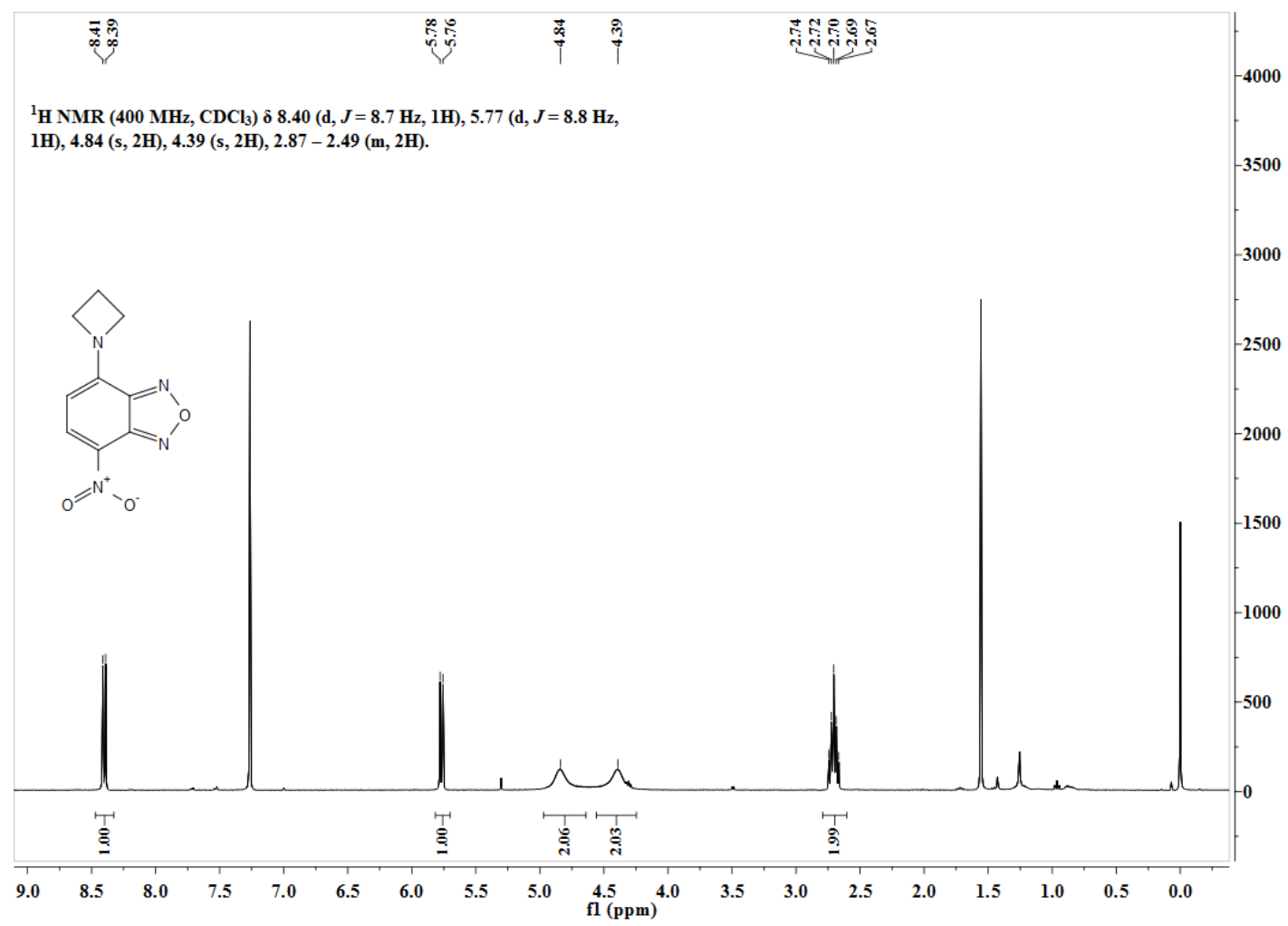

Figure S83. ${ }^{1} \mathrm{H}$ NMR of 4-azetidinly-7-nitrobenzofurazan 17 in $\mathrm{CDCl}_{3}$. 


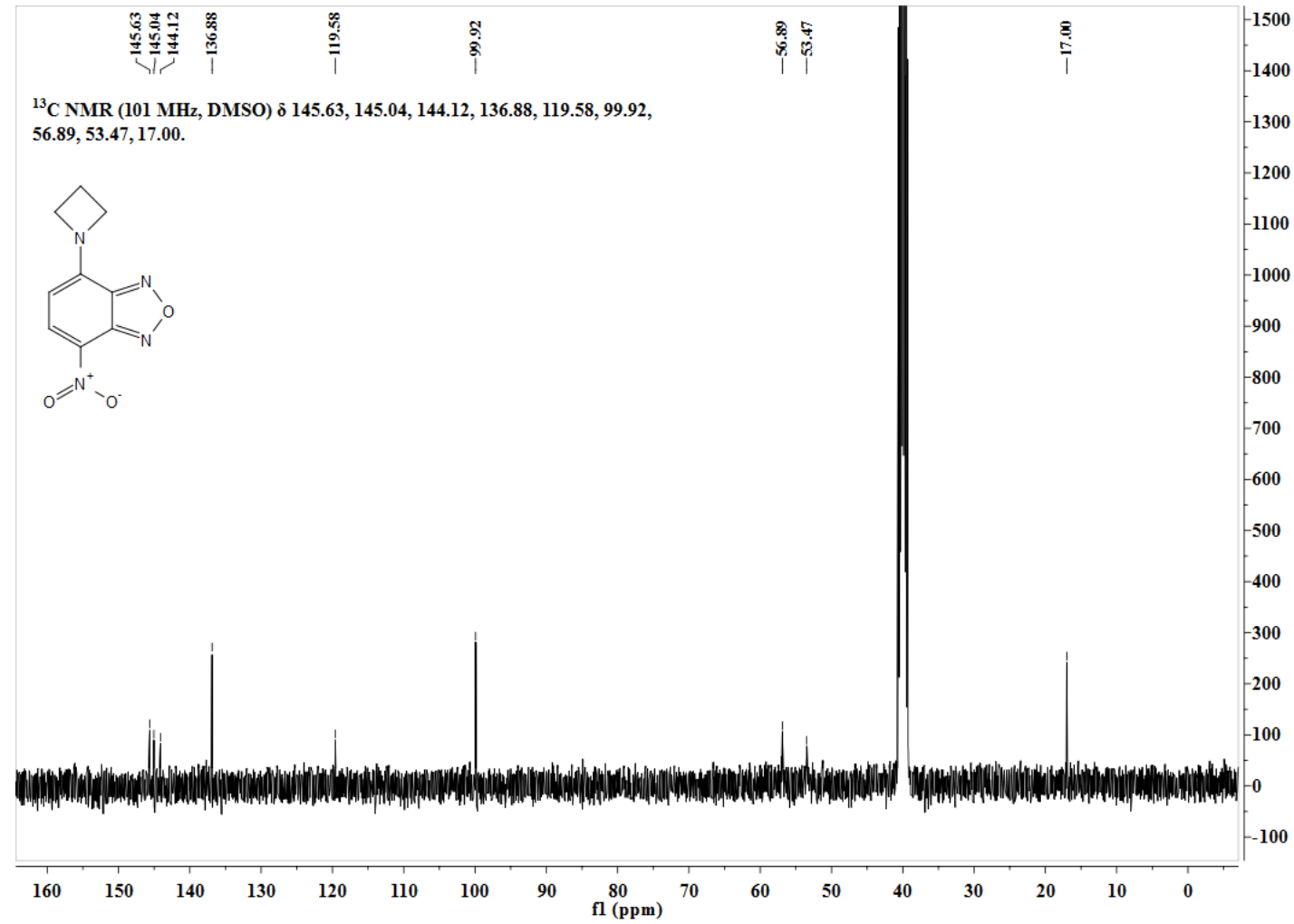

Figure S84. ${ }^{13} \mathrm{C}$ NMR of 4-azetidinly-7-nitrobenzofurazan 17 in DMSO- $d_{6}$.

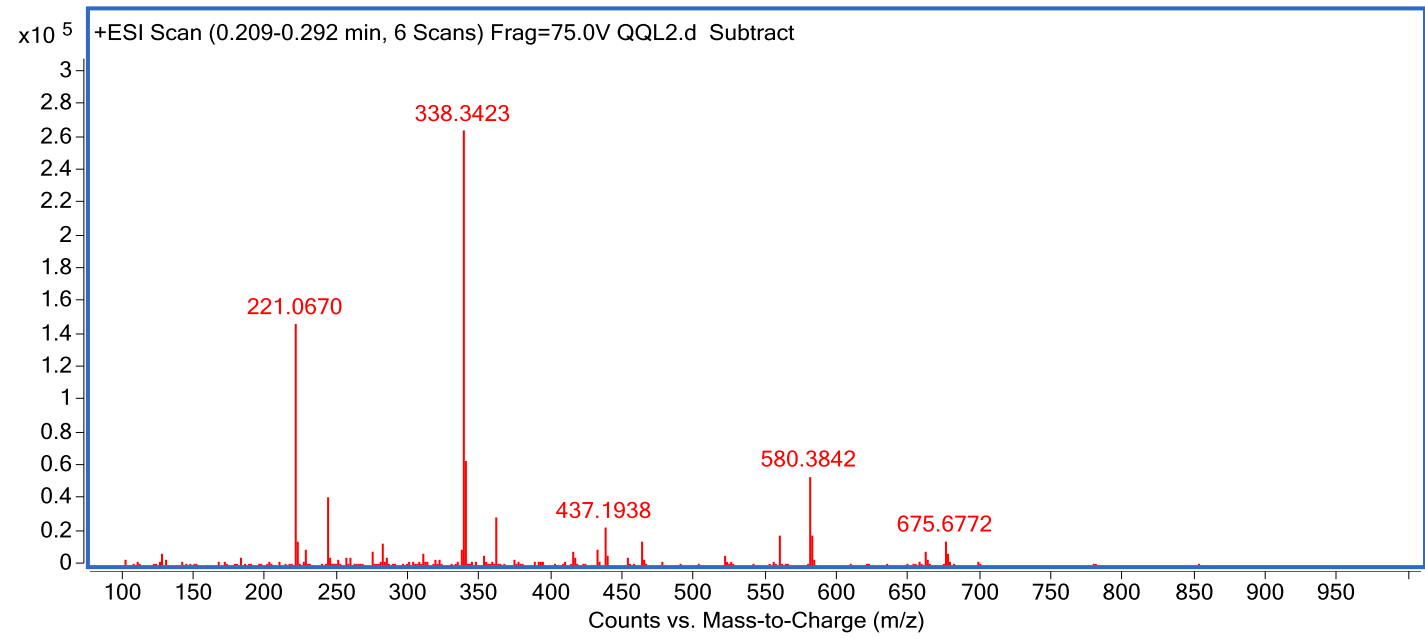

Figure S85. HRMS of 4-azetidinly-7-nitrobenzofurazan 17. 


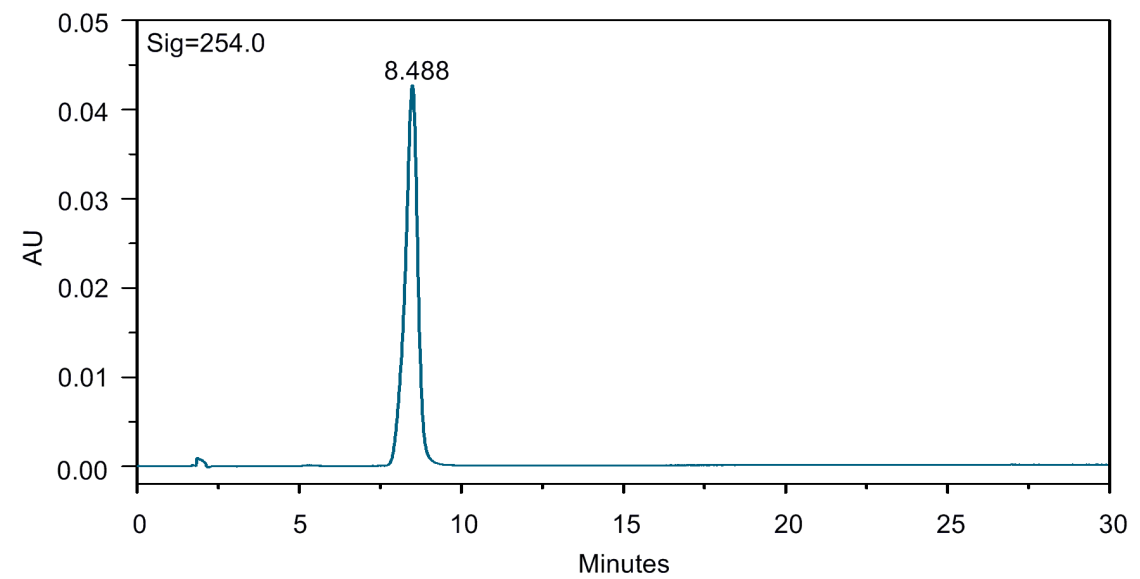

Figure S86. Analytical HPLC spectrum of 4-azetidinly-7-nitrobenzofurazan 17. 
2.4 UV - vis and fluorescence spectral data of $\mathbf{1}-\mathbf{9}$

Table S5. Peak UV - vis absorption wavelengths $\left(\lambda_{\mathrm{abs}}, \mathrm{nm}\right)$, peak emission wavelengths $\left(\lambda_{\mathrm{em}}\right.$, $\mathrm{nm})$ and the Stokes shifts $(\Delta \lambda, \mathrm{nm})$ of $\mathbf{1}-\mathbf{7}$ in various solvents.

\begin{tabular}{|c|c|c|c|c|c|c|}
\hline \multirow[t]{2}{*}{ Compound } & \multicolumn{3}{|c|}{$n$-Hexane } & \multicolumn{3}{|c|}{ Chloroform } \\
\hline & $\lambda_{\text {abs }}$ & $\lambda_{\mathrm{em}}$ & $\Delta \lambda$ & $\lambda_{\text {abs }}$ & $\lambda_{\mathrm{em}}$ & $\Delta \lambda$ \\
\hline 1 & 368 & 472 & 104 & 383 & 484 & 101 \\
\hline 2 & 416 & 493 & 78 & 441 & 504 & 64 \\
\hline 3 & 417 & 482 & 64 & 441 & 502 & 61 \\
\hline 4 & 378 & 480 & 102 & 393 & 502 & 109 \\
\hline 5 & 388 & 477 & 89 & 411 & 512 & 101 \\
\hline 6 & 402 & 479 & 77 & 435 & 520 & 85 \\
\hline 7 & 388 & 477 & 89 & 415 & 502 & 86 \\
\hline \multirow[t]{2}{*}{ Compound } & \multicolumn{3}{|c|}{ Acetonitrile } & \multicolumn{3}{|c|}{ Ethanol } \\
\hline & $\lambda_{\text {abs }}$ & $\lambda_{\mathrm{em}}$ & $\Delta \lambda$ & $\lambda_{\text {abs }}$ & $\lambda_{\mathrm{em}}$ & $\Delta \lambda$ \\
\hline 1 & 381 & 504 & 123 & 382 & 509 & 127 \\
\hline 2 & 441 & 526 & 85 & 445 & 533 & 88 \\
\hline 3 & 442 & 522 & 80 & 448 & 529 & 81 \\
\hline 4 & 391 & 525 & 134 & 394 & 531 & 137 \\
\hline 5 & 405 & 534 & 128 & 409 & 533 & 124 \\
\hline 6 & 431 & 526 & 94 & 437 & 525 & 88 \\
\hline 7 & 415 & 523 & 108 & 419 & 527 & 108 \\
\hline \multirow[t]{2}{*}{ Compound } & \multicolumn{3}{|c|}{ DMSO } & \multicolumn{3}{|c|}{ Water } \\
\hline & $\lambda_{\text {abs }}$ & $\lambda_{\mathrm{em}}$ & $\Delta \lambda$ & $\lambda_{\text {abs }}$ & $\lambda_{\mathrm{em}}$ & $\Delta \lambda$ \\
\hline 1 & 387 & 511 & 124 & 380 & 531 & 151 \\
\hline 2 & 447 & 535 & 88 & 462 & 555 & 93 \\
\hline 3 & 451 & 531 & 80 & 467 & 550 & 83 \\
\hline 4 & 398 & 543 & 145 & 396 & - & - \\
\hline 5 & 413 & 539 & 126 & 405 & - & - \\
\hline 6 & 442 & 535 & 93 & 463 & 552 & 89 \\
\hline 7 & 425 & 525 & 100 & 440 & 585 & 145 \\
\hline
\end{tabular}




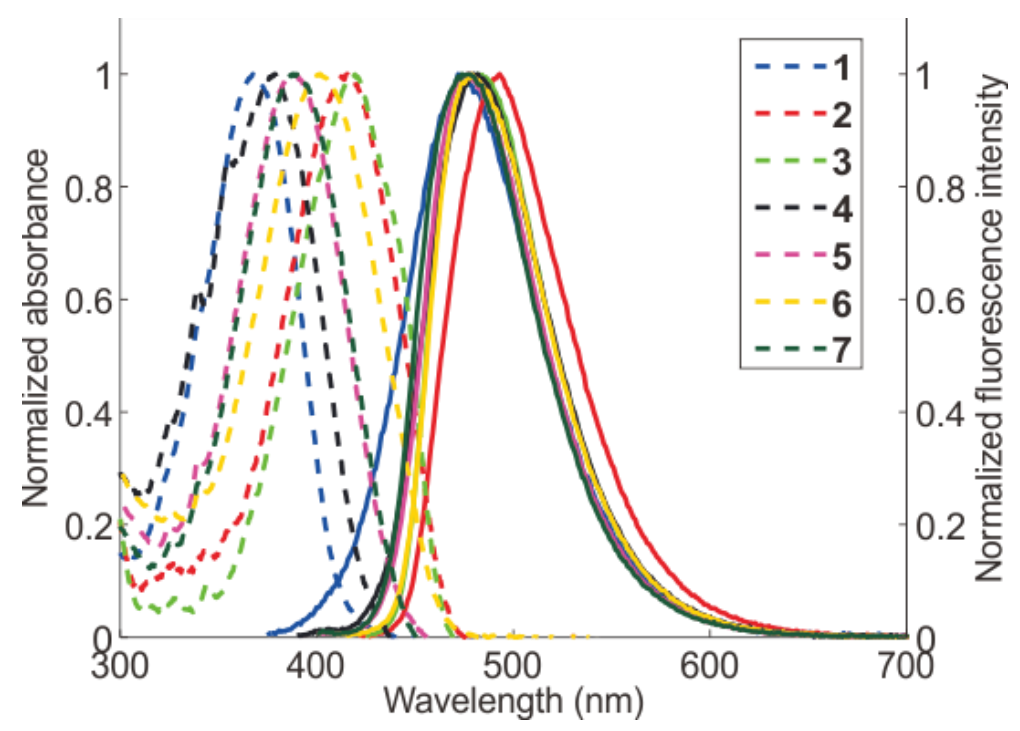

Figure S87. Normalized UV—vis absorption (dotted lines) and fluorescence (solid lines) spectra of $\mathbf{1}-\mathbf{7}$ in $n$-hexane.

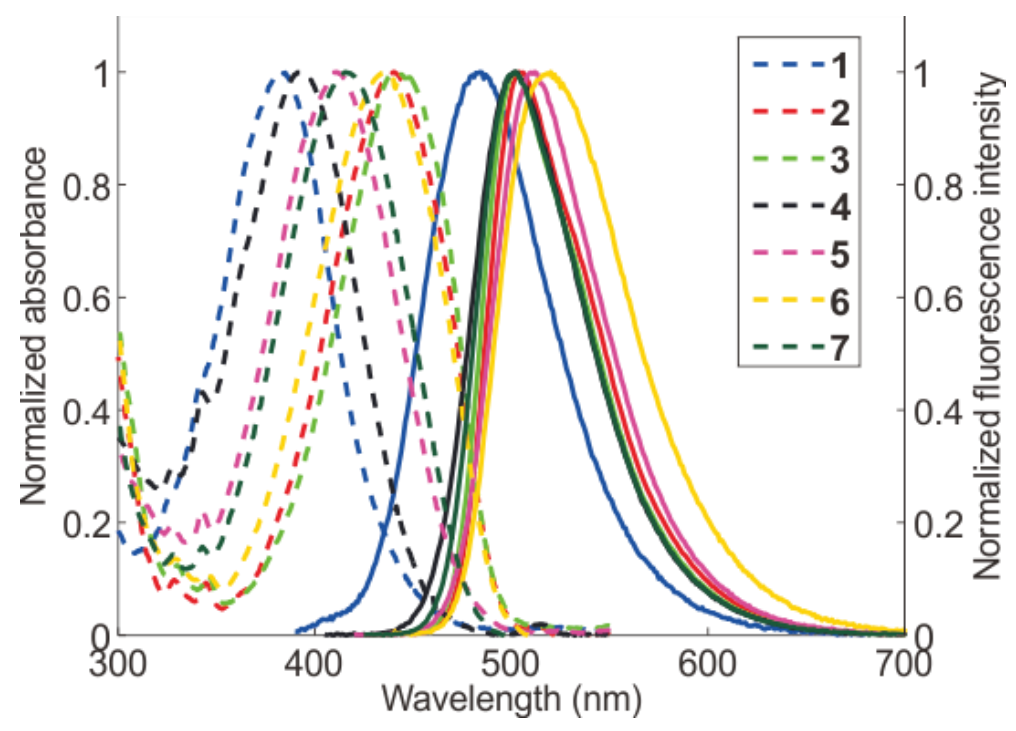

Figure S88. Normalized UV — vis absorption (dotted lines) and fluorescence (solid lines) spectra of $\mathbf{1}-\mathbf{7}$ in chloroform. 


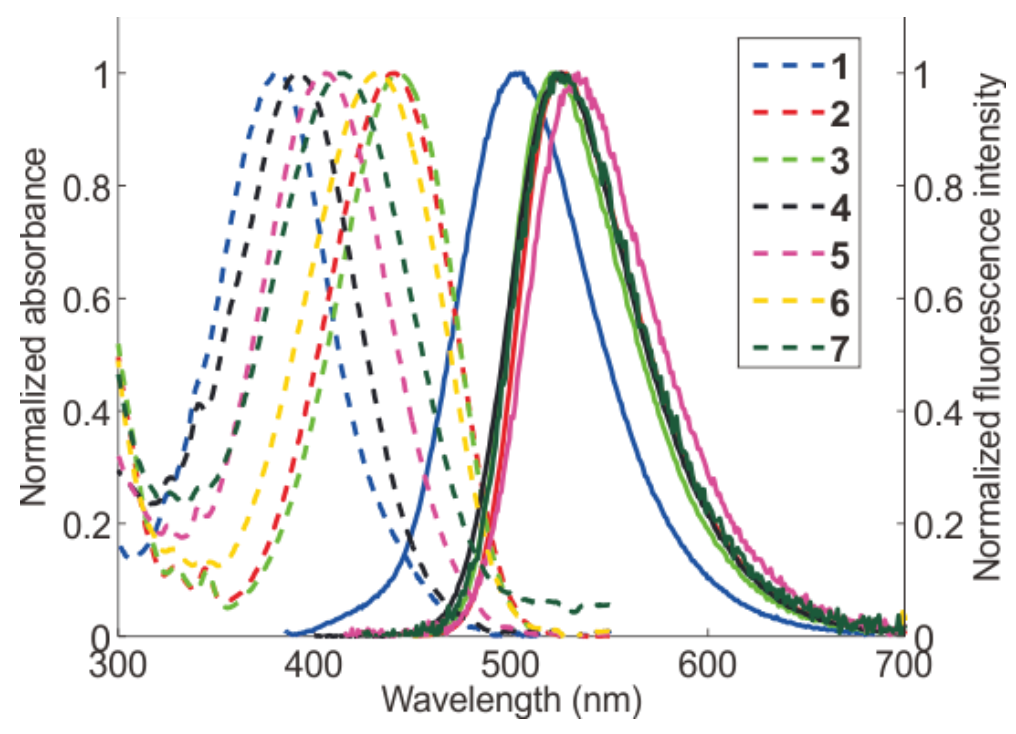

Figure S89. Normalized UV—vis absorption (dotted lines) and fluorescence (solid lines) spectra of 1-7 in acetonitrile. Weak emission spectra are not shown, due to high noise levels.

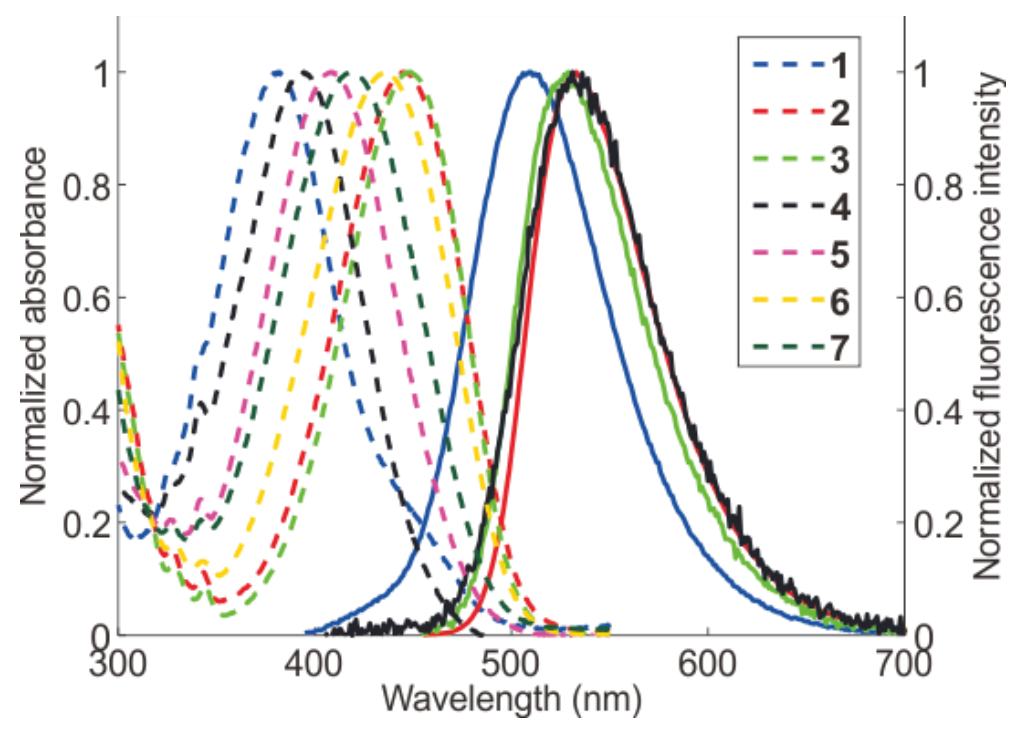

Figure S90. Normalized UV — vis absorption (dotted lines) and fluorescence (solid lines) spectra of $1-7$ in ethanol. Weak emission spectra are not shown, due to high noise levels. 


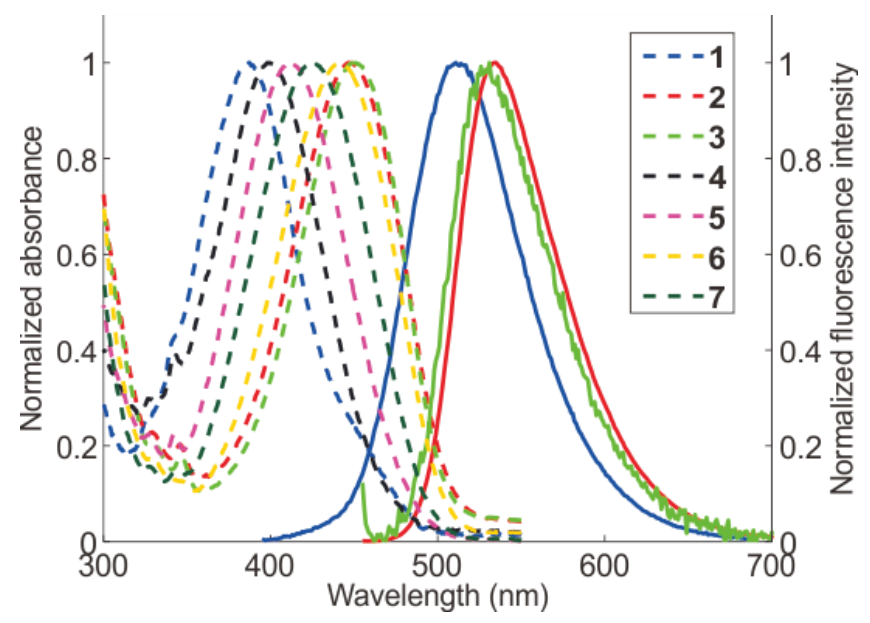

Figure S91. Normalized UV - vis absorption (dotted lines) and fluorescence (solid lines) spectra of $\mathbf{1}-\mathbf{7}$ in DMSO. Weak emission spectra are not shown, due to high noise levels.

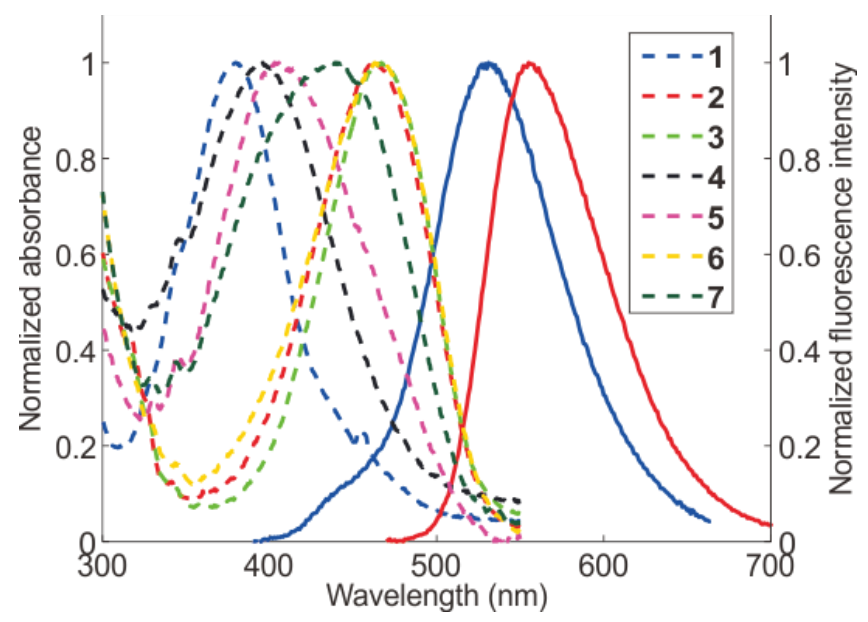

Figure S92. Normalized UV - vis absorption (dotted lines) and fluorescence (solid lines) spectra of $\mathbf{1}-\mathbf{7}$ in water. Weak emission spectra are not shown, due to high noise levels.

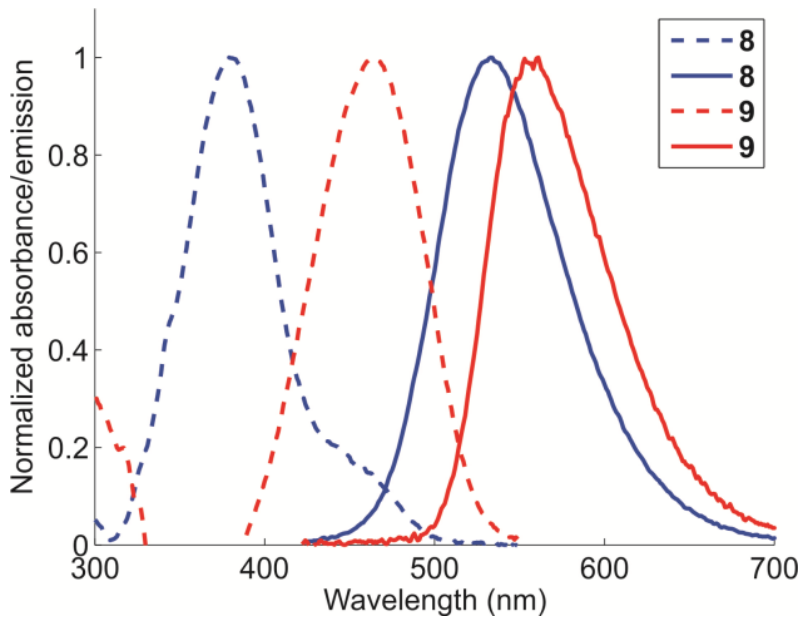

Figure S93. Normalized UV — vis absorption (dotted lines) and fluorescence (solid lines) spectra of $\mathbf{8}$ and $\mathbf{9}$ in water. 


\subsection{Fluorescence lifetime of $\mathbf{1}-\mathbf{7}$}

\subsubsection{Fluorescence lifetime of $1-7$ in ethanol}

The fluorescence lifetime of $\mathbf{1}-\mathbf{7}$ was measured in ethanol (Table S6).

Both 1 and 2 demonstrate large fluorescence lifetime $(\tau)$, in conjunction with bright fluorescence intensities. The bright fluorescence of $\mathbf{1}$ and $\mathbf{2}$ is from the local excited (LE) emission (Table S6).

The fluorescence decay dynamics of 3-7 fit better to double-exponential decays. These fittings suggest the presence of two emissive states: the LE and weakly emissive twisted-intramolecular-charge-transfer (TICT) states. The TICT emission has a long lifetime, but its intensity/contribution is rather low. The contribution of the LE emission is significantly higher in 3-7. However, the LE emission lifetime of 3-7 is much lower than that of $\mathbf{1}$ and $\mathbf{2}$, owing to substantial TICT formation rates in 3 -7. Consequently, the overall emission intensities of $\mathbf{3}-\mathbf{7}$ are very weak.

Table S6. Fluorescence lifetime ( $\tau$ ) of $\mathbf{1}-\mathbf{7}$ in ethanol, and the associated statistical goodnessof-fitting, $\chi^{2}$. For double-exponential fluorescence decays, the relative contributions of both time constants are given in brackets.

\begin{tabular}{|c|c|c|}
\hline Compound & $\tau(\mathrm{ns})$ & $\chi^{2}$ \\
\hline $\mathbf{1}$ & 9.58 & 1.2486 \\
\hline $\mathbf{2}$ & 9.36 & 1.183 \\
\hline $\mathbf{3}$ & $0.24(93.4 \%)$ & 1.1857 \\
& $8.39(6.6 \%)$ & \\
\hline $\mathbf{4}$ & $0.62(98.5 \%)$ & 1.018 \\
& $4.31(1.5 \%)$ & \\
\hline $\mathbf{5}$ & $0.08(98.2 \%)$ & 1.0207 \\
& $7.43(1.8 \%)$ & \\
\hline $\mathbf{6}$ & $0.04(84.0 \%)$ & 1.2824 \\
& $8.06(16.0 \%)$ & \\
\hline $\mathbf{7}$ & $0.08(94.7 \%)$ & 1.026 \\
& $7.79(5.3 \%)$ & \\
\hline
\end{tabular}

\subsubsection{Fluorescence lifetime of $\mathbb{1}$ and $\mathbf{2}$ in various solvents}

The fluorescence decay dynamics of both $\mathbf{1}$ and $\mathbf{2}$ fit well to single-exponential decays in various tested solvents (Table S7). The lifetime of $\mathbf{1}$ and $\mathbf{2}$ is high in general.

However, the lifetime of $\mathbf{2}$ drops substantially in water, indicating a large TICT formation rate. In contrast, the lifetime of $\mathbf{1}$ remains high in water. These results show that $\mathbf{1}$ is resistant to TICT, even in water. These observations are in excellent agreement with our theoretical calculations. 
Table S7. Fluorescence lifetime (ns) of $\mathbf{1}$ and $\mathbf{2}$ in various solvents.

\begin{tabular}{|l|c|c|}
\hline Solvent & $\mathbf{1}$ & $\mathbf{2}$ \\
\hline Chloroform & 8.16 & 8.86 \\
\hline Acetonitrile & 9.60 & 9.64 \\
\hline Ethanol & 9.58 & 9.36 \\
\hline DMSO & 9.54 & 10.30 \\
\hline Water & 7.40 & 4.37 \\
\hline
\end{tabular}

\subsection{Quantum yields of $\mathbf{1}-\mathbf{7}$ in various solvents}

Table S8. Quantum yields of $\mathbf{1}-\mathbf{7}$ in various solvents at room temperature.

\begin{tabular}{|c|c|c|c|c|c|c|}
\hline Compound & $n$-Hexane & Chloroform & Acetonitrile & Ethanol & DMSO & Water \\
\hline $\mathbf{1}$ & 0.7695 & 0.8587 & 0.6961 & 0.7082 & 0.7268 & 0.4319 \\
\hline $\mathbf{2}$ & 0.7342 & 0.8000 & 0.6237 & 0.6312 & 0.6395 & 0.1985 \\
\hline $\mathbf{3}$ & 0.7595 & 0.8338 & 0.0684 & 0.0229 & 0.0136 & 0.0030 \\
\hline $\mathbf{4}$ & 0.7698 & 0.8413 & 0.3427 & 0.0495 & 0.0264 & 0.0018 \\
\hline $\mathbf{5}$ & 0.8256 & 0.8073 & 0.0546 & 0.0131 & 0.0056 & 0.0007 \\
\hline $\mathbf{6}$ & 0.6510 & 0.4070 & 0.0056 & 0.0033 & 0.0035 & 0.0008 \\
\hline $\mathbf{7}$ & 0.7463 & 0.8715 & 0.0269 & 0.0090 & 0.0035 & 0.0005 \\
\hline
\end{tabular}

\subsection{Photo-physical properties of $\mathbf{8}$ and $\mathbf{9}$ in water}

Table S9. Peak UV-vis absorption wavelengths $\left(\lambda_{\mathrm{abs}}, \mathrm{nm}\right)$, peak emission wavelengths $\left(\lambda_{\mathrm{em}}\right.$, $\mathrm{nm})$, the Stokes shifts $(\Delta \lambda, \mathrm{nm})$, molar extinction coefficients $(\varepsilon)$ and quantum yields of $\mathbf{8}$ and 9 in water.

\begin{tabular}{|c|c|c|c|c|c|}
\hline & $\lambda_{\text {abs }}(\mathrm{nm})$ & $\varepsilon\left(\mathrm{M}^{-1} \mathrm{~cm}^{-1}\right)$ & $\lambda_{\text {em }}(\mathrm{nm})$ & $\Delta \lambda(\mathrm{nm})$ & $\varphi$ \\
\hline $\mathbf{8}$ & 379 & 9775 & 538 & 159 & 0.5035 \\
\hline $\mathbf{9}$ & 464 & 16840 & 561 & 97 & 0.2730 \\
\hline
\end{tabular}

\subsection{Photostability of $\mathbf{8}$ and $\mathbf{9}$ in water}

The fluorescence photostability tests of $\mathbf{8}$ and $\mathbf{9}$ were conducted on an IX81 microscope (Olympus, Japan) coupled with a EMCCD camera (DU-897U-CS0-\#BV, Andor, UK). Aqueous solution of 8 and $9(5 \mu \mathrm{M})$ was injected into polydimethylsiloxane (PDMS) microfluidic channels via a syringe, separately. The microfluidic channels were designed with AutoCAD (software) and fabricated using conventional soft lithographic techniques. ${ }^{11}$ 
These samples were excited with a supercontinuum white-light laser (SC400-PP, Fianium, UK). The excitation wavelength was set to $416 \mathrm{~nm}$, since the excitation spectra of $\mathbf{8}$ and $\mathbf{9}$ intersected at this wavelength. The excitation laser beam was defocused to form a homogeneous excitation spot of $\sim 350 \mu \mathrm{m}$ in diameter through a $10 \times$ air objective lens $(\mathrm{NA}=0.4$, Olympus UPLSAPO). The laser intensity was adjusted via a neutral density filter and monitored with a power meter (PM100D S130VC, ThorLabs, USA). The excitation intensity was $3.3 \mathrm{~W} \mathrm{~cm}^{-2}$ during the experiments. The fluorescence signal was collected using the EMCCD equipped with a band pass filter $(545 \pm 37.5 \mathrm{~nm}$; Figure S94).

The up-up conformed $\mathbf{8}$ demonstrates a stronger photostability than the planar $\mathbf{9}$ (Figure 1g; Figure S95).

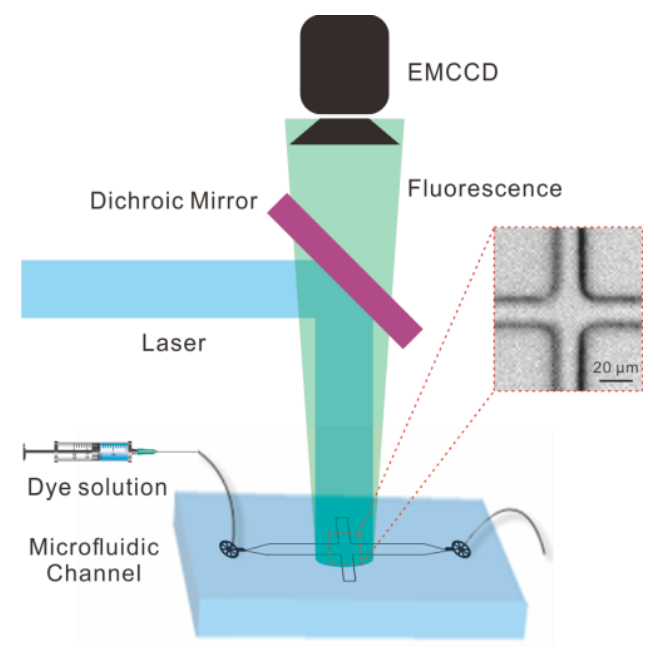

Figure S94. Illustration of the experimental set-up to test the photostability of $\mathbf{8}$ and $\mathbf{9}$ in water (laser wavelength $=416 \mathrm{~nm}$ ).

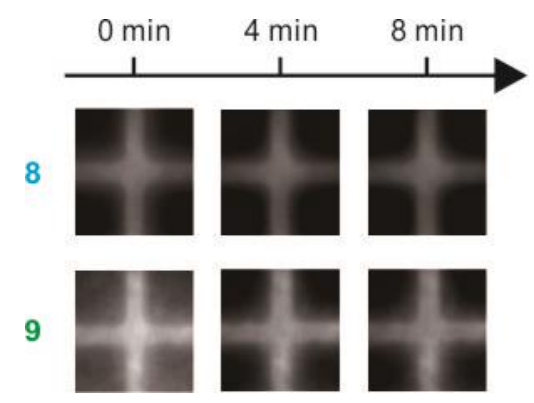

Figure S95. Representative fluorescence images of $\mathbf{8}$ and $\mathbf{9}$ during the laser photostability tests in water. Compound $\mathbf{9}$ experienced a more substantial intensity drop.

\subsection{Chemical stability of $\mathbf{1}$ in water}

We also investigated the chemical stability of $\mathbf{1}$ in aqueous solutions of various $\mathrm{pH}$ values. The $\mathrm{pH}$ values of these samples were adjusted using $\mathrm{HCl}$ and $\mathrm{NaOH}$. After 10 min of settling time, the fluorescence spectra and peak emission intensities of these 
samples were measured. The fluorescence intensities of $\mathbf{1}$ remained stable from $\mathrm{pH}$ 4.24 to 10.80 (Figure S96).
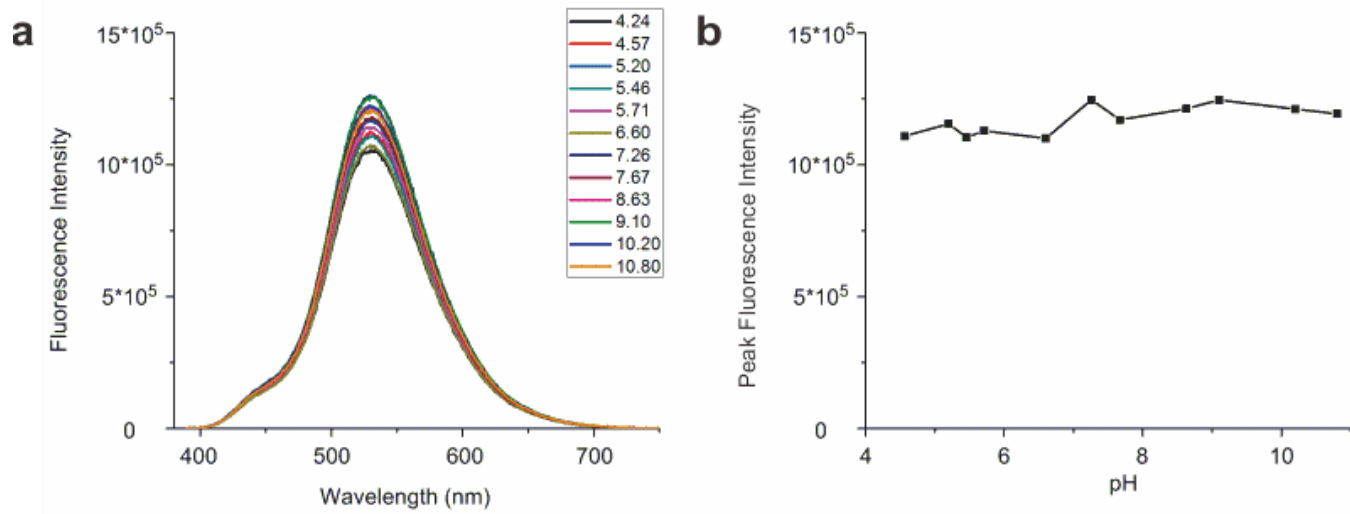

Figure S96. (a) Fluorescence spectra and (b) peak emission intensities of $\mathbf{1}$ in aqueous solutions of various $\mathrm{pH}$ values.

\subsection{Quantum yields of conventional dialkylamino fluorophores}

The quantum yields of conventional dialkylamino fluorophores in aqueous solution have been compiled from previous reports (Table S10).

Table S10. Quantum yields of selected dialkylamino fluorophores in aqueous solution.

\begin{tabular}{|c|c|c|}
\hline Molecular structure & Quantum yields & References \\
\hline
\end{tabular}




\section{References}

(1) Frisch, M.; Trucks, G.; Schlegel, H. B.; Scuseria, G.; Robb, M.; Cheeseman, J.; Scalmani, G.; Barone, V.; Mennucci, B.; Petersson, Gaussian 09 (software), 2009.

(2) Becke, A. D. J. Chem. Phys. 1993, 98, 5648.

(3) Lee, C.; Yang, W.; Parr, R. G. Phys. Rev. B 1988, 37, 785.

(4) Stephens, P. J.; Devlin, F. J.; Chabalowski, C. F.; Frisch, M. J. J. Phys. Chem. 1994, 98, 11623.

(5) Rassolov, V. A.; Ratner, M. A.; Pople, J. A.; Redfern, P. C.; Curtiss, L. A. J. Comput. Chem. 2001, 22, 976.

(6) Yanai, T.; Tew, D. P.; Handy, N. C. Chem. Phys. Lett. 2004, 393, 51.

(7) Wiggins, P.; Williams, J. G.; Tozer, D. J. J. Chem. Phys. 2009, 131, 091101.

(8) El-Azhary, A. A.; Suter, H. U. J. Phys. Chem. 1996, 100, 15056.

(9) Grimm, J. B.; English, B. P.; Chen, J.; Slaughter, J. P.; Zhang, Z.; Revyakin, A.; Patel, R.; Macklin, J. J.; Normanno, D.; Singer, R. H.; Lionnet, T.; Lavis, L. D. Nat. Methods 2015, 12, 244.

(10) Würth, C.; Grabolle, M.; Pauli, J.; Spieles, M.; Resch-Genger, U. Nat. Protoc. 2013, 8, 1535.

(11) Duffy, D. C.; McDonald, J. C.; Schueller, O. J.; Whitesides, G. M. Anal. Chem. 1998, 70, 4974.

(12) Abe, I.; Koga, J.; Kuroki, N. Nippon Kagaku Kaishi 1974, 9, 1744.

(13) Vázquez, M. E.; Blanco, J. B.; Imperiali, B. J. Am. Chem. Soc. 2005, $127,1300$.

(14) Singha, S.; Kim, D.; Roy, B.; Sambasivan, S.; Moon, H.; Rao, A. S.; Kim, J. Y.; Joo, T.; Park, J. W.; Rhee, Y. M. Chem. Sci. 2015, 6, 4335.

(15) Saha, S.; Samanta, A. J. Phys. Chem. A 1998, 102, 7903. 